\title{
Application of a Device for Uniform Web Drying and Preheating Using Microwave Energy
}

\section{Final Report}

September 2003

Program/Project Identification No.

DE-FC07-00ID13872

\author{
Submitted by: \\ Frederick W. Ahrens \\ Georgia Institute of Technology \\ Institute of Paper Science and Technology \\ $50010^{\text {th }}$ Street, N.W. \\ Atlanta, GA 30318
}


Recipient: Institute of Paper Science and Technology (IPST)

Award Number: DE-FC07-00ID13872

Subcontractor: Industrial Microwave Systems (IMS)

Other Partners: IPST member companies: support of an IPST doctoral student (until Sept. 2000), an undergraduate summer intern (Summer 2001 and Summer 2002), an undergraduate fall and spring intern (Fall semester 2001 and Spring semester 2002), and an IPST MS student (beginning Sept. 2001).

Contact: Fred Ahrens (404-894-6496) fred.ahrens@ipst.edu

Project Team: David Robertson (DOE-Idaho), Energy Performance Task Group, and Serelia Woods (IPST)

IPST Technical Team: F. Ahrens, C. Habeger, J. Loughran, T. Patterson 


\section{TABLE OF CONTENTS}

Executive Summary

Chapter I. Introduction 1

Chapter II. CD Applicator - Introduction and Theory 8

Chapter III. CD Applicator - Experimental 24

Chapter IV. MD Applicator - Introduction and Theory 27

Chapter V. MD Applicator - Experimental $\quad 34$

Chapter VI. Energy and Economic Assessment - MD Applicator 40

Chapter VII. Concluding Remarks 56

$\begin{array}{ll}\text { Chapter VIII. Suggested Future Work } & 60\end{array}$

Appendix: Determination of the Absorption Coefficient in Dielectrically Dried Paper 61 (“1”) 


\section{EXECUTIVE SUMMARY}

The project summarized in this report dealt with an evaluation of new microwave applicator ideas for paper preheating and drying. The technical basis for success in this project is the fact that Industrial Microwave Systems (IMS) has recently identified certain previously unrecognized wave guide "design variables" and hardware implementation concepts that can be employed to greatly improve the uniformity of microwave energy distribution for continuous flow processes. Two applicator concepts were ultimately evaluated, a Cross-Machine Direction (CD) oriented applicator and a Machine Direction (MD) oriented applicator. The economic basis for success is the result of several factors. Since 1985, the capital expenditure required for an industrial microwave applicator system has decreased by a factor of four. The maintenance costs have decreased by a factor of 10 and the life expectancy of the magnetron has increased by more than a factor of four to in excess of 8,000 hours (nearly one year at 24 hours/day operation).

The overall objectives of this project were to:

- Evaluate the technical and economic feasibility/value of applying new design ideas concerning the uniform application of microwave energy to planar materials to various processes on the paper machine. These processes would include: web preheating (to enhance liquid water removal and to increase drying productivity); moisture profile leveling (to reduce over-drying); and incremental high-rate, highefficiency, low-investment drying.

- Move the technology from the laboratory/concept stage to the commercializationready stage. This objective was not achieved, because the project received an early termination of funding.

The following final status of the various project tasks is used to provide a summary of the project.

Task 1. Low Power, Narrow Web, Laboratory Experiments (using the CD-oriented concept).

Earlier efforts by IMS to design an adjustable-geometry capability for the first (CDoriented) prototype led to the recognition that the complexity is too high to be worthwhile, so we elected to build two single-pass, fixed-geometry applicators of the original CD-oriented (transverse feed) style, instead. These were fabricated by IMS, and were received at IPST in July 2001. They comprise one unit with curved top and bottom walls (i.e., "ideal slot geometry"), and one unit with a straight-line approximation ("linear slot") to the ideal geometry (i.e., straight, but inclined, top and bottom walls). The units have an active waveguide length of 6 feet, and use a generator whose maximum power is $3 \mathrm{~kW}$. Testing is complete for both applicator variants. The work included experiments comparing use of a short and a load as termination conditions. We used infrared temperature sensors to monitor the local heating rate. We tested the design theory and investigated the robustness (ability to handle variations in in-going moisture 
level) during off-design operation. For both variants, we found evidence (alternating wet/dry patches in the sheet) of a standing wave component of the heating, even with a load as termination condition. We also found the expected results, that there is an optimum water basis weight (WBW, mass of water/unit area) at which heating is the most nearly uniform, and that efficiency increases with WBW. Also as expected, we found that the efficiency is generally greater with a short (reflector) as termination, compared to a load, and that the ideal slot applicator offers the best combination of efficiency and tendency toward uniformity. We used an empirical approach to determine the WBW which best matches the "slot geometry" and length combination, in terms of heating uniformity. The limitation on use of fixed slot geometry is that we are not able to test the ability of an adjustable applicator to provide uniform heating for a range of offdesign conditions. As suggested above, and supported by the experimental observation of lack of real uniformity from the ideal slot applicator, it appeared better to focus most project attention on the more promising MD-oriented geometry applicator.

Task 2. MD-Oriented Prototype Applicator Experiments [formerly Wide Web, Low Power Density Laboratory Experiments].

This Task originally called for design and testing of a 25 -foot wide CD-oriented applicator. However, as discussed above, we believed it best to focus on the more promising MD-oriented applicator configuration. In this Task we have investigated the performance of a single waveguide MD-oriented applicator, using narrow, but long, paper samples conveyed along the axis of the waveguide.

Prior to designing a prototype for use in the project, we performed some paper heating/drying experiments, on the existing IMS "curing chamber" unit. The first set was performed in March, but two additional sets were performed in May/June 2001. The IMS single-waveguide unit is somewhat similar to the design needed for paper drying applications, except that its conveyor belt travels along a path inclined to the waveguide centerline (due to IMS' desire not to overheat certain types of food materials at the power input end of the unit). The unit initially had a water load at the opposite end from the generator, whereas the preferred paper-drying unit would likely have a "short" (reflector), in order to increase the opportunity for energy absorption by the sheet. We ran a range of basis weights and ingoing solids levels, thus giving a range of initial "water basis weights." Our theoretical work has shown that heating efficiency and drying rate should increase with water basis weight. The experiments fully confirmed this expectation. A preliminary comparison of the experimental results with a simplified theoretical analysis (using an estimated relationship for dielectric loss coefficient as a function of moisture content) indicated that our loss coefficient estimate is low (actual efficiency was greater than predicted). In principle, as we acquire a larger database and develop a more complete model, we should be able to use experimental performance results to infer the dependence of dielectric loss coefficient on moisture content and temperature. In particular, results for cases at low power and/or high speed, in which the moisture change is small, will be especially useful for inferring the loss coefficient.

The more recent experiments on the IMS axial unit involved use of a short to reflect power back along the sample. This increased efficiency, as expected. We also 
investigated the effect of co-current vs. counter-current operation (with respect to the direction of microwave propagation relative to direction of sample travel), but found little difference in performance between the two cases. Our theoretical work indicates that counter-current operation should have a somewhat better efficiency.

Design and construction of the IPST prototype MD-oriented applicator is complete; delivery occurred in early July 2001. It has an active length of about 11 feet, and has been operated with a $3 \mathrm{~kW}$ generator. Testing began in Nov. 2001, and is now complete. Results indicate that, for given total water load (WBW x Active applicator length), the MD applicator efficiency is appreciably higher than that of either of the $\mathrm{CD}$ applicators tested in Task 2. This is reasonable, since the sample is located at the mid-plane, where the field strength is a maximum. We have also found the expected results that efficiency increases with WBW, and that efficiency is greater (for given ingoing WBW) when the "machine speed" is higher. The latter effect is due to the higher average WBW along the length at higher speed (less drying). We again observed evidence of a standing wave heating component, even with a load, but this is not really a problem with the MDoriented applicator; it is just the cumulative absorption as the sheet travels along the waveguide that matters. Experiments have included looking at the effect of a reflector vs. a dummy load as the termination condition (an important effect), and the (less-important) effect of inputting the microwave energy at the upstream end vs. the downstream end (relative to the direction of sheet travel).

Task 3. Low Speed, Low Power, Pilot Paper Machine Experiments.

The purposes of this task are to work out issues associated with continuous operation and use of multiple/parallel waveguide MD-oriented applicators, and to check the paper properties impacts of using microwave drying. We originally planned to pursue this task at NC State. We expected to base the work on use of a three-waveguide MD-oriented applicator, probably with either a $75 \mathrm{~kW}$ generator or multiple $5 \mathrm{~kW}$ generators. However, if funding had not been discontinued, we would now do this work on IPST's newly acquired Continuous Web System. Conceivably, wet paper rolls produced on the NCSU pilot machine could be used in some of the experiments. Because this project was terminated, we have cancelled our order for a four-waveguide MD applicator from IMS, accompanied by a $75 \mathrm{~kW}$ generator.

Task 4. High Speed, High Power, Pilot Paper Machine Demonstration Trials. The purposes of this task are to demonstrate the microwave drying of continuous paper webs at higher speeds, to confirm the efficiency and design principles, and to deal more with web transport and ventilation issues. The experiment was to be run on a Herty Foundation pilot machine in 2002. We had expected to base the work on use of a multiple-waveguide MD-oriented applicator, with at least one $75 \mathrm{~kW}$ generator. As discussed above, if the project had not been terminated, we would now do this work on IPST's newly acquired Continuous Web System. Thus, Tasks 3 and 4 would have been combined.

Task 5. Develop Design/Scale-up Model. 
The most recent modeling efforts have been focused on the new MD-oriented waveguide concept to support the Task 2 experimental work. A simplified, uniform temperature model has been completed for the case with a load at the end opposite the power-input end of the waveguide. The model can be extended to the general case with variable temperature and the option of a short or a load at the end. An interesting theoretical and practical question can be addressed: whether a countercurrent or co-current configuration (direction of sheet motion vs. direction of microwave propagation) is better for efficiency.

In support of our design/scale-up model development, our M.S. student (D. Cameron) been considered the experimental approaches for determining the dielectric loss coefficient as a function of moisture and basis weight. We decided to abandon the offline approach in favor of using selected sample heating/drying experiments in the MDoriented applicator. In effect, the dielectric loss coefficient was "back-calculated," by matching theory and experiment for various water loads and sheet temperatures. In spite of the lack of continuing DOE support, D. Cameron continued his efforts, at IPST's expense, until April 2003. Portions of his report are included in the Appendix.

Task 6. Develop Design Guidelines.

This Task was not completed, due to lack of continued funding. However, the theory and experimental data presented here would serve as a basis for the design of microwave applicators.

Task 7. Energy and Economic Analysis.

We completed an energy and economic analysis of the microwave technology, and submitted a report to the Task Group and DOE in mid 2002. The MD-oriented microwave applicator performance model for assessing energy efficiency and required equipment size was based on appropriate scale-up projections using our low power laboratory data. To complement this model of microwave-applicator performance, we adapted a model of the conventional multi-cylinder dryer section, recently developed in connection with another IPST drying project, to the simulation of various scenarios for incorporating microwave technology on the paper machine. This integrated model allowed us to make estimates of the productivity benefits of using microwave technology for various purposes. The results served as input to the energy/economic analysis.

The scenarios considered for employing microwave technology were of two types, reflecting the most promising applications. In one, the microwave applicator was placed before the last press nip, for the purpose of preheating the sheet to achieve higher postpress solids (and temperature). In the other, the microwave applicator was placed at the beginning of the dryer section, before the first dryer can, to preheat/pre-dry the sheet. In both cases, the higher sheet temperature and solids content resulting from microwave application before the first dryer can was assumed to be capable of reducing picking and sticking enough to allow elimination of temperature graduation in the first dryer section. For the microwave cases, it was also assumed that, by using CD control of power input to the various waveguides, any non-uniform sheet moisture profile at the reel can be eliminated. 
The economic assessment of microwave paper heating/drying technology showed:

1) The time to recover the capital and installation cost should be appreciably less than 2.5 years for most dryer limited machines and implementation scenarios. For high basis weight machines $\left(200 \mathrm{~g} / \mathrm{m}^{2}-400 \mathrm{~g} / \mathrm{m}^{2}\right)$, the time to recover capital and installation costs is only 0.5 to 1.0 year.

2) Increases of over $30 \%$ in machine speeds can be realized. Additional revenue is proportional to the increase in machine speed (assuming no additional down time).

3) The greatest economic benefits will be realized if the microwave applicator is positioned before a final press nip. This can yield drying energy (per ton) savings of about $20 \%$. 


\section{INTRODUCTION}

In this report, the main results of a recent investigation of the technical feasibility and potential energy and economic benefits of using microwave energy for web preheating, moisture profiling and incremental web heating/drying on a paper machine are presented. Using microwave energy for preheating/drying a paper web has a decisive advantage over other, more established, web-heating technologies, especially for high basis weight grades. Traditional technologies for web preheating and drying, such as steam box, IR, hot gas impingement, and contact with a dryer cylinder, rely on thermal conduction to transfer the heat into the thickness of the paper. They are not always effective for heating high basis weight grades and highly refined sheets. Because the microwave energy absorption efficiency increases with greater water loads, microwave technology is especially suited for heating/drying high basis weight grades and for heating before the conventional dryer section. For lower basis weight sheets, or sheets with lower moisture content, larger microwave applicators are needed to achieve high absorption efficiencies.

The technical basis for success in this project is the fact that Industrial Microwave Systems (IMS) has recently identified certain previously unrecognized wave guide "design variables" and hardware implementation concepts that can be employed to greatly improve the uniformity of microwave energy distribution for continuous flow processes. Two applicator concepts were ultimately evaluated, a Cross-Machine Direction (CD) oriented applicator and a Machine Direction (MD) oriented applicator. The economic basis for success is the result of several factors. Since 1985, the capital expenditure required for an industrial microwave applicator system has decreased by a factor of four. The maintenance costs have decreased by a factor of 10 and the life expectancy of the magnetron has increased by more than a factor of four to in excess of 8,000 hours (nearly one year at 24 hours/day operation). Additionally, use of microwave energy for preheating can reduce the total evaporation load and increase productivity on the paper machine.

\section{BACKGROUND}

Microwave heating principles and industrial applications have been reviewed in Metaxas ${ }^{1}$ [1991]. Microwave heating or drying systems comprise a power generation unit, an applicator (in which the useful heating takes place), and a control unit. For planar materials, the applicator is typically a slotted waveguide, of rectangular cross-section. Microwave power is supplied at one end, and is progressively (and usefully) absorbed by the moist planar material (at a rate dependent on the amount and composition of the absorbing material within the waveguide) as it propagates along the length of the waveguide.

\footnotetext{
${ }^{1}$ For the convenience of the reader and the authors, this report is presented in a chapter format, with references at the end of each chapter. Figures are also at the end of each chapter.
} 
Microwave heating can be classified as a volumetric heat source. Therefore, microwave drying-rates are not limited by the usual conductive or convective heat input resistances. The volumetric heating rate for moist paper (and other moist materials) depends on three variables: the local electric field intensity and its frequency, and a material property, the dielectric loss coefficient [Schmidt, et al, 1992]. In turn, the loss coefficient is frequency and temperature dependent, and tends to increase with moisture content [Habeger and Baum, 1983; Schmidt, et al., 1992)]. This feature can lead to a moisture-leveling capability for microwave dryers. An overview of student research to determine the moisture and temperature dependence of the loss coefficient is included in the Appendix.

The cross-sectional dimensions of the waveguide are dictated by the wavelength. The microwave frequencies that are allowed for industrial heating applications are 0.915 and $2.45 \mathrm{GHz}$, with wavelengths of $32.8 \mathrm{~cm}$ and $12.2 \mathrm{~cm}$, respectively. The $0.915 \mathrm{GHz}$ frequency was used for the experiments reported here. The height and width dimensions for this frequency are typically about $24.8 \mathrm{~cm}$ by $12.4 \mathrm{~cm}$. These dimensions allow for a tight range of wavelengths to propagate down the waveguide length. The waveguide dimensions for the $2.45 \mathrm{GHz}$ frequency are significantly smaller. Figure 1 illustrates the microwave electric field distribution in a waveguide. The magnitude of the field strength is greatest at the mid-plane of the height dimension (b); the field strength is zero at the top and bottom conducting walls. The field strength is uniform across the width.

Microwave drying of paper has been investigated periodically since the 1960's [Williams, 1966]. One of the first studies completed [Hankin, et al, 1970] reported the experience gleaned from operation of a $30 \mathrm{~kW}$ microwave dryer tested on a pilot paper machine. The slotted, $\mathrm{CD}$ - oriented waveguide configuration having slots that are located along the centerline of the vertical walls of the waveguide (see Figure 2) has been favored up until recent times [Jones and Rowley, 1996]. The microwave transmission travels transverse to the sheet movement in the CD-oriented waveguide system. Consequently, any non-uniform field strength distribution in the waveguide length direction will produce non-uniform drying across the sheet width. Energy absorption by the moist material and standing waves are the primary causes of non-uniform field strength along the waveguide length, and must be dealt with in order to attain a uniform $\mathrm{CD}$ moisture profile. To achieve high absorption efficiency, multiple waveguide passes can be employed (serpentine applicator).

Two configurations for serpentine, slotted waveguide applicator systems are depicted in Figure 3. Type (a) has a reflector (short) at the termination end, and a circulator and load at the supply end, while type (b) has a dummy load at the termination end to prevent (or minimize) standing waves. The dummy load is a water source that absorbs most of the radiation that is not absorbed by the wet sheet, ideally preventing reflections off the termination wall of the waveguide. It is reflections that cause standing wave patterns (i.e., hot and cold spots) along the waveguide length. In type (a), energy not absorbed in the paper after travel from the source to the short will be reflected, and have the opportunity to be partially absorbed before it reaches the load. This design will have a standing wave along the applicator, making it challenging to achieve uniform heating of the paper. Note that a special case of each of the serpentine systems in Figure 3 would be a corresponding 
single-pass version. In the analysis to follow, the single-pass system will be the initial focus, but the results will then be extended to the multi-pass configuration.

It has recently been recognized [Joines and Drozd, 1999] that the use of slots that are not necessarily located along the centerline should have an important advantage, relative to the possibility of achieving uniform energy absorption across the whole width of the paper machine. This is an improvement over all earlier applicator concepts, involving passing the paper through the waveguide centerline, for which the heating rate must decrease with CD position (due to absorption effects). The Joines and Drozd concept uses a diagonal sheet feed slot (in the $\mathrm{CD}$ direction). The diagonal slot allows for the edge of the sheet nearest the microwave source to be fed into the waveguide at a position (height) that is not at the maximum microwave field strength. This tends to compensate for the greatest strength of the microwave field being at the source end of the applicator. The edge of the sheet that is farthest from the source enters the waveguide at the mid-plane, the position of highest field strength at that end. A given slot angle will produce a reasonably uniform heating profile for a single water load. The slot angle would need to be adjusted if the water basis weight changes (e.g., due to a grade change). Additionally, an inherent trade-off for feeding the sheet away from the maximum field strength plane is lower heat absorption efficiency, for a given waveguide length.

As part of our work on this project, we have developed a design intended to further improve the heating uniformity of CD-oriented microwave applicators. We considered the non-linearity of microwave power dissipation and the non-linearity of the microwave field strength distribution in the vertical (y) direction within the waveguide (see Figure 1) and calculated an "ideal" slot shape. Here, the term slot shape refers to the variation of slot height above the bottom of the waveguide, as a function of position (z) along the waveguide. Unfortunately, an "ideal" slot shape will produce a uniform heating profile for only a single water load, and a mechanism for slot shape adjustment must be designed in order to optimally run multiple grades. The value of this concept is, at least theoretically, also limited to the situation where the "downstream end" of the applicator terminates in a dummy load rather than a reflector.

Recently, another previously unrecognized microwave applicator concept has been identified [Drozd, 2000 - 2002], which has significant technical advantages, especially with respect to achieving CD uniformity of heat input on a paper machine. The novel feature of the new approach is that the waveguide is aligned with the machine direction (MD), as shown in Figure 4. Appropriate web input/output ports are needed at the applicator ends. The application of microwave energy across the full machine width would then be accomplished by placing multiple waveguides side-by-side. In this case, the waveguide sidewalls are common to adjacent waveguides, and are slotted, so that a wide paper web can be conveyed along the length (MD). Furthermore, since heating uniformity along the MD is not required, the paper can be located along the waveguide centerline, to absorb maximum power. This would allow a given efficiency to be achieved with the shortest possible waveguide length. The MD - oriented waveguides can also be configured with a reflector plate at the waveguide termination end (dummy load not needed), further increasing the overall energy absorption by the sheet. Of 
concern is the behavior of the microwave field strength at the slots between adjacent waveguides. Those zones (at the sidewall slots) might produce a non-uniform heating intensity. However, this effect has not yet been studied.

Conceptually, the MD-oriented waveguide application system can be used to control the $\mathrm{CD}$ moisture profile. The control process requires adding established CD control to the microwave generators supplying the various side-by-side waveguides. The microwave generators act as the actuators. The amount of microwave energy delivered by individual generators/actuators will control heating/drying at corresponding response zones in the $\mathrm{CD}$ profile. A desired CD profile will be realized by manipulating individual actuators.

The performance results for both types of microwave applicator (CD - oriented waveguide and $\mathrm{MD}$ - oriented waveguide) are presented in the following chapters. In the case of the $\mathrm{CD}$ - oriented waveguide, both the diagonal slot and the ideal slot shape designs were tested. Because the MD - oriented applicator showed the greatest technical benefits, it was the focus of our energy and economic evaluation.

\section{PROJECT OBJECTIVES}

In light of the background discussed above, the overall objectives of this project were to:

- Evaluate the technical and economic feasibility/value of applying the new design ideas concerning the uniform application of microwave energy to planar materials to various processes on the paper machine. These processes would include: web preheating (to enhance liquid water removal and to increase drying productivity); moisture profile leveling (to reduce over-drying); and incremental high-rate, highefficiency, low-investment drying.

- Move the technology from the laboratory/concept stage to the commercializationready stage. This objective was not achieved, because the project received an early termination of funding.

\section{REFERENCES}

Drozd, M., Industrial Microwave Systems, personal communications (2000 - 2002).

Habeger, C., and Baum, G.A., "The Microwave Dielectric Constants of Water-Paper Mixtures: The Role of Sheet Structure and Composition," Journal of Applied Polymer Science, 28, 1983, p.969-981.

Hankin, J.W., Leidigh, W.J., and Stephansen, E.W., "Microwave Paper Drying Experience and Analysis," TAPPI Journal, 53(6), 1970, p.1063-1070.

Joines, W. T., and Drozd, J. M., "Method and Apparatus for Electromagnetic Exposure of Planar or Other Materials,” U. S. Patent 5,958,275 (Sept. 28, 1999). 
Jones, P.L., "High Frequency Dielectric Heating in Paper Making," Drying Technology, 4(2), 1986, p.217-244.

Jones, P.L. and Rowley, A.T., "Dielectric Drying,” Drying Technology, 14(5), 1996, p.1063-1098.

Metaxas, A. C., 1991, Microwave Heating, Power Engineering J., Sept., pp. 237-247.

Schmidt, P.S., Bergman, T.L., Pearce, J.A., and Chen, P., "Heat and Mass Transfer Considerations in Dielectrically-Enhanced Drying," Drying '92, Book 1, Elsevier Science, 1992, p.137.

Williams, N.H., "Moisture leveling in paper, wood, textiles, and other mixed dielectric sheets," Journal of Microwave Power, 1(3), 1966, p.73-80. 


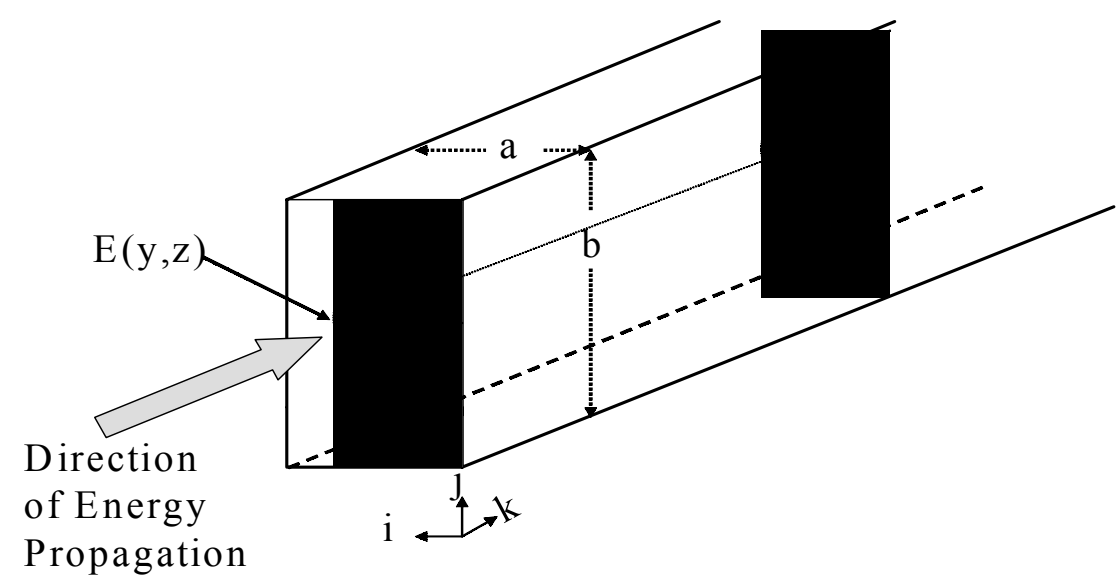

Figure 1. Waveguide Microwave Intensity

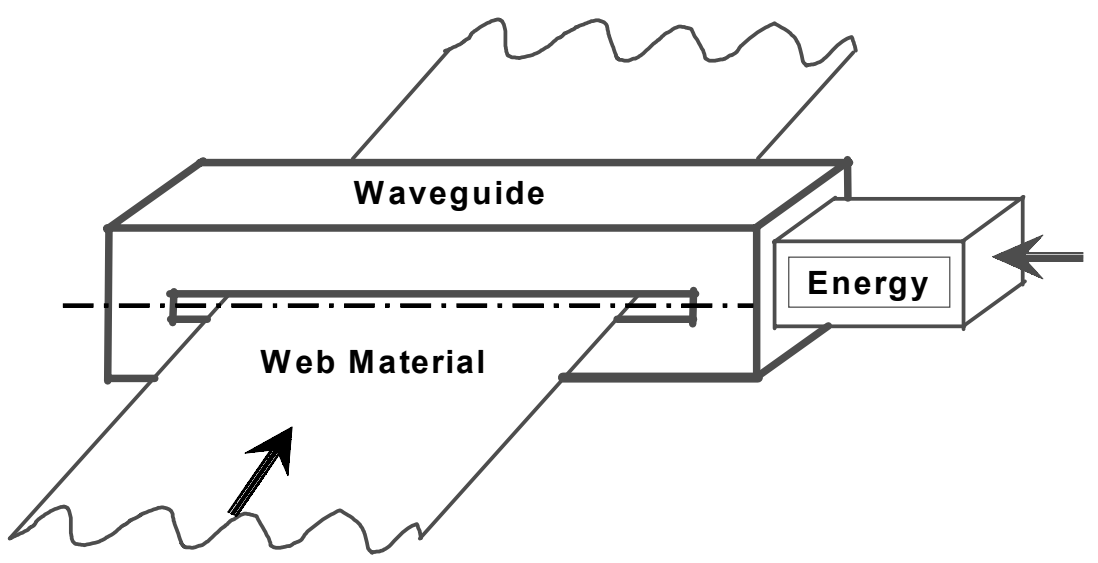

Figure 2. CD-Oriented Waveguide 


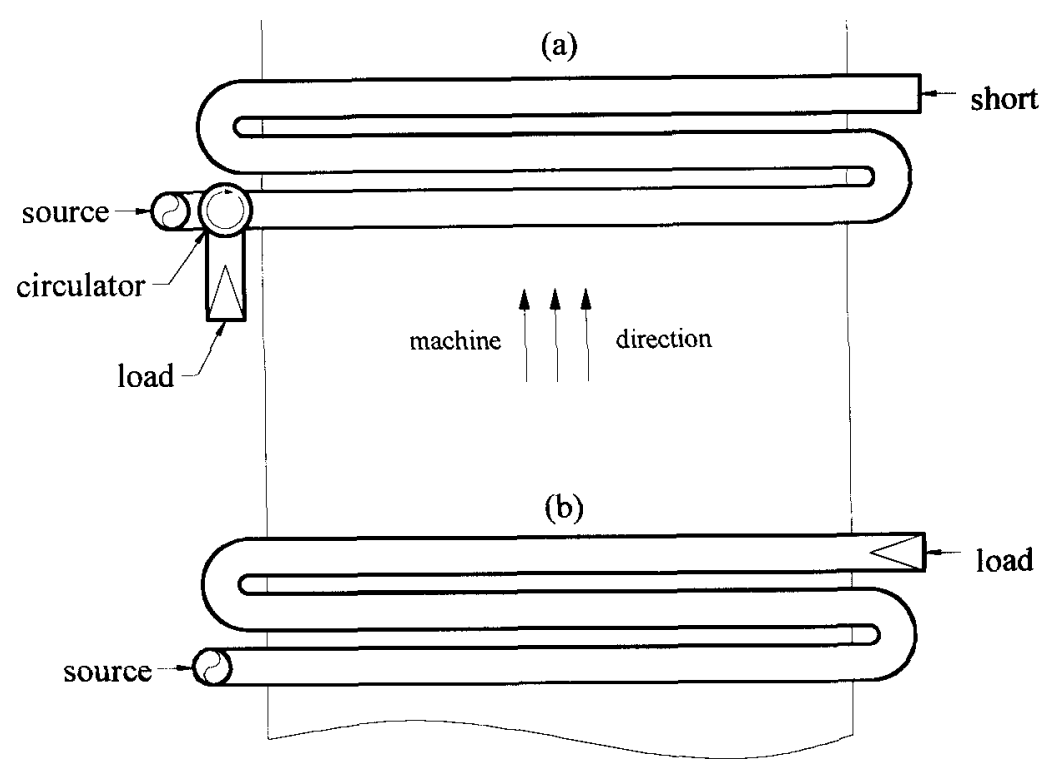

Figure 3. Two Serpentine Microwave Applicator Configurations: (a) Short at Termination End; (b) Dummy Load at Termination End.

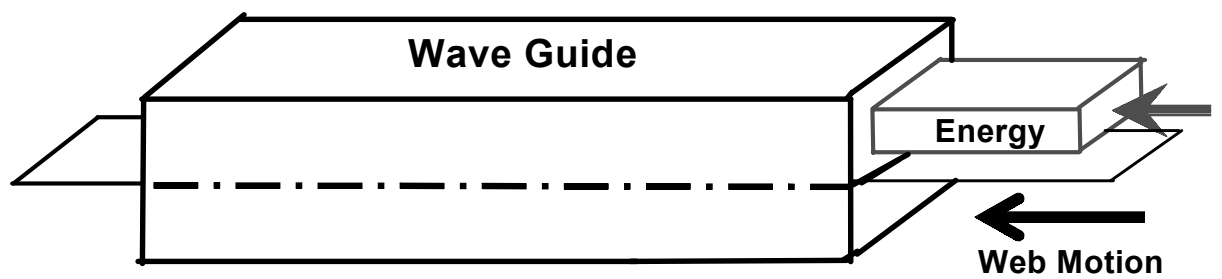

Figure 4. MD-Oriented Waveguide 


\section{CD APPLICATOR: INTRODUCTION AND THEORY}

\section{INTRODUCTION}

Microwave drying of paper has been investigated periodically since the 1960's (Williams, 1966). One of the first studies completed (Hankin, et al, 1970) reported the experience gleaned from operation of a $30 \mathrm{~kW}$ microwave dryer tested on a 24 " wide pilot paper machine. The microwave applicator was based on a multi-pass (serpentine), slotted waveguide, with a dummy load at the end to absorb energy not absorbed by the moist paper. The slots were located along the centerline of the broad walls of the waveguide, in order to place the paper in the plane of maximum electric field. The research demonstrated effective drying of several different paper grades, with improvements in moisture profiles dependent on type of stock, basis weight, and white water dielectric properties. In addition, the paper stretch, rupture energy, and folding strength properties were found to improve versus conventional drying techniques, while stiffness decreased. These changes were attributed to the unconstrained shrinkage of the paper web during microwave drying.

Calculation of microwave heating rates requires knowledge of the effective dielectric loss coefficient. This quantity is dependent on moisture content, temperature, microwave frequency, and water impurity concentration (Schmidt, et al, 1992). Data on the moisture dependence of the loss coefficient for paper, at room temperature and 9.6 GHZ, are available (Habeger and Baum, 1983). The frequency dependence of the loss factor, in combination with the size, cost and available power levels of magnetrons at the two frequencies allowed for industrial heating applications $(0.915$ and $2.45 \mathrm{GHz})$, would need to be considered in designing the most cost-effective system for a particular papermaking application.

The slotted waveguide configuration having slots that are located along the centerline of the broad walls of the waveguide has been favored up until recent times (Jones and Rowley, 1996). However, it has now been recognized (Joines and Drozd, 1999) that the use of slots that are not necessarily located along the centerline should have an important advantage, relative to the possibility of achieving uniform energy absorption across the whole width of the paper machine. Although use of off-center slots raises the issue of escape of electromagnetic energy, the use of suitable choke flanges should result in negligible losses (Joines and Drozd, 1999). Considering first the traditional on-centerline approach, it is clear that if absorption is occuring, the peak electric field will progressively decrease with cross-machine position. Since dissipation in the material is proportional to the square of the field strength (Jones, 1986), uniformity will be impossible. On the other hand, with the new approach, one could start the slot (at the supply end of the applicator) off-center, where the field is lower, and gradually bring it toward the center as a function of cross-machine position. This holds the potential for achieving uniformity. An example of this configuration is shown in Figure 1. If the slot height function of interest is linear, there is no implementation problem. If it is a curve, one might have to use a curved waveguide with a straight-line slot to achieve the desired 
effect. The remainder of the chapter considers the design for uniformity and other design issues in more detail.

\section{ANALYTICAL RESULTS FOR DESIGN OF SLOTTED WAVEGUIDES FOR UNIFORM PAPER HEATING VIA MICROWAVE ENERGY}

The approach to be used here is to apply fundamental microwave heating principles, with a minimal number of approximations, to the case of a single-pass slotted waveguide applicator having power supplied at one end and a load at the other. The analysis follows a z-directional course along the moist paper web to account for the local rate of conversion of electromagnetic energy to thermal energy. The focus of the analysis is on the heating problem (i.e., assuming that the moisture and temperature-dependent loss coefficient is specified). Coupling to the full-fledged heat and mass transfer problem will be considered in a future paper (in order to predict local web temperature, changes in temperature and moisture content from one pass to another, etc.). Since multiple passes and even multiple serpentine units would likely be needed to accomplish heating/drying over a useful moisture range, at high machine speeds, the results derived here should serve as a suitable 'building block.'

\section{Principles and Approximations}

The approximation of an ideal system in which the only loss of electromagnetic power is that due to dissipation in the wet paper (i.e., no dissipation in the waveguide walls or leakage out the slot) seems reasonable. The rate of dissipation per unit volume of paper is given by (Jones, 1986):

$$
D_{v}(z)=\omega \varepsilon_{0} \varepsilon_{r}^{\prime \prime} E_{p}^{2}(z)
$$

where $E_{p}(z)$ is the electric field at the location of the paper and slot, $h(z)$ (see Figure 1). If we multiply by the paper cross-sectional area (at) (dimensions defined in Figure 1), we get the total rate of dissipation per unit z-directional distance:

$$
D^{\prime}(z) \equiv a t D_{v}(z)=a t \omega \varepsilon_{0} \varepsilon_{r}^{\prime \prime} E_{p}^{2}(z)
$$

At the waveguide cross-section located at any $z$, the total electromagnetic power propagating into that cross-section is $\mathrm{P}(\mathrm{z})$. The law of conservation of energy is:

$$
\frac{d P(z)}{d z}=-D^{\prime}(z)
$$

Since paper is a very thin material compared to the waveguide height (b), a good approximation for the E-field distribution at a waveguide cross-section at any $\mathrm{z}$ is:

$$
E(y, z)=E_{\max }(z) \sin \left(\frac{\pi y}{b}\right)
$$


$E_{\max }(z)$ is the amplitude and occurs at the mid-plane $(\mathrm{y}=\mathrm{b} / 2)$. If the thin wet paper web is located at the elevation: $\quad y=h(z)$

it would thus experience an E-field:

$$
E_{p}(z)=E_{\max }(z) \sin \left(\frac{\pi h(z)}{b}\right)
$$

Because of the sinusoidal variation in $\mathrm{E}$, the total electromagnetic power propagating in the $\mathrm{z}$-direction inside the waveguide at the cross-section located at any $\mathrm{z}$ is adequately approximated by:

$$
P(z)=\frac{a b}{2 Z} E_{\max }^{2}(z)
$$

where $\mathrm{Z}$ is the waveguide impedance (not dependent on the wet paper properties).

We will need no additional principles in order to examine how well various candidate paper elevation profiles $[\mathrm{h}(\mathrm{z})]$ can experience a degree of uniformity of heating (i.e., of dissipation of electromagnetic power). Of course, we can also determine the elevation profile shapes that would provide complete uniformity.

To facilitate the analysis, we can combine equations $(2,3,6$ and7) to achieve a differential equation that describes the variation of E-field experienced by the paper with position, $\mathrm{z}$ :

$$
\frac{d}{d z}\left(\frac{E_{p}^{2}(z)}{\sin ^{2}\left(\frac{\pi h(z)}{b}\right)}\right)=-\frac{2 t Z \omega \varepsilon_{0} \varepsilon_{r}^{\prime \prime}}{b} E_{p}^{2}(z)
$$

The general solution of equation 8 is:

where:

$$
E_{p}(z)=\left(\frac{\sin \left(\frac{\pi h(z)}{b}\right)}{\sin \left(\frac{\pi h(0)}{b}\right)}\right) E_{p}(0) e^{-\bar{\alpha} z}
$$

$$
\mathrm{h}(0)=\text { paper elevation at the inlet }(\mathrm{z}=0)
$$

$\mathrm{E}_{\mathrm{p}}(0)=\mathrm{E}$-field at the inlet, at $\mathrm{y}=\mathrm{h}(0)$, calculable from the input power $\mathrm{P}_{\text {in }}=\mathrm{P}(0)$, using equations (6) and (7).

It is useful to recognize the grouping of parameters:

$$
L_{0} \equiv b /\left(Z \omega \varepsilon_{0} \varepsilon_{r}^{\prime \prime} t\right)
$$


as representing a meaningful length scale for absorption of microwave energy by the moist paper. Normalizing the waveguide (single-pass) length by this quantity defines a dimensionless waveguide length parameter:

$$
\bar{L} \equiv L / L_{0}
$$

Intuitively, a large $\bar{L}$ would correspond to a length over which the moist web absorbs much of the input energy. We can introduce a dimensionless position along the waveguide as:

$$
\bar{z}=z / L
$$

Furthermore, we can normalize the slot (and paper) location by height $b$ :

$$
\bar{h}(\bar{z})=h(\bar{z}) / b
$$

Using equations (12-14), equation (10) can be rewritten:

$$
\bar{\alpha} z=\int_{0}^{\bar{z}} \bar{L} \sin ^{2}(\pi \bar{h}(\bar{z})) d \bar{z}
$$

It can be noticed that, for the special case of $h(z)=$ constant:

$$
E_{p}(\bar{z})=E_{p}(0) e^{-\bar{\alpha} z}
$$

In this case, $\bar{\alpha}$ is constant (but dependent on the value selected for $h(0)$, due to the $\sin ^{2}$ term in equation 15). However, in the general case, $h(z)$ not constant, $\bar{\alpha}$ varies with $\mathrm{z}$, and there is also a variable factor before the exponential term in equation 9.

\section{Special Case 1: Uniform Paper Heating - The Ideal Slot Design}

It is of interest to know the slot design $[\mathrm{h}(\mathrm{z})]$ that provides uniform heating of the paper across the width of the paper machine. This corresponds to the special case of $E_{p}(z)=$ constant. The solution of equation 8 (in dimensionless variables) is then:

$$
\bar{h}(\bar{z}) \equiv h(\bar{z}) / b=\frac{1}{\pi} \sin ^{-1}\left\{\left[\frac{1}{\sin ^{2}\left(\frac{\pi h(0)}{b}\right)}-2 \bar{L} \bar{z}\right]^{-\frac{1}{2}}\right\}
$$

It is useful to recognize that, for a given initial slot height $(\bar{h}(0))$, there is a maximum value of $\bar{L}$ that can be used for uniform heating via the variable slot height technique. This value corresponds to $\bar{h}(\bar{z}=1)=0.5$, signifying that the 
slot ends at the mid-plane of the waveguide. This "ideal dimensionless length" is, from equation (17):

$$
\bar{L}_{\text {ideal }}=\frac{1}{2}\left(\frac{1}{\sin ^{2}(\pi \bar{h}(0))}-1\right)
$$

The variation of ideal length with initial slot height is shown in Figure 2.

Example slot shapes, computed by inserting the ideal length values into equation (17), are shown in Figure 3. Note that slots starting farther from the midplane have much more curvature near the outlet end of the waveguide. Of course, they also provide more complete absorption of the input power by the paper. The completeness of absorption can be measured by an efficiency, defined as:

$$
\eta=\left(P_{\text {in }}-P_{\text {out }}\right) / P_{\text {in }}
$$

For ideal slots (uniform absorption and termination at the mid-plane), it can be shown that :

$$
\eta=2 \bar{L}_{\text {ideal }} /\left(1+2 \bar{L}_{\text {ideal }}\right)
$$

This relation, and an alternate one in terms of $\bar{h}(0)$ (via equation (18)), are shown in Figures 4 and 5.

While efficiency is important, so, too, is drying rate (per unit area). With a view toward use of multi-pass (serpentine) applicator units, the machine-direction (MD) length (per pass) can be (arbitrarily) defined as $\left(a / f_{W G}\right)$, which includes both the open (nonwaveguide) area between passes and the waveguide MD width. A reference drying rate, based on the absorption length and on the approximation that all energy absorbed produces evaporation, can then be defined as:

$$
\dot{m}_{D, \text { Ref }}^{\prime \prime} \equiv f_{W G} P_{i n} /\left(\lambda a L_{0}\right)
$$

The actual (dimensionless) drying rate for an ideal-length waveguide can be shown to be:

$$
\overline{\dot{m}}_{D}^{\prime \prime} \equiv \dot{m}_{D}^{\prime \prime} / \dot{m}_{D, \operatorname{Ref}}^{\prime \prime}=\left(\frac{2}{1+2 \bar{L}}\right)=2(1-\eta)
$$

This relationship is shown in Figure 6. Considering Figures 5 and 6 together, it is clear that there is a tradeoff between efficiency (operating cost) and drying intensity (space and capital cost). This is, of course, true for most thermal/energy systems. 


\section{Special Case 2: Linear Variation of Slot Height with Distance Along the Waveguide}

Because the ideal slot design is a curve, it is also of interest to know whether a slot design with linear variation of slot height with cross-machine position would provide adequate uniformity. Considering a case for which the slot starts at a position $\bar{h}(0)$ and ends at the mid-plane $(\bar{h}(1)=1 / 2)$, the term $\bar{\alpha} z$ (equation $(15))$ becomes:

$$
\bar{\alpha} z=\frac{\bar{L}}{2}\left\{\left(\frac{\bar{h}(\bar{z})-\bar{h}(0)}{\Delta \bar{h}}\right)-\left(\frac{1}{2 \pi \Delta \bar{h}}\right)[\sin (2 \pi \bar{h}(\bar{z}))-\sin (2 \pi \bar{h}(0))]\right\}
$$

If we further desire to achieve equal dissipation rates at the two ends of the waveguide (a potentially reasonable design constraint), it can be shown that we must select $\bar{L}$ as:

$$
\bar{L}_{\text {linear }}=2 \ln \left(\frac{1}{\sin (\pi \bar{h}(0))}\right) /\left(1+\left(\frac{1}{2 \pi \Delta \bar{h}}\right) \sin (2 \pi \bar{h}(0))\right)
$$

For low values of $\bar{h}(0)$, the deviation from the ideal length (for uniform absorption) becomes significant (see Figure 7). The resulting local dissipation (normalized to the value at the inlet) is shown in Figure 8. It is seen that a "linear slot" is best suited to situations with a relatively large initial slot height. For the 'worst case' from Figure 8, the effect of increasing $\bar{L}$ is illustrated in Figure 9. This change has the effect of reducing the peak dissipation, but it, unfortunately, also causes the absorption near the outlet end to decrease to undesirably low levels.

\section{EXTENSION OF IDEAL SLOT RESULTS TO SERPENTINE (MULTI-PASS) APPLICATORS}

For paper manufacture applications, the ranges of basis weight and moisture content of interest, together with the selected frequency $(0.915 \mathrm{GHz}$ or $2.45 \mathrm{GHz})$, will correspond to a wide range of $L_{0}$ values. In combination with the range of typical paper machine widths $\left(L_{P M}\right)$, a wide range of $\bar{L}_{\text {ideal }}$ is, thus, to be expected. The results presented in the preceding section imply that there will surely be some paper manufacture applications for which a single-pass applicator would have an unacceptably low efficiency. In this situation, additional passes to absorb energy not absorbed in the first pass, would be indicated.

Two alternative multi-pass system design strategies can be considered. One strategy (\#1) would be to select the same "initial slot height" for each pass, ending the slot at the midplane for each pass. The other (\#2) would be to consider the total active length of the multi-pass system to be equivalent to one longer pass, with the slot shape varying continuously over the entire unit (reaching the mid-plane only at the end of the final 
pass). For these strategies, the initial slot height for (\#1) would clearly have to exceed that for (\#2), assuming $L_{0}$ is constant. It appears that strategy (\#1) will always yield higher efficiency than strategy (\#2), for a given number of passes.

For strategy (\#1), with $\mathrm{N}$ passes, the following results are easily derived:

$$
\eta_{\text {overall }}=1-\left(1-\eta_{1-\text { pass }}\right)^{N}
$$

and, (using equation 22 to get the second form):

$$
\overline{\dot{m}}_{D, \text { overall }}^{\prime \prime}=\overline{\dot{m}}_{D, 1-\text { pass }}^{\prime \prime}\left[\frac{\sum_{i=1}^{N}\left(1-\eta_{1-\text { pass }}\right)^{i-1}}{N}\right]=2\left[\frac{\sum_{i=1}^{N}\left(1-\eta_{1-\text { pass }}\right)^{i}}{N}\right]
$$

Thus, the efficiency of a multi-pass system increases, but the average drying rate decreases, compared to those for a 1-pass system.

\section{PRELIMINARY APPLICATION OF ANALYTICAL RESULTS}

To apply the results in the preceding section, we must specify parameters of the waveguide (frequency, dimensions, and impedence), the moist paper (dielectric loss coefficient), and the paper machine (cross-direction length and water loadings). Data on the loss coefficient for paper at the two 'allowed' frequencies $(0.915$ and $2.45 \mathrm{GHz}) \mathrm{do}$ not appear to be available, and we are in the process of measuring this parameter over a meaningful range of moisture and temperature. Here, we will utilize approximate values for water, together with data for moist paper at another frequency (Habeger and Baum, 1983), to make a preliminary estimate (via a procedure outlined below) of the required loss coefficients. The waveguide parameters and water loss coefficient values are given in Table 1. The wide ranges of water loadings (the product of paper basis weight and moisture ratio) and cross-direction lengths ( $\left.\mathrm{L}_{\mathrm{PM}}\right)$ of potential interest for the paper industry (encompassing applications from web heating through the drying process) are given in Table 2.

Table 1. Waveguide and Water Loss Coefficient Parameters.

\begin{tabular}{|c|c|c|c|c|c|c|}
\hline $\begin{array}{c}\mathrm{f}(\mathrm{GHz}) \\
\text { frequency }\end{array}$ & $\begin{array}{c}\mathrm{fc}(\mathrm{GHz}) \\
\text { [cutoff } \\
\text { frequency] }\end{array}$ & $\mathrm{Z}(\mathrm{ohm})$ & $\mathrm{a}(\mathrm{m})$ & $\mathrm{b}(\mathrm{m})$ & $\begin{array}{c}\varepsilon_{\mathrm{r}}{ }^{\prime \prime}, \text { water } \\
\text { at } \\
25^{\circ} \mathrm{C}\end{array}$ & $\begin{array}{c}\varepsilon_{\mathrm{r}}{ }^{\circ}, \text { water } \\
\text { at } \\
50{ }^{\circ} \mathrm{C}\end{array}$ \\
\hline 0.915 & 0.605 & 503 & 0.124 & 0.2477 & 3.5 & 1.8 \\
\hline 2.45 & 2.078 & 712 & 0.034 & 0.0721 & 9 & 5 \\
\hline
\end{tabular}


Table 2. Typical Paper Manufacture Parameter Ranges.

\begin{tabular}{|c|c|c|c|c|}
\hline & BW, $g / \mathrm{m}^{2}$ & $\begin{array}{c}\mathrm{m}_{\mathrm{r}}, \\
\text { kgwater/kgsolid }\end{array}$ & $\mathrm{m}_{\mathrm{w}}{ }^{\prime}, \mathrm{g} / \mathrm{m}^{2}$ & L $_{\mathrm{PM}}, \mathrm{m}$ \\
\hline Min (approx.) & 15 & 0.1 & 1.5 & 1 (pilot PM) \\
\hline Max (approx.) & 300 & 2 & 600 & 10 \\
\hline
\end{tabular}

The analysis in the preceding section has shown that it is actually the product $\varepsilon_{\mathrm{r}}$ "t that is important in characterizing applicator performance. The available data on loss coefficient for moist paper (Habeger and Baum, 1983) indicate that, above moisture contents of about $12 \%$, the loss coefficient is approximately directly proportional to the apparent density of water in the structure (i.e., the mass of water per unit volume of paper). Therefore, multiplying both the loss coefficient and the apparent water density by thickness, we see that $\varepsilon_{\mathrm{r}}$ ”t is a function of water loading $\left(\mathrm{m}_{\mathrm{w}}{ }^{\prime}, \mathrm{g} / \mathrm{m}^{2}\right)$, for a given frequency and temperature. The cited data also indicate that, at water apparent densities approaching unity, the loss coefficient is only about half that for pure water. Extrapolating the above observations to the case of other frequencies and temperatures, we find an approximate relationship for $\varepsilon_{\mathrm{r}}$ "t:

$$
\varepsilon_{r}^{\prime \prime} t \approx 0.5 \times 10^{-6} \varepsilon_{r, w a t e r}^{\prime \prime} m_{w}^{\prime \prime}
$$

if $\mathrm{t}$ is in meters and $m_{w}^{\prime \prime}$ in $\mathrm{g} / \mathrm{m}^{2}$.

With the approximate relationship described by equation 27 , we can employ data from Tables 1 and 2 to calculate the values of the absorption length for frequencies and water loadings of interest. The results of such calculations are given in Table 3.

Table 3. Estimated Absorption Length (L0) Values.

\begin{tabular}{|c|c|c|r|r|}
\hline $\mathrm{f}(\mathrm{GHz})$ & $m_{w}^{\prime \prime}\left(\mathrm{g} / \mathrm{m}^{2}\right)$ & Temperature $\left({ }^{\circ} \mathrm{C}\right)$ & \multicolumn{1}{c|}{$\varepsilon_{\mathrm{r}}{ }^{\prime \prime} \mathrm{t}(\mathrm{m})$} & \multicolumn{1}{c|}{$\mathrm{L} 0(\mathrm{~m})$} \\
\hline 0.915 & 1.5 & 25 & 0.000002625 & 3687.09 \\
\hline 0.915 & 30 & 25 & 0.0000525 & 0.00105 \\
\hline 0.915 & 600 & 25 & 0.00000135 & 784.35 \\
\hline 0.915 & 1.5 & 50 & 0.000027 & 3.21 \\
\hline 0.915 & 30 & 50 & 0.00054 & 17.36 \\
\hline 0.915 & 600 & 50 & 0.00000675 & 110.11 \\
\hline 2.45 & 1.5 & 25 & 0.000135 & 5.50 \\
\hline 2.45 & 30 & 25 & 0.0027 & 0.27 \\
\hline 2.45 & 600 & 25 & 0.00000375 & 198.21 \\
\hline 2.45 & 1.5 & 50 & 0.000075 & 9.91 \\
\hline 2.45 & 30 & 25 & 0.0015 & 0.49 \\
\hline 2.45 & 600 & 50 & & \\
\hline
\end{tabular}

There are some soft constraints on the range of waveguide designs that are of practical interest. First, there must be a lower bound on the initial height ratio, $h(0) / b$, because it 
would be difficult to ensure that the paper could travel very close to the bottom wall of the waveguide. A suggested lower bound for this ratio would be about 0.1 . According to equation 18 , this would constrain the ideal dimensionless length to $\bar{L}_{\text {ideal }} \leq 4.74$.

A second constraint would be related to the desire that the single-pass efficiency not be too low, because otherwise the number of passes need to get good overall efficiency would become large (see equation 25), causing the average drying rate to become small (see equation 26). For example, if the number of passes were limited to five, a single-pass efficiency of at least about $30 \%$ would be needed to achieve an overall efficiency above $80 \%$. Using a single-pass efficiency of $30 \%$ as a suggested bound, the corresponding bound on ideal dimensionless length would be (approximately): $\bar{L}_{\text {ideal }} \geq 0.21$.

If we consider an example paper machine width of $5 \mathrm{~m}$, we can combine the definition of dimensionless length (equation 12) with the upper and lower bounds just identified, to establish a corresponding range of absorption length values: $1.06 m \leq L_{0} \leq 23.7 \mathrm{~m}$. This range should correspond to the most promising papermaking applications for the technology under consideration. The water loading range and frequency combinations that correspond to this absorption length range are suggested by the results in Table 3 . It appears that the use of $0.915 \mathrm{GHz}$ is best suited for the mid-to-upper portion of the loading range, while the $2.45 \mathrm{GHz}$ frequency may be advantageous for lower water loading situations. It must be emphasized that these are very preliminary observations, and more thorough evaluation, using more accurate loss coefficient data, is needed.

\section{CONCLUDING REMARKS}

The use a variable waveguide applicator slot height has been shown to provide a way to achieve uniform heating of wide paper webs. Based on the calculations using estimated loss coefficients, it appears that at least a significant portion of the spectrum of meaningful paper machine width and water loading combinations should be suited to the application of the technology investigated here. Future work will include collection and application of improved loss coefficent data. The design model described here will then be applied to the design of low power density experimental applicator units corresponding to promising ranges of papermaking variables. This will allow us to verify the ability to design for energy absorption uniformity, and to investigate the robustness of the applicator with respect to variations in the initial moisture or temperature levels, or their degree of uniformity. Additional work will include development of a full drying model, and its application to design of a high power pilot unit.

\section{REFERENCES}

Habeger, C., and Baum, G.A., "The Microwave Dielectric Constants of Water-Paper Mixtures: The Role of Sheet Structure and Composition," Journal of Applied Polymer Science, 28, 1983, p.969-981. 
Hankin, J.W., Leidigh, W.J., and Stephansen, E.W., "Microwave Paper Drying Experience and Analysis," TAPPI Journal, 53(6), 1970, p.1063-1070.

Joines, W. T., and Drozd, J. M., "Method and Apparatus for Electromagnetic Exposure of Planar or Other Materials," U. S. Patent 5,958,275 (Sept. 28, 1999).

Jones, P.L., "High Frequency Dielectric Heating in Paper Making," Drying Technology, 4(2), 1986, p.217-244.

Jones, P.L. and Rowley, A.T., "Dielectric Drying," Drying Technology, 14(5), 1996, p.1063-1098.

Schmidt, P.S., Bergman, T.L., Pearce, J.A., and Chen, P., "Heat and Mass Transfer Considerations in Dielectrically-Enhanced Drying," Drying '92, Book 1, Elsevier Science, 1992, p.137.

Williams, N.H., "Moisture leveling in paper, wood, textiles, and other mixed dielectric sheets," Journal of Microwave Power, 1(3), 1966, p.73-80. 


\section{NOTATION}

a

b

BW

$\mathrm{D}_{\mathrm{v}}$

$\mathrm{D}^{\prime}$

E

f, $f_{0}$

$\mathrm{h}$

L

$\mathrm{L}_{0}$

$\dot{m}_{D}^{\prime \prime}$

$\mathrm{m}_{\mathrm{r}}$

$m_{w}^{\prime \prime}$

$\mathrm{N}$

$\mathrm{P}$

$\mathrm{t}$

$\mathrm{y}$

$\mathrm{z}$

Z

Greek

$\bar{\alpha}$

$\varepsilon_{0}$

$\varepsilon_{r}^{\prime \prime}$

$\lambda$

$\eta$

$\omega$

$\Delta \bar{h}$

$\begin{array}{lll}\text { Subscripts } & & \text { Subscripts } \\ \text { ideal } & \text { ideal slot height variation case } & \text { PM } \\ \text { in } & \text { waveguide inlet (power input end) } & \text { Ref } \\ \text { linear } & \text { linear slot height variation case } & \text { 1-pass } \\ \text { max } & \text { maximum, at a given cross-section } & \text { water } \\ \text { out } & \text { waveguide exit (load end) } & \\ \text { overall } & \text { for all N passes } & \text { over bar } \\ \mathrm{p} & \text { paper } & \end{array}$

$\mathrm{m}$

$\mathrm{m}$

$\mathrm{g} / \mathrm{m}^{2}$

$\mathrm{W} / \mathrm{m}^{3}$

$\mathrm{W} / \mathrm{m}$

$\mathrm{V} / \mathrm{m}$

$\mathrm{GHz}$

$\mathrm{m}$

m

$\mathrm{m}$

$\mathrm{kg} /\left(\mathrm{m}^{2}-\mathrm{s}\right)$

$\mathrm{g}$ water/g solid

$\mathrm{g} / \mathrm{m}^{2}$

W

$\mathrm{m}$

$\mathrm{m}$

$\mathrm{m}$

ohm

$1 / \mathrm{m}$

farads $/ m$

$\mathrm{kJ} / \mathrm{kg}$

$1 / \mathrm{s}$

$\mathrm{m}$

paper machine

reference value

one (first) pass

water only

dimensionless quantities, defined in text by equations

$12,13,14,22$ 


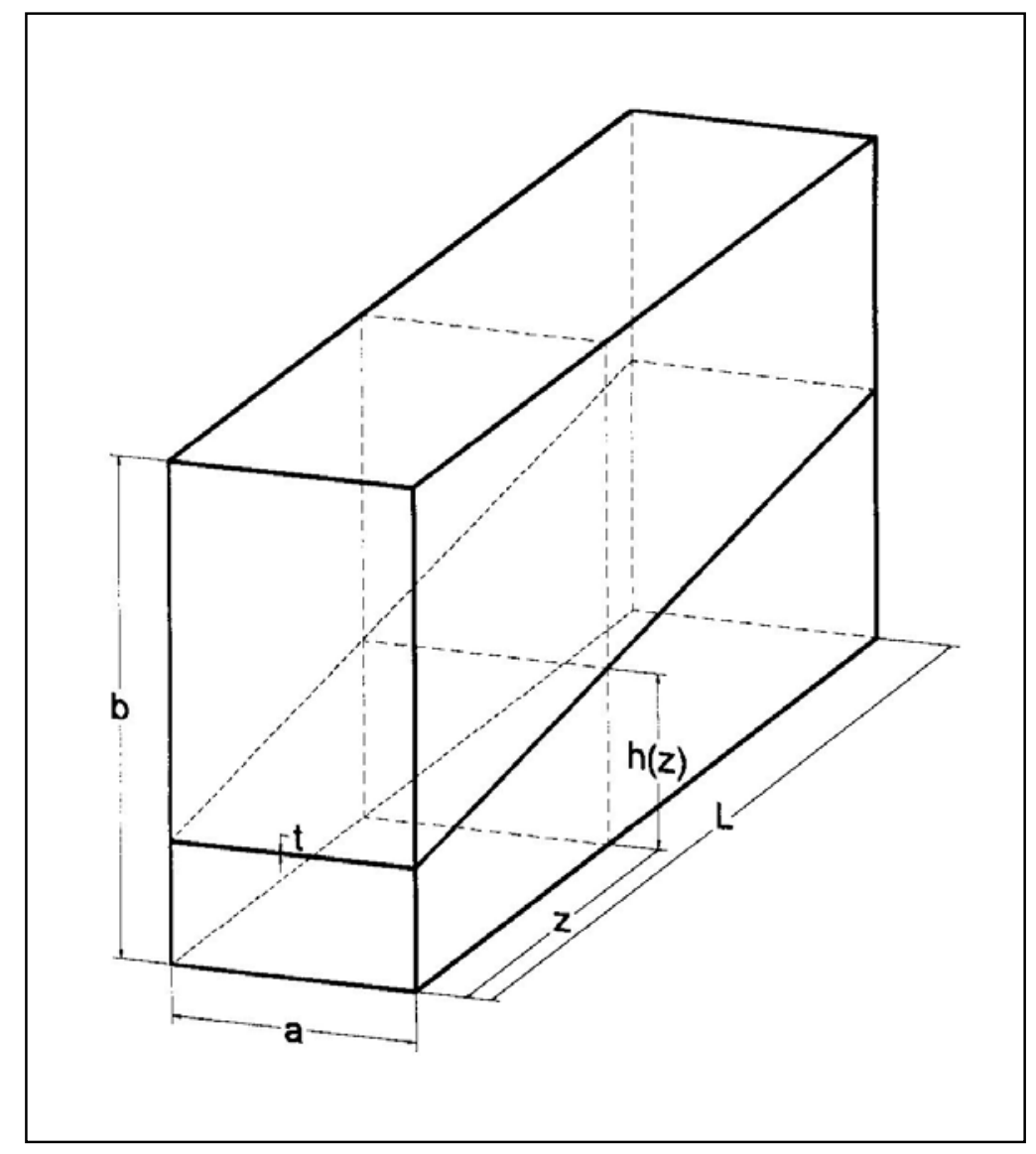

FIGURE 1. Definition of Slot (and Paper) Location within the Waveguide. The cross-machine coordinate is $\mathrm{z}$ and $\mathrm{h}(\mathrm{z})$ is the local elevation of the slot above the bottom of the waveguide. The overall active cross-machine length is $\mathrm{L}$.

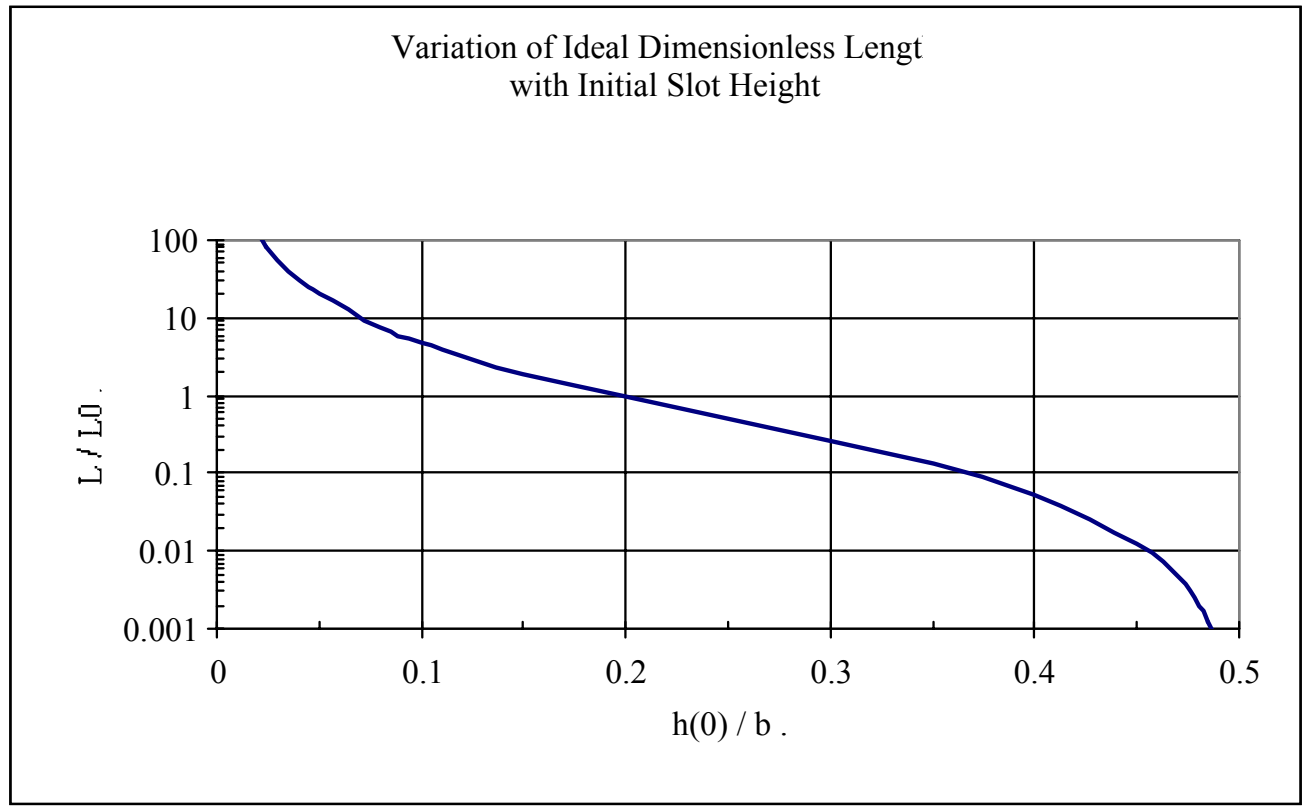

FIGURE 2. Ideal Dimensionless Length vs. Initial Slot Height. 


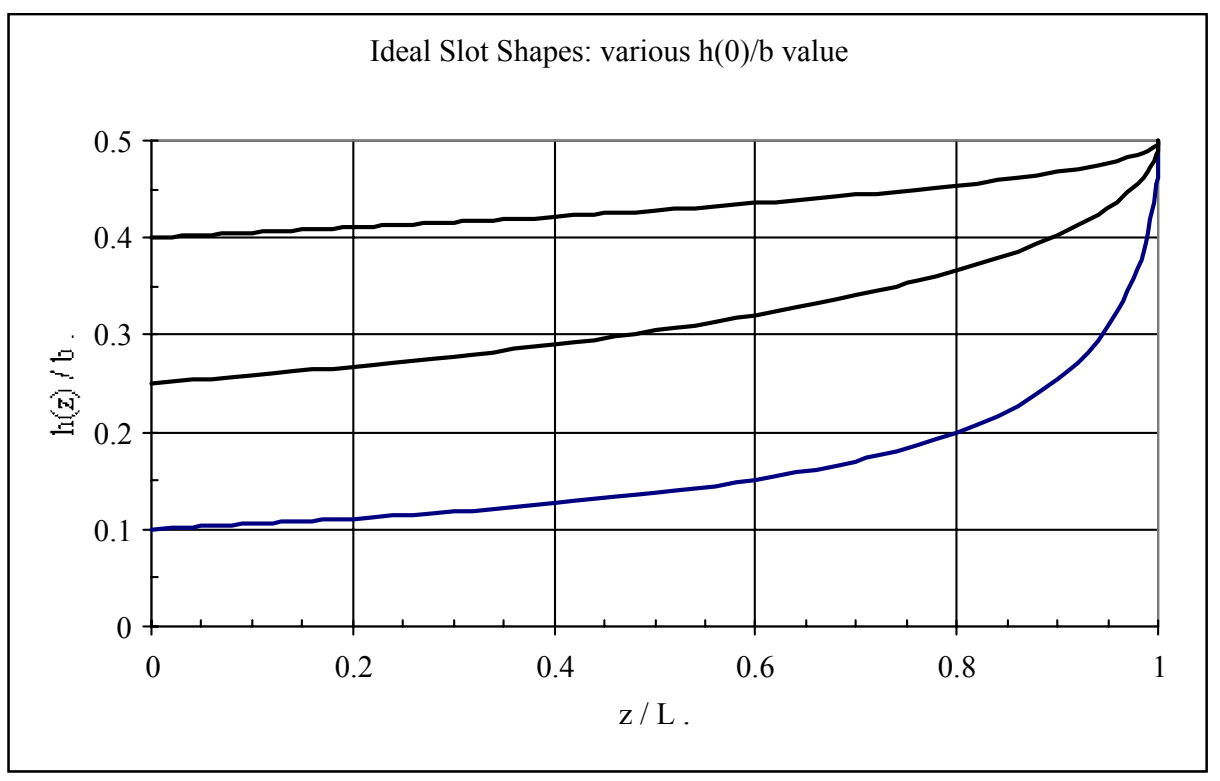

FIGURE 3. Ideal Slot Shapes for $h(0) / b=0.1,0.25,0.4$.

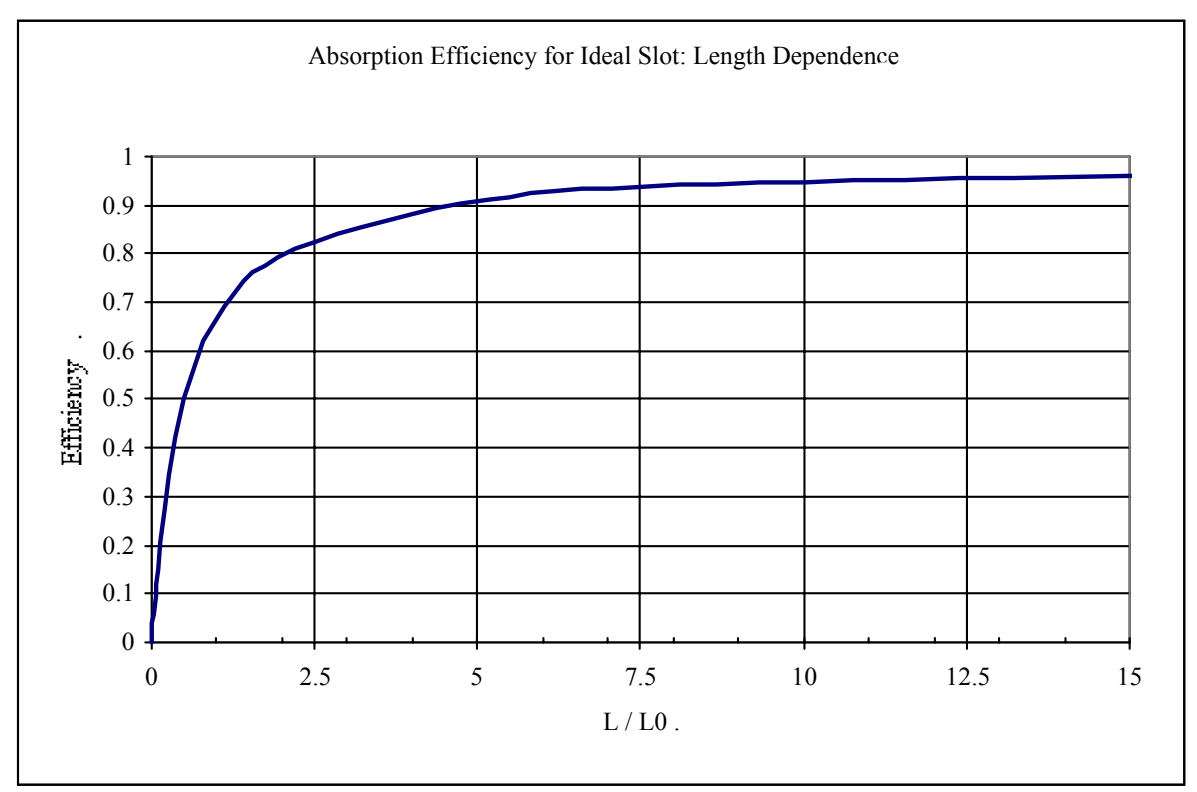

FIGURE 4. Efficiency vs. Ideal Dimensionless Length. 


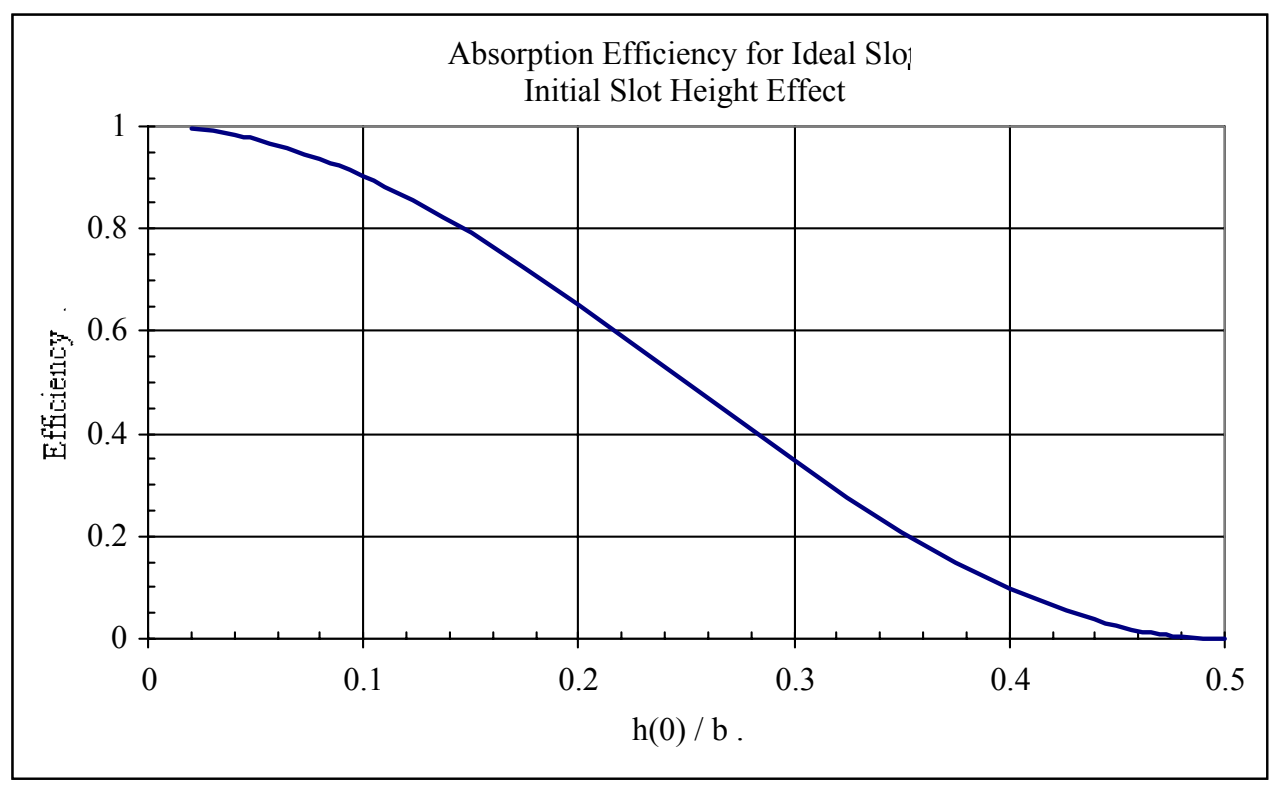

FIGURE 5. Efficiency (at Ideal Length) vs. Initial Height.

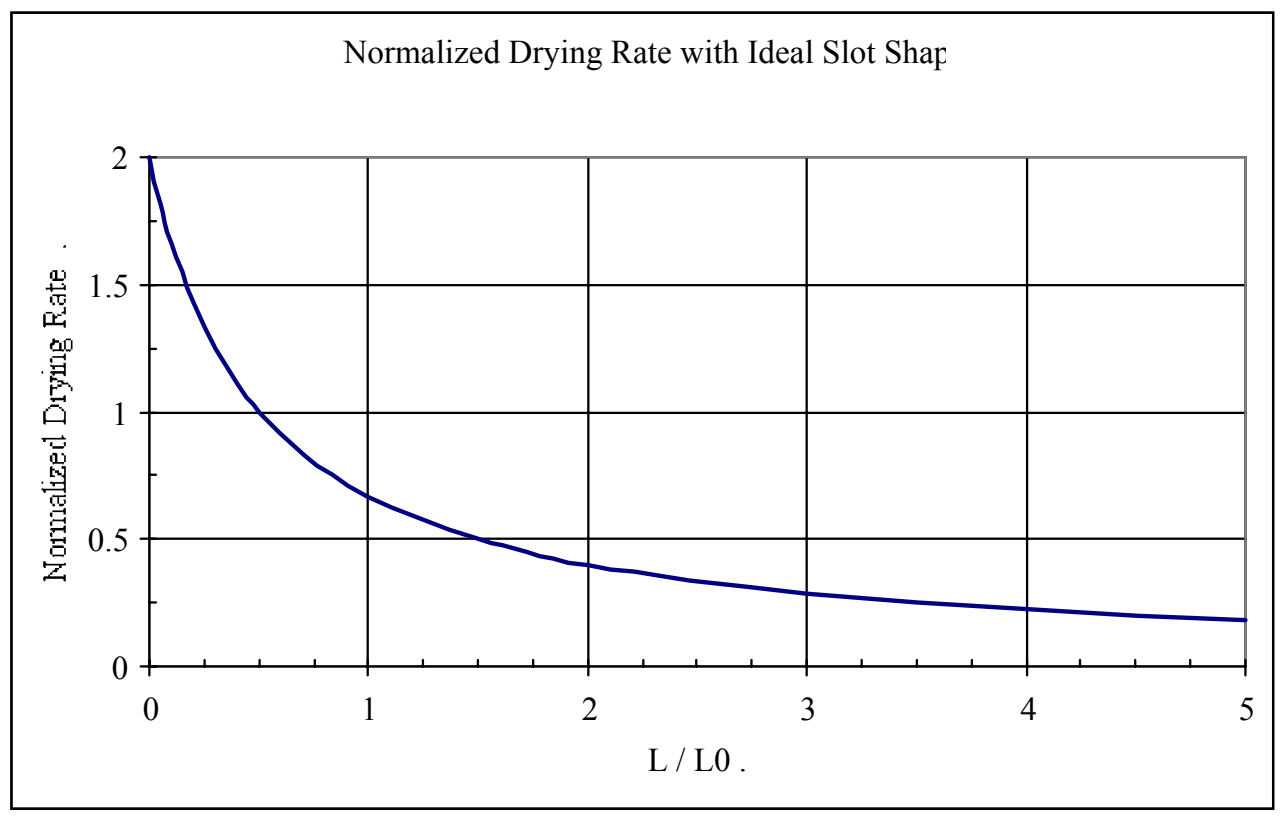

FIGURE 6. Normalized Drying Rate for Ideal Length. 


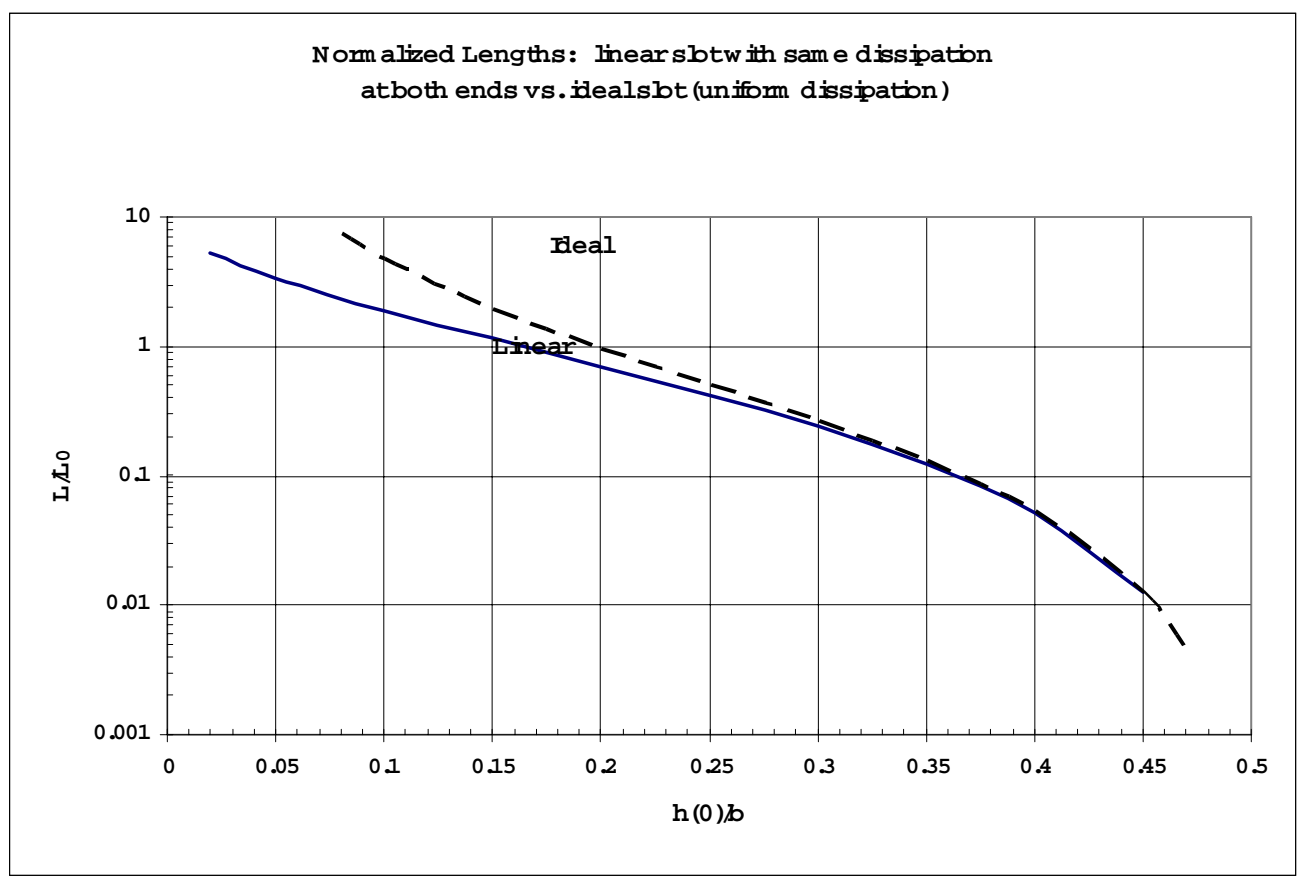

FIGURE 7. Comparison of Dimensionless Lengths.

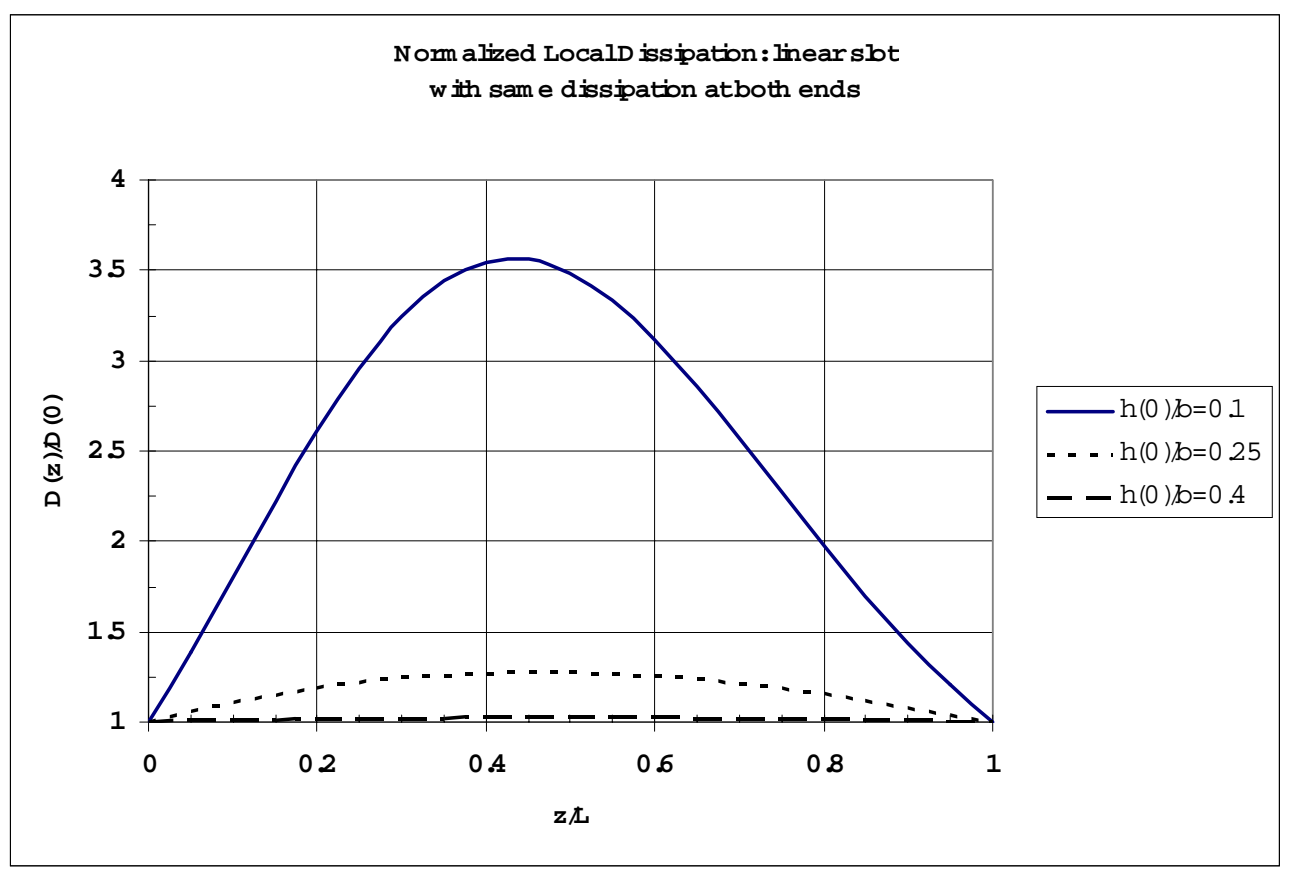

FIGURE 8. Variation in Local Dissipation (Linear Slots). 


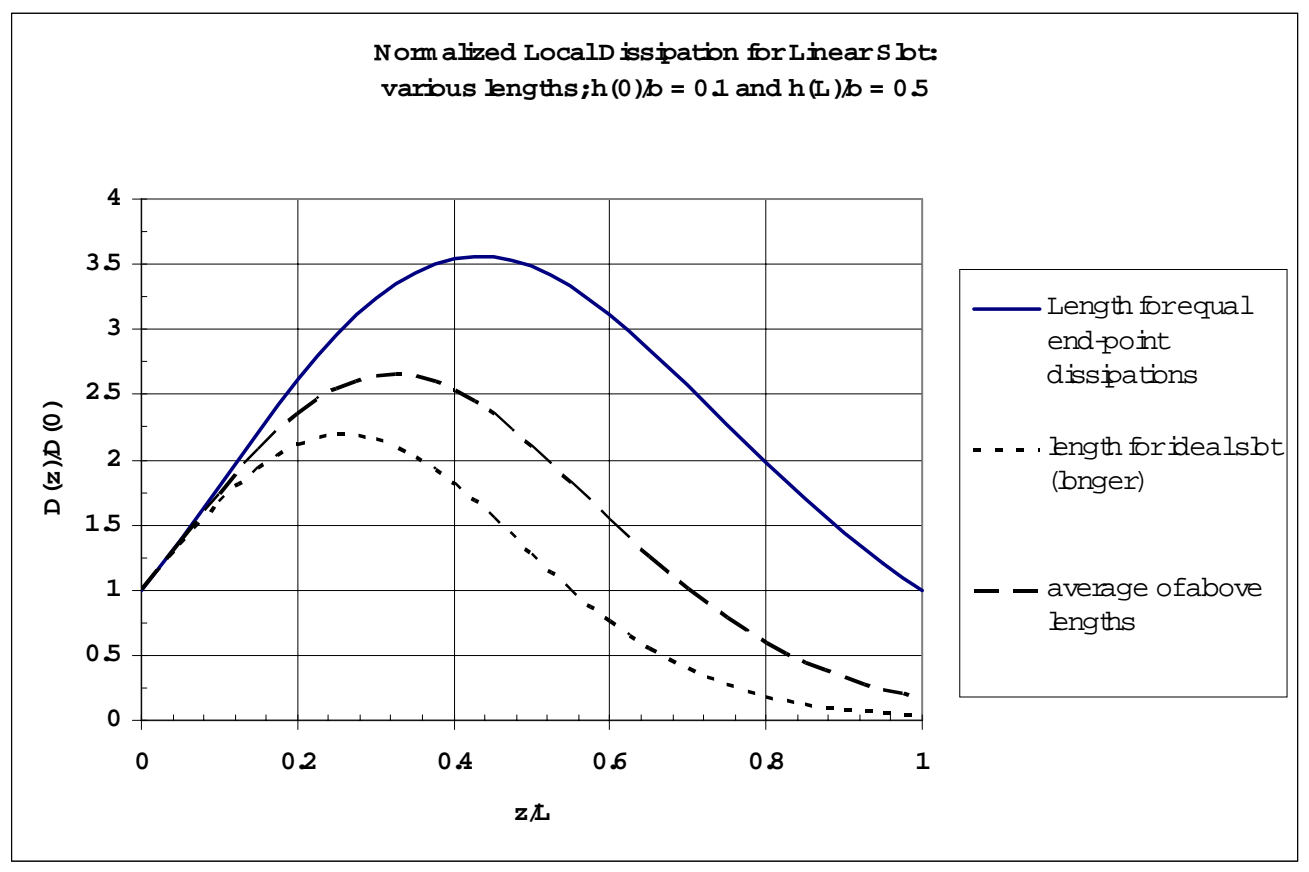

FIGURE 9. Effect of Length Change on Dissipation Profile. 


\section{CD APPLICATOR: EXPERIMENTAL}

\section{INTRODUCTION}

As discussed in Chapter II, a CD - oriented applicator with the ideal slot geometry has the potential (in theory) to provide uniform heating of a paper web, provided a dummy load is placed at the termination end of the waveguide to prevent reflections. The ideal slot geometry was shown to depend on the water basis weight in the applicator. In this chapter, we describe experiments performed to test these ideas.

\section{SCOPE AND RESULTS}

Both heating uniformity and process efficiency were evaluated over a wide range of water loads for two waveguide geometries ("linear (diagonal) slot" and "ideal slot"). The waveguides were configured with either a reflector plate or a dummy load at the termination end (both were tested). A $3 \mathrm{~kW}$ microwave generator (915 MHz), supplied by Industrial Microwave Systems (IMS), was used for the tests. The uniformity of the heating profile was measured using six IR temperature sensors that recorded the sheet temperature across the waveguide length (i.e., corresponding to the paper machine CD) during the test. The presence of field strength peaks (hot spots) and valleys (cold spots) was detected by checking for relative dry and wet spots on the test sheet at the conclusion of a test. Absorption efficiencies were determined by using the generator electrical power reading for the supply power and thermodynamic principles (mass and energy balances) for calculating the power absorbed by the test sheet.

As expected, the presence of a standing wave was apparent when the waveguides were configured with a reflector plate at the termination end. Unexpectedly, a standing wave was also produced when the waveguides were configured with a dummy load. The amplitude of the strength peaks and valleys were slightly less when the waveguides were configured with a dummy load, but significant nevertheless. The wet and dry zones were observed at about $22.5 \mathrm{~cm}$ intervals (peak to peak) for all waveguide test conditions. There was a phase shift in the wet zone locations between the linear slot waveguide and the ideal slot shape waveguide. Figure 1 is an illustration of a typical sheet after a test.

Both the linear slot and the "ideal" slot shape waveguide did produce a uniform "overall" moisture profile (i.e., after averaging the peaks and valleys effect), at a single water basis weight. More drying occurred near the source end of the waveguide in the tests where the water basis weights were higher. More drying occurred near the termination end of the waveguide in the tests where the water basis weights were lower. For example, Figure 1 shows a sheet that is drier near the termination end of the waveguide, indicating that the tested water weight was "too low" for the slot geometry employed.

Figure 2 shows absorption efficiency of the $\mathrm{CD}$ oriented waveguide as a function of the waveguide water load. The water load is defined as the product of the average water basis weight of the sheet in the waveguide and the waveguide length. In turn, average water 
basis weight is defined as the product of the dry basis weight and the average moisture ratio of the test sheet. The solid line is the absorption efficiency of a sheet that is at the mid-plane and having a reflector plate at the termination end of the waveguide. That trend is based on the results from MD oriented waveguide tests, discussed later, and can be considered to be the maximum absorption potential. Because the feed slots for the linear and ideal waveguides are not at the mid-plane, the absorption efficiency is significantly less than the maximum absorption potential. This means that much longer waveguides are needed to attain a given efficiency. The presence of a dummy load also reduces the absorption efficiency.

\section{DISCUSSION OF RESULTS}

The CD-oriented microwave application requires appreciable design complexity in order to produce a uniform $\mathrm{CD}$ moisture profile. The additional design elements tend to lower absorption efficiencies. A CD-oriented applicator with the non-centerline feed (to compensate for attenuation) needs a waveguide that is more than 5 times the length of that required if the sheet travels through the mid-plane (i.e., as is the case for the MDoriented applicator to be discussed in Chapters IV and V). The efficiency will be even less if a dummy load is needed to prevent reflections (hot spots), which cause nonuniform drying (such as shown in Figure 1). In many paper manufacture applications, a single-pass CD-oriented applicator would have unacceptably low efficiency. In those cases, additional passes are needed to absorb energy not absorbed in the first pass. Because of the additional length requirement (for acceptable efficiencies), the machine floor area savings that the MD-oriented system provides (over conventional steam dryer cans) is lost.

In order to control the $\mathrm{CD}$ moisture profile and/or to be able to accommodate a range of water basis weights, the ability to vary the applicator feed slot geometry is needed. The process becomes even more complex if phase shifters are needed to offset hot and cool spot exposures.

\section{CONCLUDING REMARKS}

The experimental research reported here has suggested that a cross-machine direction applicator system for microwave energy (CD-oriented waveguides) is not a viable method for web preheating and incremental web heating/drying, because the heating uniformity suggested by theory does not seem to materialize in practice. However, as will be discussed in a later chapter, CD moisture profile control can be incorporated into the MD-oriented applicator system. The MD-oriented concept is preferred over the CDoriented concept because it 1) is less complex, 2) requires less floor space for the equipment and 3) is better suited for CD moisture control. 


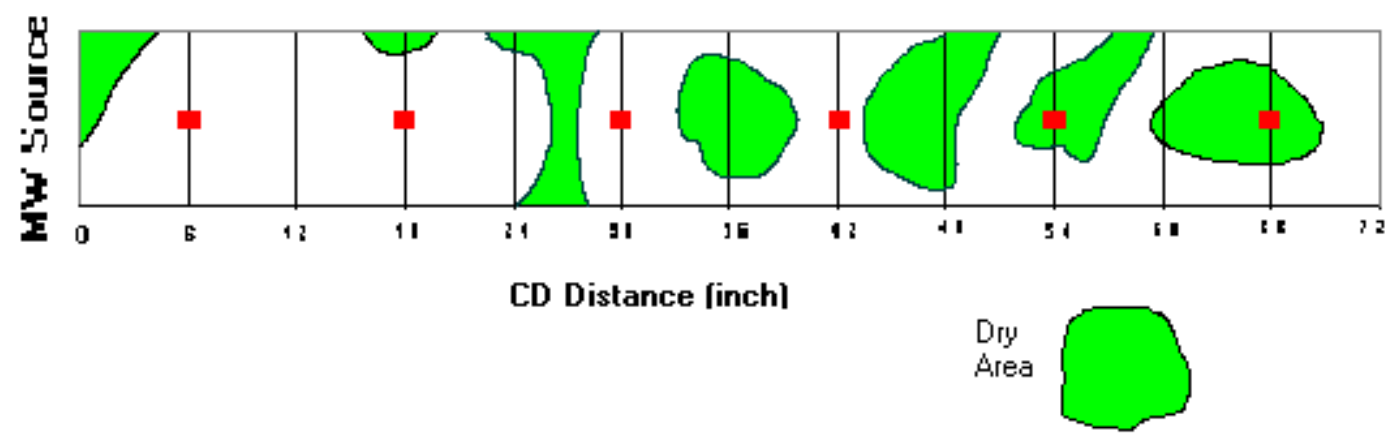

Figure 1. Example of Non-Uniform Drying in the CD-Oriented Applicator

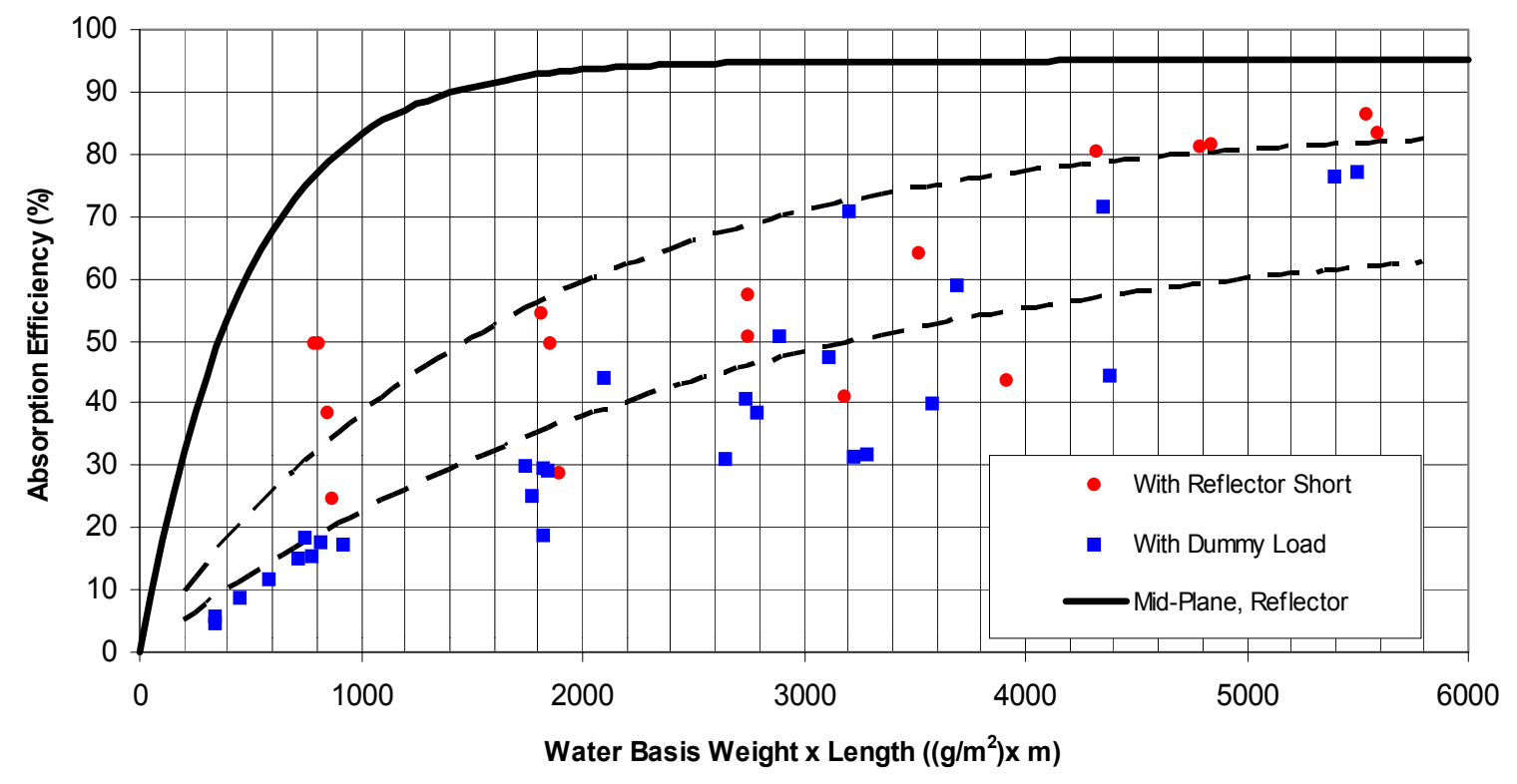

Figure 2. CD Oriented Waveguide Absorption Efficiency 


\section{MD APPLICATOR: INTRODUCTION AND THEORY}

\section{INTRODUCTION}

Recently, a previously unrecognized microwave applicator concept has been identified [Drozd, 2000 - 2002], which has significant technical advantages, especially with respect to achieving CD uniformity of heat input on a paper machine. The novel feature of the new approach is that the waveguide is aligned with the machine direction (MD), as shown in Figure 1. Appropriate web input/output ports are needed at the applicator ends. The application of microwave energy across the full machine width would then be accomplished by placing multiple waveguides side-by-side. In this case, the waveguide sidewalls are common to adjacent waveguides, and are slotted, so that a wide paper web can be conveyed along the length (MD). Furthermore, since heating uniformity along the MD is not required, the paper can be located along the waveguide centerline, to absorb maximum power. This would allow a given efficiency to be achieved with the shortest possible waveguide length. The MD - oriented waveguides can also be configured with a reflector plate at the waveguide termination end (dummy load not needed), further increasing the overall energy absorption by the sheet. Of concern is the behavior of the microwave field strength at the slots between adjacent waveguides. Those zones (at the sidewall slots) might produce a non-uniform heating intensity. However, this effect has not yet been studied.

Conceptually, the MD-oriented waveguide application system can be used to control the $\mathrm{CD}$ moisture profile. The control process requires adding established $\mathrm{CD}$ control to the microwave generators supplying the various side-by-side waveguides. The microwave generators act as the actuators. The amount of microwave energy delivered by individual generators/actuators will control heating/drying at corresponding response zones in the $\mathrm{CD}$ profile. A desired CD profile will be realized by manipulating individual actuators.

\section{THEORETICAL}

An analysis of the more traditional $\mathrm{CD}$ - oriented applicator, focusing on design of the "ideal slot geometry" for uniform heating, has been presented in Chapter II. Here, we present an analysis of the MD - oriented applicator, leading to an expression for the absorption efficiency.

As an electromagnetic wave propagates along the waveguide, it is continuously attenuated due to absorptive losses. In our application, absorptive losses are dominated by energy usefully absorbed by the wet paper in the waveguide. Other absorptive losses, such as conductor losses (i.e., the waveguide walls) are not significant.

The rate of dissipation per unit volume of paper is given by Jones [1986]:

$$
D_{v}=\omega \varepsilon_{0} \varepsilon_{r}^{\prime \prime} E_{p}^{2}(z)
$$


where $E_{p}(z)$ is the electric field at the location of the paper. If we multiply by the paper cross-sectional area (at) (dimension a defined in Figure 2; $t$ is the paper thickness), we get the total rate of dissipation per unit $\mathrm{z}$-directional distance:

$$
D^{\prime}(z) \equiv a t D_{v}(z)=a t \omega \varepsilon_{0} \varepsilon_{r}^{\prime \prime} E_{p}^{2}(z)
$$

At the waveguide cross-section located at any $\mathrm{z}$, the total electromagnetic power propagating into that cross-section is $\mathrm{P}(\mathrm{z})$. The law of conservation of energy is:

$$
\frac{d P(z)}{d z}=-D^{\prime}(z)
$$

Since paper is a very thin material compared to the waveguide height (b), a good approximation for the E-field distribution at a waveguide cross-section (see Figure 1) at any $z$ is:

$$
E(y, z)=E_{\max }(z) \sin \left(\frac{\pi y}{b}\right)
$$

$E_{\max }(z)$ is the amplitude and occurs at the mid-plane $(\mathrm{y}=\mathrm{b} / 2)$. If the thin wet paper web is located at the mid-plane, it would thus experience an E-field:

$$
E_{p}(z)=E_{\max }(z)
$$

The time-average electromagnetic power propagating in the z-direction inside the waveguide at a cross-section located at any $\mathrm{z}$ is found by integrating the axial component of the Poynting vector over the cross-section, which gives [Harrington, 1961]:

$$
P(z)=\frac{a b}{2 Z} E_{\max }^{2}(z)
$$

where $\mathrm{Z}$ is the waveguide impedance (not dependent on the wet paper properties).

To facilitate the analysis, we can combine equations (2,3,5 and 6) to achieve a differential equation that describes the variation of E-field experienced by the paper with position, $\mathrm{z}$ :

$$
\frac{d}{d z} E_{p}^{2}(z)=-\frac{2 t Z \omega \varepsilon_{0} \varepsilon_{r}^{\prime \prime}}{b} E_{p}^{2}(z)
$$

The solution of equation 7 is:

$$
E_{p}(z)=E_{p}(0) e^{-\bar{\alpha} z}
$$


where:

$$
\bar{\alpha} z=\int_{0}^{z}\left(\frac{t Z \omega \varepsilon_{0} \varepsilon_{r}^{\prime \prime}}{b}\right) d z
$$

$\mathrm{E}_{\mathrm{p}}(0)=\mathrm{E}$-field at the inlet, calculable from the input power $\mathrm{P}_{\mathrm{in}}=\mathrm{P}(0)$, using equations (5) and (6).

Applying equation (9) to the whole waveguide length (if the waveguide terminates with a load), or to twice the waveguide length (if it has a reflector), yields:

$$
\bar{\alpha} L=\frac{Z \omega \varepsilon_{0} L}{b}\left(\overline{t \varepsilon_{r}^{\prime \prime}}\right)
$$

where the overbars denote average values over the length.

As discussed in Chapter II, the data of Habeger and Baum [1983] imply that the product $t \varepsilon_{r}^{\prime \prime}$ is, for the range of moisture contents investigated here, directly proportional to the "water basis weight" $\left(m_{w}^{\prime \prime}=m_{r} B W\right)$. The proportionality "constant" is expected to be temperature dependent (see Chapter II). However, if the temperature range is not too wide (e.g., for a well-ventilated waveguide, or at low power), one can use $t \varepsilon_{r}^{\prime \prime} \approx C m_{w}^{\prime \prime}$ (with $\mathrm{C}$ taken to be a constant). For this case,

$$
\bar{\alpha} L=\frac{C Z \omega \varepsilon_{0}}{b}\left(\overline{m_{w}^{\prime \prime}}\right)
$$

where $\overline{m_{w}^{\prime \prime}}$ is the average water basis weight in the applicator.

At $\mathrm{z}=\mathrm{L}$, equations (6) and (8) combine to show that the power not absorbed is:

$$
P_{\text {out }}=P(L)=P_{\text {in }} \exp \left(-C^{\prime} L \overline{m_{w}^{\prime \prime}}\right)
$$

where $C^{\prime}$ is an overall combination of constants.

The absorption efficiency is readily found, using equation (12), as:

$$
\eta=\left(P_{\text {in }}-P_{o u t}\right) / P_{\text {in }}=1-\exp \left(-C^{\prime} L \overline{m_{w}^{\prime \prime}}\right)
$$

For the purpose of supporting the experimental work described below, $C^{\prime}$ is viewed as an empirical parameter. It will be seen that the form of equation 13 fits the MD - oriented applicator data quite well.

The efficiency relation can be used to compute the average heat into flux the paper within the microwave applicator:

$$
\overline{q^{\prime \prime}}=\eta P_{i n} /(a L)
$$


Later, microwave applicator heat fluxes computed with equation 14 will be compared to typical heat flux levels provided by steam-heated dryer cylinders. 


\section{NOTATION}

\begin{tabular}{|c|c|c|}
\hline $\mathrm{a}$ & narrow dimension of waveguide cross-section & $\mathrm{m}$ \\
\hline $\mathrm{b}$ & broad dimension of waveguide cross-section & $\mathrm{m}$ \\
\hline $\mathrm{BW}$ & paper (dry) basis weight & $\mathrm{g} / \mathrm{m}^{2}$ \\
\hline $\mathrm{D}_{\mathrm{v}}$ & volumetric dissipation rate in moist paper & $\mathrm{W} / \mathrm{m}^{3}$ \\
\hline $\mathrm{D}^{\prime}$ & dissipation rate per unit distance along guide & $\mathrm{W} / \mathrm{m}$ \\
\hline $\mathrm{E}$ & electric field & $\mathrm{V} / \mathrm{m}$ \\
\hline $\mathrm{f}, \mathrm{f}_{0}$ & microwave frequency, cutoff frequency & $\mathrm{GHz}$ \\
\hline $\mathrm{L}$ & $\begin{array}{l}\text { waveguide length (if it terminates with a load); } \\
\text { twice the waveguide length (if it has a reflector) }\end{array}$ & $\mathrm{m}$ \\
\hline$\dot{m}_{D}^{\prime \prime}$ & drying rate & $\mathrm{kg} /\left(\mathrm{m}^{2}-\mathrm{s}\right)$ \\
\hline $\mathrm{m}_{\mathrm{r}}$ & moisture ratio & g water/g solid \\
\hline$m_{w}^{\prime \prime}$ & water basis weight & $\mathrm{g} / \mathrm{m}^{2}$ \\
\hline $\mathrm{P}$ & electromagnetic power & $\mathrm{W}$ \\
\hline$\overline{q^{\prime \prime}}$ & average heat flux into sheet & $\mathrm{W} / \mathrm{m}^{2}$ \\
\hline $\mathrm{t}$ & paper thickness & $\mathrm{m}$ \\
\hline $\mathrm{y}$ & distance above bottom of waveguide & $\mathrm{m}$ \\
\hline $\mathrm{z}$ & distance along waveguide & $\mathrm{m}$ \\
\hline $\mathrm{Z}$ & waveguide impedance & ohm \\
\hline \multicolumn{3}{|c|}{ Greek } \\
\hline $\bar{\alpha}$ & mean absorption coefficient (equation 9) & $1 / \mathrm{m}$ \\
\hline$\varepsilon_{0}$ & permittivity of free space $\left(8.85 \times 10^{-12}\right)$ & farads $/ \mathrm{m}$ \\
\hline$\varepsilon_{\mathrm{r}} "$ & dielectric loss coefficient & - \\
\hline$\eta$ & absorption efficiency & - \\
\hline & angular frequency & $1 / \mathrm{s}$ \\
\hline
\end{tabular}

\section{Subscripts}

in waveguide inlet (power input end)

max maximum, at a given cross-section

out waveguide exit (load or reflector end)

$\mathrm{p} \quad$ paper

w water 


\section{REFERENCES}

Drozd, M., Industrial Microwave Systems, personal communications (2000 - 2002).

Habeger, C., and Baum, G.A., 1983, The Microwave Dielectric Constants of Water-Paper Mixtures: The Role of Sheet Structure and Composition, Journal of Applied Polymer Science, 28, pp.969-981.

Harrington, R.F., 1961, Time-Harmonic Electromagnetic Fields, McGraw-Hill, New York, pp. 70-71.

Jones, P.L., 1986, High Frequency Dielectric Heating in Paper Making, Drying Technology, 4(2), pp.217-244.

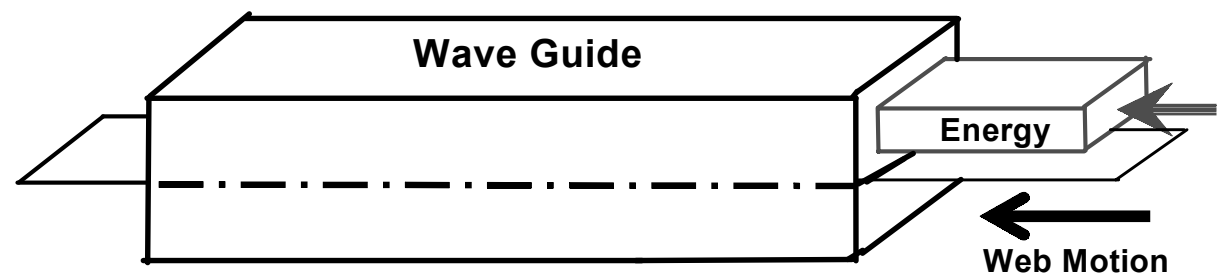

Figure 1. MD-Oriented Waveguide 


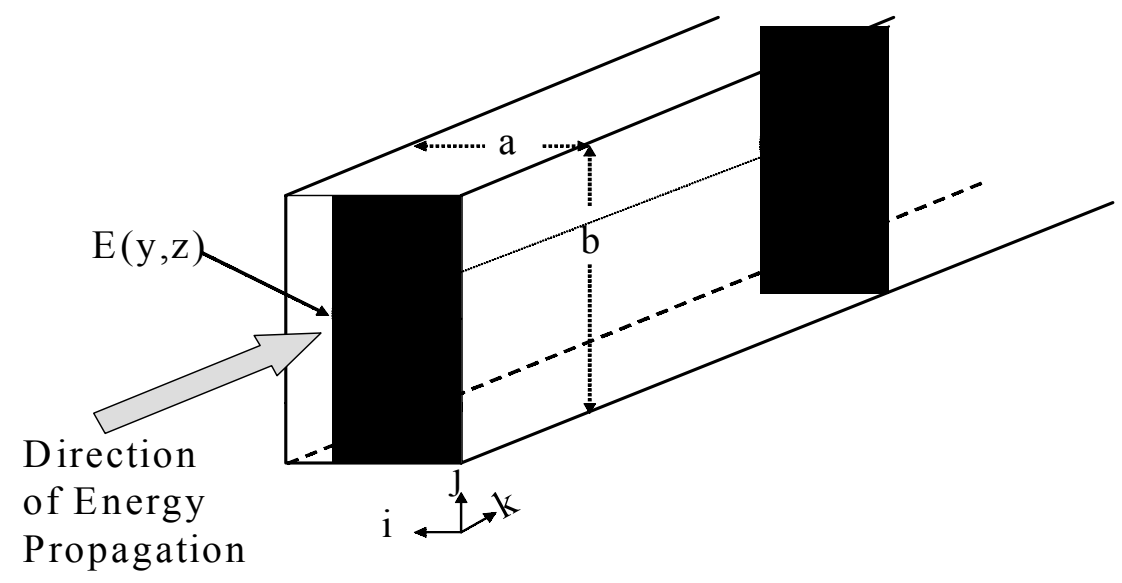

Figure 2. Waveguide Microwave Intensity 


\section{MD APPLICATOR: EXPERIMENTAL}

\section{INTRODUCTION}

The potential advantages of the MD - oriented applicator were discussed in the previous chapter. The results from testing an MD - oriented microwave applicator are reported in this chapter. The primary factor studied is the absorption efficiency of the process.

\section{SCOPE AND RESULTS}

The $3 \mathrm{~kW}$ microwave generator (915 MHz), supplied by Industrial Microwave Systems (IMS), was used for the tests. Absorption efficiencies were determined by using power sensor readings (located at the waveguide inlet) for the supply power and mass/energy balances for calculating the power absorbed by the test sheet. An Agilent Technologies 8480 series power sensor and an EPM series power meter were used to measure the power entering the waveguide. An IR temperature sensor, located at the waveguide exit, was used to measure the sheet temperature so that the sensible heat absorbed by the sheet fiber and moisture could be calculated. The latent heat for evaporation was determined by measuring the water weight loss of the sheet (during the test).

Figure 1 shows absorption efficiency of the MD oriented waveguide as a function of the waveguide water load. The water loads (for the tests) were varied by varying the length of the test waveguide or by varying the initial water basis weight of the test sheet. Two waveguide lengths were tested ( 2.13 meters and 3.66 meters). The test sheets were $26 \mathrm{lb}$ $\left(127 \mathrm{~g} / \mathrm{m}^{2}\right), 42 \mathrm{lb}\left(205 \mathrm{~g} / \mathrm{m}^{2}\right), 69 \mathrm{lb}\left(337 \mathrm{~g} / \mathrm{m}^{2}\right)$ and two plies of $69 \mathrm{lb}$ (total of $673 \mathrm{~g} / \mathrm{m}^{2}$ ) linerboard. The initial moisture content of the test sheets was 50 percent (nominal). The residence time in the waveguide was also varied.

The different symbols in Figure 1 represent varying test conditions such as waveguide length, fiber basis weight and residence time. The tests confirm that microwave absorption efficiency depends only the average water load in the microwave and is independent of the test sheet fiber weight and independent of residence time. A curve fit for the data, having the form of theoretical equation 13 (in Chapter IV), is:

$$
\eta(\%)=100\left[1-\exp \left(-0.00208 L \overline{m_{w}^{\prime \prime}}\right)\right]
$$

where $\eta(\%)$ is the absorption efficiency (in \%), $\overline{m_{w}^{\prime \prime}}$ is the product of dry basis weight of the test sheet $\left(\mathrm{BW}, \mathrm{g} / \mathrm{m}^{2}\right)$ and the average moisture ratio of the test sheet, and $\mathrm{L}$ is the length of the waveguide (in $\mathrm{m}$ ).

\section{DISCUSSION OF RESULTS}

The current maximum power levels of industrial microwave generators are approaching $150 \mathrm{~kW}$, for a $915 \mathrm{MHz}$ frequency unit [Drozd, 2000-2002]. Multiple high power generators will be needed for commercial papermaking applications. The reasonable 
assumption that absorption efficiency relationships are independent of the source power level can be made for design scale-up. On that basis, the efficiency relation in Figure 1 can be used (in equation 14 of Chapter IV) to calculate the average heat flux provided by the applicator, assuming use of a nominal $100 \mathrm{~kW}$ generator. The results of such calculations are presented in Table 1 . When the waveguides are of sufficient length to produce $80 \%$ efficiencies, the paper web temperature will increase by least $30^{\circ} \mathrm{C}$. The heat fluxes in Table 1 are an order of magnitude greater than the heat flux of conventional steam dryer cans. Because of the high heat transfer rate potential in a microwave application, much less machine space is needed to increase the production rate compared to adding more steam dryer cans to the machine (for a dryer limited machine). When floor space is at a premium, such as in machine rebuilds, using microwave technology to add drying capacity could be a reasonable consideration.

The experimental results (Figure 1) show that $80-85 \%$ absorption efficiencies can be attained. Because the microwave absorption efficiency depends on the water load in the waveguide, lower basis weight grades need longer waveguides to achieve efficiencies in that range. For products with basis weights of $50 \mathrm{~g} / \mathrm{m}^{2}$ and with a 1.5 moisture ratios, a 9 $\mathrm{m}$ waveguide is needed to attain $80 \%$ efficiencies, while $400 \mathrm{~g} / \mathrm{m}^{2}$ products (at $1.5 \mathrm{MR}$ ) need only a $3 \mathrm{~m}$ waveguide to attain $80 \%$ efficiencies.

The absorption efficiency is greater than $80 \%$ when the water load exceeds $800 \mathrm{grams} / \mathrm{m}^{2}$ $\mathrm{x} \mathrm{m}$. For sheets with lower water basis weights, waveguide lengths need to be proportionally longer in order to achieve prescribed absorption efficiency targets. For 26 lb linerboard $\left(127 \mathrm{~g} / \mathrm{m}^{2}\right.$ dry BW) with a moisture ratio of 1.5 , a 4.45 -meter waveguide is required to achieve $80 \%$ efficiency. For $42 \mathrm{lb}$ linerboard $\left(205 \mathrm{~g} / \mathrm{m}^{2}\right.$ dry BW) with a moisture ratio of 1.5 , a 2.75 -meter waveguide is required to achieve $80 \%$ efficiency. For $69 \mathrm{lb}$ linerboard $\left(337 \mathrm{~g} / \mathrm{m}^{2}\right.$ dry BW) with a moisture ratio of 1.5 , only a 1.65 -meter waveguide is required to achieve $80 \%$ efficiency.

Figure 2 shows the expected speed increase for a dryer limited machine if advantage is taken of microwave preheating. The amount that various elements contribute to the speed increase is shown. These data were derived from a relatively detailed computer model that was recently developed and validated in connection with another project [Ahrens and Rudman, 2003]. The model was extended so that a machine with microwave drying capabilities can be compared to a conventional multi-cylinder machine. Included are machine speed increases for products that have basis weights that range from $50 \mathrm{~g} / \mathrm{m}^{2}$ to $400 \mathrm{~g} / \mathrm{m}^{2}$. The initial moisture content corresponds to $40 \%$ solids. Listed are examples of the machine speed increases that can be expected if the microwave applicator is positioned before the last press and positioned between the last press and the dryer section. Potential speed increases of 35\% for the pre-press position application, and $20 \%$ for the post-press application, are typical.

Figure 3 shows the machine direction length needed to produce the additional drying capacity for the speed increases that are shown in Figure 2. The space needed for microwave applicators is compared to the space needed to achieve the same speed increase using additional steam dryer cans. Substantially less MD floor space is required 
for the microwave application compared to installation of additional steam cans. A typical microwave applicator requires $4.5-6 \mathrm{~m}$ of machine length. The concept of installing a microwave applicator before the last press is illustrated in Figure 4. For the same production increase, via conventional drying technology, 15 to $45 \mathrm{~m}$ of additional MD machine space is required for additional dryer cans.

\section{CONCLUDING REMARKS}

The experimental research reported here has shown that a machine direction applicator system for microwave energy (MD-oriented waveguides) can be a viable method for web preheating and incremental web heating/drying. CD moisture profile control can be incorporated into the MD-oriented applicator system. The MD-oriented concept is preferred over the CD-oriented concept because it 1) is less complex, 2) requires less floor space for the equipment and 3) is better suited for CD moisture control.

For microwave preheating applications, the largest production rate increases are realized when the waveguide is positioned before a final press nip. The primary reason for preheating the web prior to pressing is to increase the effectiveness of the pressing operation. Heating the web lowers the viscosity of the water in the sheet and softens the fiber network. A rule-of-thumb is generally accepted that for every 10 degrees (Celsius) increase in sheet temperature the press solids will increase one percentage point. However, it is likely that a microwave applicator that is positioned before the press will have more engineering challenges, because a significant amount of water is carried in the press felt. In order to optimize the system for preheating the sheet prior to pressing, a way to avoid heating the press felt water would be needed.

Typically, the first dryer section of a paper machine is run with a gradual increase in the cylinder temperature. The purpose of dryer cylinder temperature graduation is to reduce problems such as picking, dryer surface contamination, cockle, and sheet sealing. Preheating the sheet to an appropriate level before the first dryer section (prior to or after the pressing operation) may eliminate picking and should enable high constant rate evaporation much earlier in the drying process, permitting significant production increases (in a dryer limited machine).

Other potentially beneficial features of microwave technology include: 1) microwave applicators have an essentially instantaneous response time, which could contribute to increased productivity during startup or grade change periods, 2 ) improved runnability (percent uptime) can be expected to result from elimination of picking and sticking (due to web preheating), 3) the microwave applicator can be oriented in an inclined or vertical configuration, to save valuable "footprint area". 


\section{REFERENCES}

Ahrens, F. and I. Rudman, "The Impact of Dryer Surface Deposits and Temperature Graduation on Drying Productivity," 2003 Tappi Spring Technical Conference, Chicago (May 2003).

Drozd, M., Industrial Microwave Systems, personal communications (2000 - 2002).

Table 1. Average Heat Flux to Paper in the Applicator, for Input Power of $100 \mathrm{~kW}$, Based on Equation 14 (Chapter IV) and Equation 1.

$\begin{array}{cccc}\text { Water Basis } & \begin{array}{c}\text { Length, } \\ \text { Weight, } \mathrm{g} / \mathrm{m}^{2}\end{array} & \begin{array}{c}\text { Efficiency, } \\ \%\end{array} & \begin{array}{c}\text { Heat Flux, } \\ \mathrm{kW} / \mathrm{m}^{2}\end{array} \\ 100 & 1 & 18.8 & 151.4 \\ 100 & 2 & 34.0 & 137.2 \\ 100 & 3 & 46.4 & 124.8 \\ 100 & 4 & 56.5 & 113.9 \\ 200 & 1 & 34.0 & 274.5 \\ 200 & 2 & 56.5 & 227.8 \\ 200 & 3 & 71.3 & 191.6 \\ 200 & 4 & 81.1 & 163.4 \\ 400 & 1 & 56.5 & 455.5 \\ 400 & 2 & 81.1 & 326.9 \\ 400 & 3 & 91.8 & 246.7 \\ 400 & 4 & 96.4 & 194.4\end{array}$




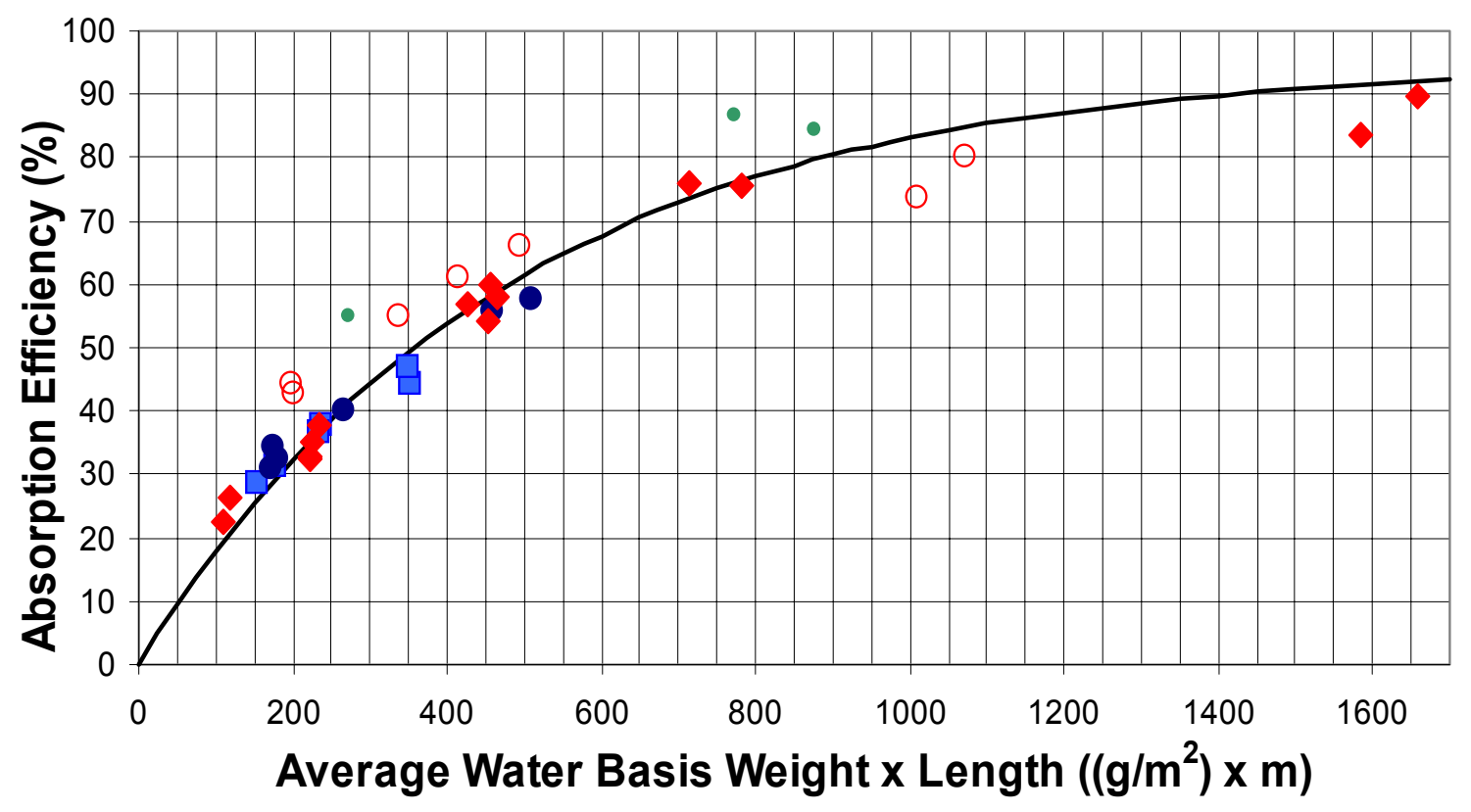

Figure 1. MD Oriented Waveguide Absorption Efficiency

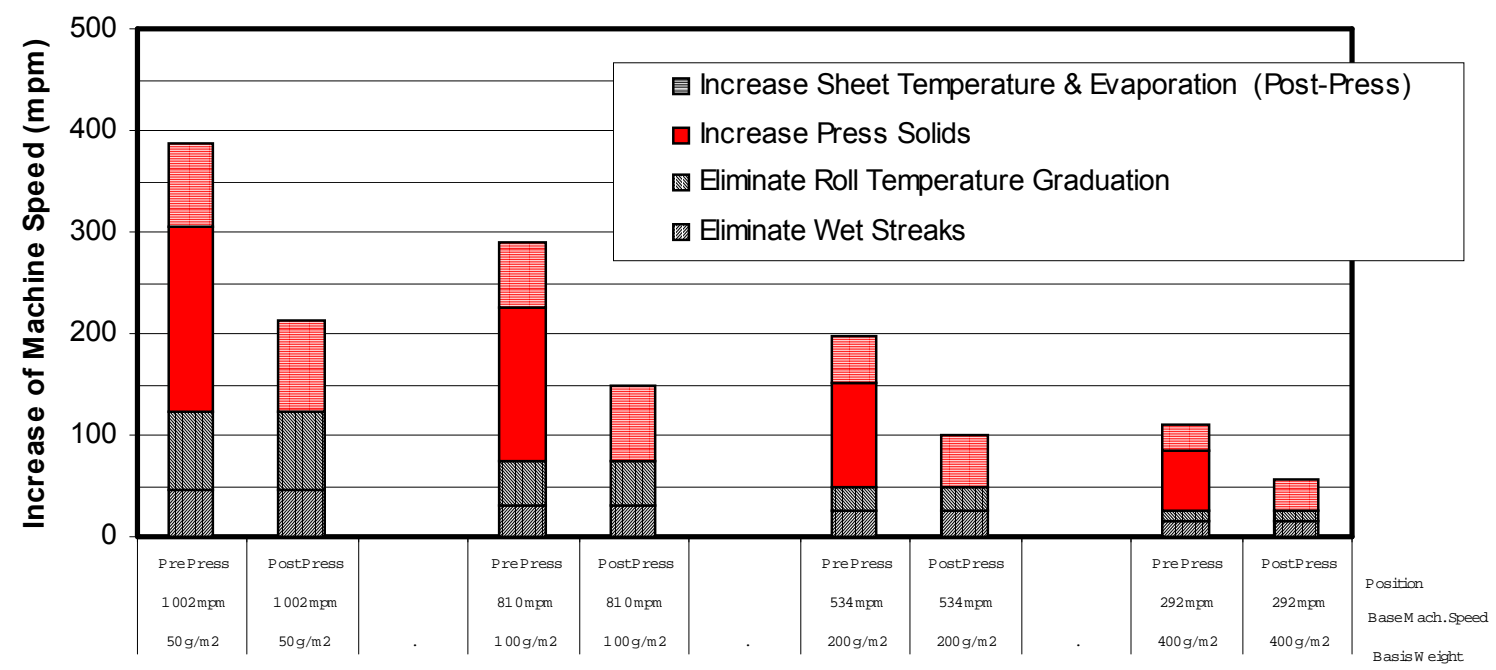

Figure 2. Primary Contributions to the Increase of Machine Speed Due to Microwave (MD applicator) 


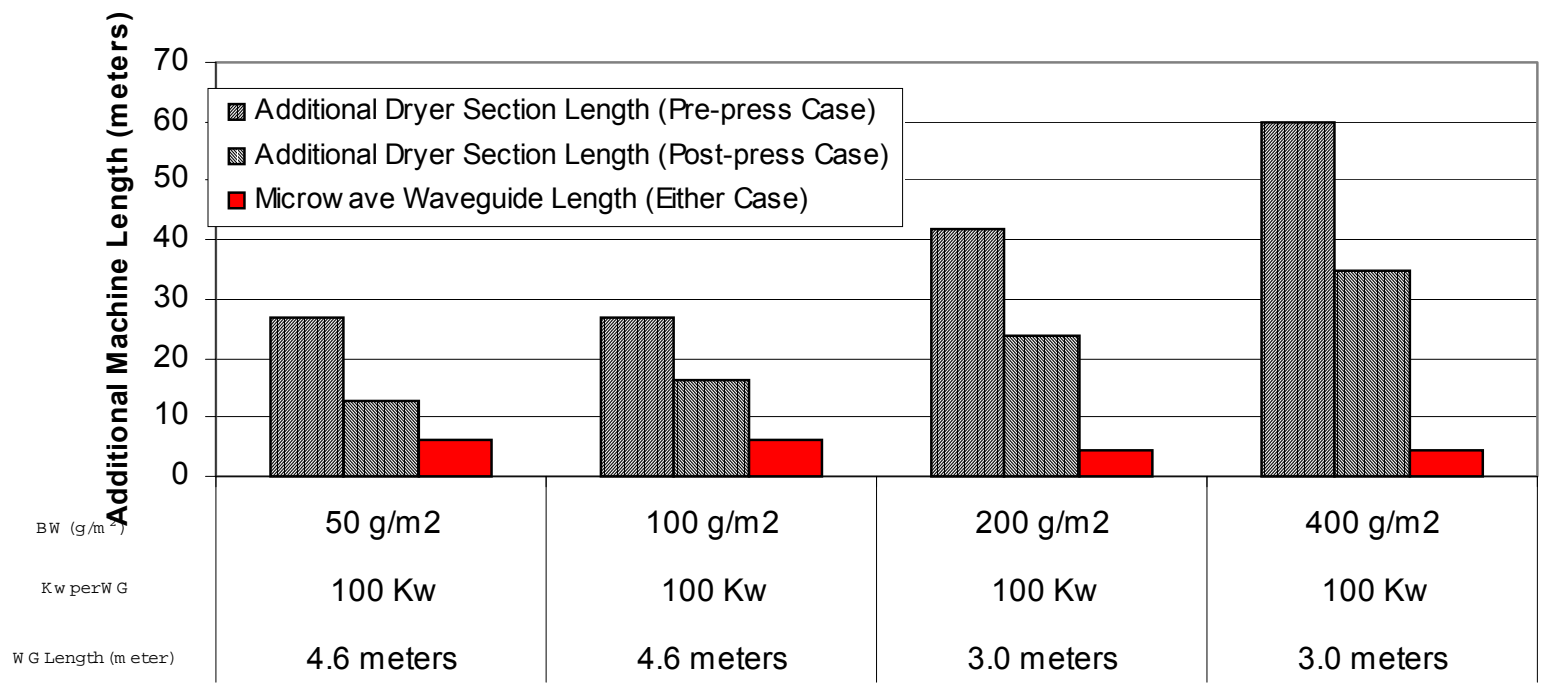

Figure 3. Additional Machine Length for the Machine Speeds Gains seen in

Figure 2. (MD applicator)

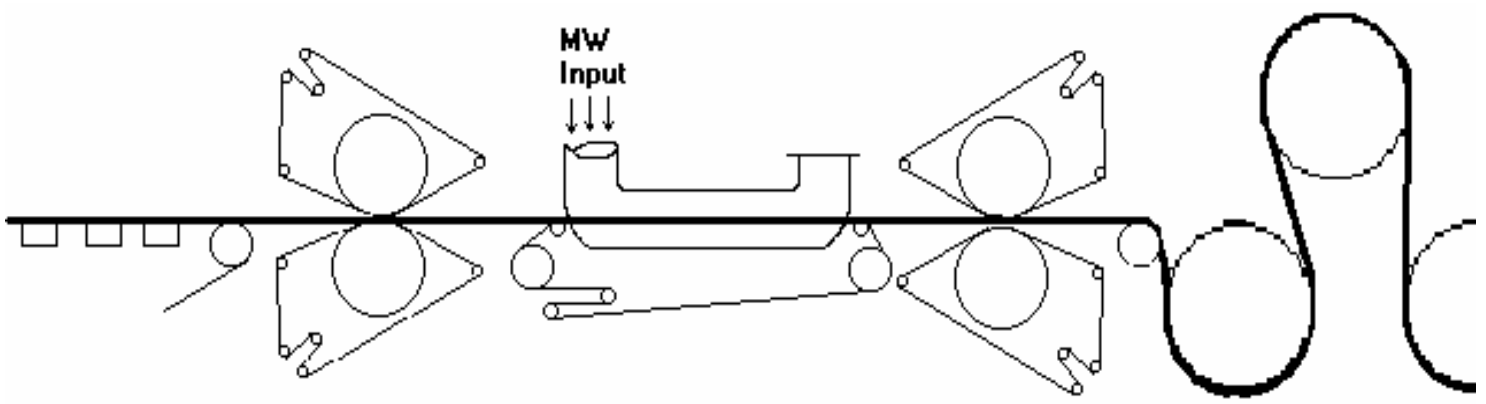

Figure 4. Schematic of a MD-Oriented Waveguide that is Positioned before the Last Press 


\section{ENERGY AND ECONOMIC ASSESSMENT - MD APPLICATOR}

\section{INTRODUCTION}

Microwave drying of paper has been investigated periodically since the 1960's (Williams, 1966). One of the first studies completed (Hankin, et al, 1970) reported the experience gleaned from operation of a $30 \mathrm{~kW}$ microwave dryer tested on a pilot paper machine. Recently, some previously unrecognized microwave applicator concepts have been identified [Drozd, 1998-2002] which have significant technical advantages, especially with respect to achieving CD uniformity of heat input. Two of these microwave applicator concepts (one with CD-oriented and one with MD-oriented waveguides) have been evaluated in this project. The technical results favor the MDoriented concept. That is the configuration assumed in the present economic study.

The economics of industrial microwave technology has also improved in recent years [Borkowski, 1998]. Since 1985, the capital expenditure required for an industrial microwave applicator system has decreased by a factor of four. The maintenance costs have decreased by a factor of 10 and the life expectancy of the magnetron has increased by more than a factor of four to in excess of 8,000 hours (nearly one year at 24 hours/day operation). Finally, the maximum power of industrial microwave generators is increasing. Current levels are approaching $150 \mathrm{~kW}$, for a $915 \mathrm{MHz}$ frequency.

The economic feasibility/value of applying the MD - oriented applicator idea to achieve a uniform application of microwave energy for various purposes on the paper machine has been evaluated. These purposes include web preheating (to enhance liquid water removal and to increase drying productivity); moisture profile leveling (to reduce overdrying); and incremental high-rate, high-efficiency, low-investment drying. The purposes of this chapter are to:

1) Summarize the results of case studies that investigate the economic feasibility of using microwave energy for paper web heating before the last press nip, and for post-press heating/drying before the first dryer cylinder.

2) Quantify the primary contributions to the potential increase in machine speed due to the microwave application.

3) Discuss costs associated with microwave application.

4) Present estimates of additional profit potential and estimates for return on capital expenditures (payback time).

5) Discuss the space advantages associated with microwave application compared to traditional stream cylinder drying.

6) Compare the water removal costs for the microwave application with those for traditional steam cylinder drying.

7) Evaluate a paper machine rebuild case study that considers use of microwave application to solve dryer limit and floor space problems. 


\section{APPROACH}

The economic assessment of microwave technology is based on consideration of a range of representative application cases/scenarios. The assessment requires a technical performance representation of both the microwave technology and conventional steam drying technology, and an economic analysis of the costs and benefits of the various scenarios. These aspects, and a definition of the cases considered, are presented in this section.

\section{Technical Basis}

The microwave applicator performance is based on projections from a low power $(3 \mathrm{~kW})$ laboratory unit. The configuration considered is one with the waveguides oriented in the machine direction ("axial feed"), with the input microwave power traveling in the same direction as the sheet ("forward"), and with a reflector at the "downstream end" of the waveguide, to increase the overall energy absorption by the sheet. Our theoretical research has indicated, and our experimental research has confirmed, that the microwave absorption efficiency depends only on the product of "average water basis weight" in the waveguide and waveguide length. Average water basis weight is defined as the product of dry basis weight and average moisture ratio. For the configuration considered, the absorption efficiency relationship is presented in Figure 1. To simulate the higher power scenarios of interest in the economic assessment, we make the reasonable assumption that the efficiency relationship is independent of power level.

The conventional multi-cylinder dryer section performance is characterized by means of a relatively detailed computer model [Ahrens and Rudman, 2003], recently developed and validated in connection with another drying project. This model has been extended, with incorporation of the microwave absorption efficiency relationship, for simulation of hybrid systems incorporating both microwave and conventional drying technologies on the paper machine. The integrated model was employed in making estimates of the productivity benefits of including microwave technology on the paper machine.

\section{Microwave Scenarios and Base Cases Considered}

It is well known that paper/board machine speeds tend to be higher for low basis weight grades and lower for high basis weight grades. Since microwave energy absorption efficiency is dependent on the product of average water basis weight and length, scenarios covering a wide range of basis weight $\left(50-400 \mathrm{~g} / \mathrm{m}^{2}\right)$ and various waveguide lengths, were considered. The scenarios considered, and the base case (i.e., with only conventional dryers) speeds assumed for them, are specified in Table 1. The base cases' number of dryer cans were determined using the IPST dryer section model. In these base case computations, the sheet was assumed to have moisture streaks necessitating overdrying to a solids level of $97 \%$, instead of a target level of $94 \%$. The base case systems were also assumed to employ dryer temperature graduation in the first dryer section (linearly increasing temperature from can to can); the details are also specified in Table1. Temperature graduation is often said to be necessary to avoid sticking and picking, or 
other problems such as cockle or sheet sealing, resulting from the low initial sheet temperature and/or solids level. All base case and microwave-augmented cases assume the initial solids level is $40 \%$.

The scenarios employing microwave technology were of two types, reflecting the most promising applications. In one, the microwave applicator was placed before the last press nip, for the purpose of preheating the sheet to achieve higher post-press solids (and temperature). In the other, the microwave applicator was placed at the beginning of the dryer section, before the first dryer can, to preheat/pre-dry the sheet. In both cases, the higher sheet temperature and solids content resulting from microwave application before the first dryer can is assumed to be capable of reducing picking and sticking (and the other potential problems cited above) enough to allow elimination of temperature graduation in the first dryer section. For all the microwave cases, it is also assumed that, by using $\mathrm{CD}$ control of power input to the various waveguides, any non-uniform sheet moisture profile at the reel can be eliminated.

For the majority of the results to be presented, the microwave applicator is envisioned as being added to the corresponding base case system (i.e., without changing the number of steam drying cylinders), thus providing a production increase. This assumes the base case machine is dryer-limited. After determining the speed increase due to the microwave input, the number of additional dryer cans needed to match that increase was calculated. Near the end of the paper, two rebuild cases are briefly discussed in which some of the steam cylinders are assumed to be removed, such that the total machine length remains constant, in order to accommodate a microwave applicator (and an additional press, in one case).

As indicated in Table 1, some microwave scenarios employ a power input of 100 $\mathrm{kW} /$ waveguide (the nominal output of one industrial $915 \mathrm{MHz}$ microwave generator), while others employ $50 \mathrm{~kW} /$ waveguide. The low power scenarios simulate systems in which each generator supplies two waveguides (to reduce the number of generators needed), since the generators constitute an appreciable portion of the microwave hardware cost.

Although we expect the conclusions of the economic assessment to be relatively insensitive to machine width, we considered a $5.08 \mathrm{~m}$ wide machine in our analysis. For the assumed $915 \mathrm{MHz}$ microwave frequency, the typical waveguide width is $12.4 \mathrm{~cm}$. Thus, 41 MD-oriented waveguides are required.

\section{Assumptions in Economic Analysis}

The various cost parameters assumed and economic factors considered in the analyses are given in Table 2 . In the interest of being conservative in the assessment of microwave technology, three potentially significant features were disregarded. First, the microwave applicator could be oriented in an inclined or vertical configuration, to save valuable "footprint area." Second, microwave applicators have an essentially instantaneous response time, which could contribute to increased productivity during startup or grade 
change periods. Third, improved runnability (percent uptime) can be expected to result from elimination of picking and sticking (due to web preheating).

\section{RESULTS AND DISCUSSION}

In this section, we present the technical performance results needed in the economic analysis, the results of the economic analysis of various scenarios, and a discussion of the potential limitations of the analysis.

\section{Performance}

The microwave applicator length has an impact on power absorption efficiency and, therefore, it has an impact on the machine speed increase. From a technical standpoint, use of longer waveguides is seen to be desirable, but analysis suggests that there is be an economic optimum. The case studies used waveguide lengths that produced about $80 \%$ absorption efficiency. Additional technical details are available in Chapter VI.

For the microwave scenarios in Table 1 involving a $3.05 \mathrm{~m}$ waveguide, with a power input of $100 \mathrm{~kW}$, the contributions to the machine speed increase are presented in Figure 2. Clearly, the increased post-press solids (typically at least 3 percentage points) resulting from microwave heating (typically at least $30^{\circ} \mathrm{C}$ ) before the last press nip plays a key role in increasing machine speed. Because the heat produced by microwaves is volumetrically dissipated across the thickness of the paper, the microwave heating is particularly effective in preheating high basis weight grades and highly refined sheets. Traditional technologies, such as steam box and IR heating, are not effective in preheating high basis weight grades and sheets with closed structures.

\section{Economics}

The details of the economic analysis of the various microwave scenarios are summarized in Tables 3 and 4. Also shown in these Tables is a summary of the economic analysis of an alternative means of achieving the same production increases, by installing extra dryer cylinders. Most of the key information is also presented in the figures to be discussed below.

The additional annual profit and the costs for the various cases are shown in Figure 3. The capital cost and the operating cost are the same for case studies with the microwave applicator in both the pre-press and the post-press positions. The additional annual profit is greater for the cases where the microwave applicator is positioned before the press because those cases take advantage of the elevated sheet temperature in pressing. However, it is likely that a microwave applicator that is positioned before the press will have more engineering challenges, because a significant amount of water is carried in the press felt. In order to optimize the economics for preheating the sheet prior to pressing, a way to avoid heating the press felt water is requisite. 
The time required to recover the capital costs (payback time) for the conditions outlined in the case studies is shown in Figure 4. This time is in an attractive range ( 0.5 to 2.5 years). The payback tends to be best for the heavier grades.

Figures 5 and 6 compare the estimated annual profit for microwave applicator scenarios with that for cases that use additional dryer cans to achieve the same production increase. The comparison generally shows similar additional profits for microwave applicator and dryer can addition because the additional production revenue (equal) is the primary factor in both cases.

The energy used for water removal per ton of production for the case studies is shown in Figure 7. The results are compared to corresponding cases where steam dryer cans are used to dry the sheet. Less energy is used in the microwave applicator cases. Notably less energy is used in cases where the microwave applicator is before the press. The associated energy cost for water removal per ton of production for case studies is given in Figure 8 . The results are compared to cases where steam dryer cans are used to dry the sheet. The energy costs are similar for high basis weight cases. The energy costs are greater for low basis weights when the microwave applicator is positioned after the press. The reason for higher costs in the microwave applicator cases is that electric energy costs more than steam energy. However, a major benefit for the microwave applicator is that the machine length required for the installation is significantly less than the length needed for extra dryer cans (see Figure 9). This can often be a decisive advantage.

The results of rebuild scenarios (for dryer limited machines) with removal of dryer cans to maintain constant machine length are given in Table 5 , for the case of $200 \mathrm{~g} / \mathrm{m}^{2}$ basis weight. When total machine length is constrained, the use of microwave technology is a way to increase production. The payback for these cases is at least as favorable as that for the other high basis weight cases considered.

\section{Limitations and Potential Issues}

The productivity gains from microwave application presented above are relative to base cases that portray the conventional dryer section as having dryer temperature graduation in the first dryer section, and the machine as having a wet streak in the sheet that results in over-drying the drier portions of the sheet. The microwave use is portrayed as enabling the elimination of both graduation and moisture profiles. If one wishes to consider other scenarios, the breakdown of relative contributions to productivity in Figure 2 can be used to estimate pro-rated economic benefits. Obviously, if the higher sheet temperature and solids content resulting from microwave application before the first dryer can is unable to reduce picking and sticking enough to eliminate graduation (or if there other problems that still require graduation), the productivity gains and economic benefits will be reduced.

Regarding the pre-press use of the microwave applicator, if the carrier felt or fabric has appreciable water, that water would absorb a portion of the microwave power. This would not likely yield much benefit. 


\section{CONCLUDING REMARKS}

The economic assessment of microwave paper heating/drying technology shows:

4) The time to recover the capital and installation cost is typically less than $0.5-2.5$ years for dryer limited machines. For high basis weight machines $\left(200 \mathrm{~g} / \mathrm{m}^{2}-400\right.$ $\mathrm{g} / \mathrm{m}^{2}$ ), the time to capital and recover installation costs is less than 1.5 years.

5) Increases of over $30 \%$ in machine speeds can be realized. Additional revenue is proportional to the increase machine speed (assuming no additional down time). Of course the increase in machine speed assumes no other speed limits other than dryer limits (e.g., drives) are active.

6) The greatest economic impact will be realized if the waveguide is positioned before a final press. Using microwave energy to preheat the web prior to pressing will require additional capital and will create some engineering challenges. A significant amount of water is carried in the press felt. In order to optimize the economics for preheating the sheet prior to pressing, a way to avoid heating the press felt water is requisite.

7) Substantially less MD floor space is required at the same production increase for the microwave application compared to additional steam cans. A typical microwave application would require 4.5 to $6 \mathrm{~m}$ of machine length. For the same production increase, 15 to $45 \mathrm{~m}$ of additional MD machine space is required for additional dryer cans, if conventional technology is used.

8) When the total length of a dryer limited machine is constrained, the use of microwave technology is a way to increase production. The payback for lengthconstrained rebuild cases at $200 \mathrm{~g} / \mathrm{m}^{2}$ basis weight is at least as favorable as that for the other high basis weight cases considered.

9) Results from the case study show that the energy required to heat and dry paper is almost always less for the microwave application cases. Water removal requires $1.13 \mathrm{MWh}$ per metric ton of paper using conventional steam dryer cans. For the case studies that use microwave application, the water removal energy numbers are in the 0.89 to $1.05 \mathrm{MWh}$ per metric ton range. Microwave power is produced by electricity. Dryer can steam is typically produced by burning gas or oil. Because the electricity cost is about three times more than gas or oil (per $\mathrm{kWh}$ ), the energy cost per ton of production can be higher for the microwave application. For high basis weight paper, energy costs are comparable.

\section{REFERENCES}

Ahrens, F. and I. Rudman, "The Impact of Dryer Surface Deposits and Temperature Graduation on Drying Productivity," 2003 Tappi Spring Technical Conference, Chicago (May 2003).

Borkowski, J., Industrial Microwave Systems, personal communications (1998). 
Drozd, M., Industrial Microwave Systems, personal communications (1998 - 2002).

Hankin, J.W., Leidigh, W.J., and Stephansen, E.W., "Microwave Paper Drying Experience and Analysis," TAPPI Journal 53(6), 1970, p.1063-1070.

Williams, N.H., "Moisture leveling in paper, wood, textiles, and other mixed dielectric sheets," Journal of Microwave Power, 1(3), 1966, p.73-80.

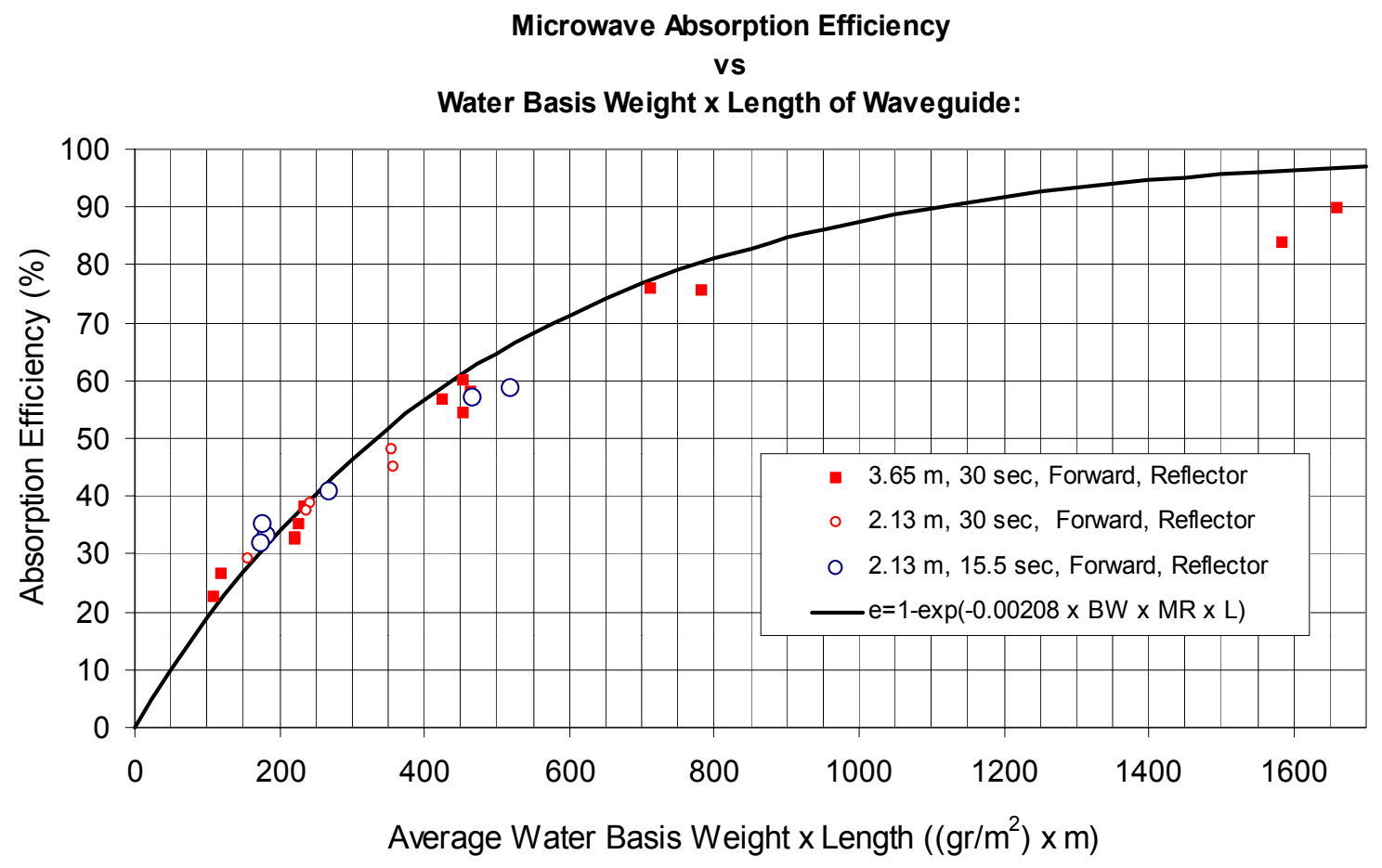

Figure 1. Microwave Absorption Efficiency 
Table 1.

Microwave Applicator and Base Case Conditions

\begin{tabular}{|c|c|c|c|c|c|c|c|c|}
\hline Basis & Active & Power & Base & Base & Base & First & Temp \\
\hline Weight & Waveguide & per & Machine & Number & Number & Can & After \\
\hline & Length & WG & Speed & Dryer & Graduated & Temp & Graduation \\
\hline$\left(\mathrm{g} / \mathrm{m}^{2}\right)$ & (meter) & $(\mathrm{Kw})$ & $(\mathrm{mpm})$ & Cans & Cans & \multicolumn{2}{c|}{$\left(\mathrm{C}^{\circ}\right)$} & $\left(\mathrm{C}^{\circ}\right)$ \\
\hline \hline 50 & 3.0 & 100 & 1000 & 30 & 7 & 112 & 154 \\
\hline 50 & 4.6 & 50 & 1000 & 30 & 7 & 112 & 154 \\
\hline 50 & 9.1 & 100 & 1000 & 30 & 7 & 112 & 154 \\
\hline 50 & 9.1 & 50 & 1000 & 30 & 7 & 112 & 154 \\
\hline 100 & 3.0 & 100 & 810 & 45 & 7 & 112 & 182 \\
\hline 100 & 4.6 & 100 & 810 & 45 & 7 & 112 & 182 \\
\hline 100 & 4.6 & 50 & 810 & 45 & 7 & 112 & 182 \\
\hline 200 & 3.0 & 100 & 535 & 70 & 9 & 112 & 182 \\
\hline 200 & 3.0 & 50 & 535 & 70 & 9 & 112 & 182 \\
\hline 400 & 3.0 & 100 & 290 & 106 & 10 & 112 & 182 \\
\hline 400 & 3.0 & 50 & 290 & 106 & 10 & 112 & 182 \\
\hline
\end{tabular}

Note: All cases assume ingoing solids $40 \%$. 
Table 2. Assumptions

Assumptions:

Machine Width:

5.1 meter

Number of Waveguides:

41 (MD - oriented)

Efficiency:

F(WBW x Length) (see Figure 1)

Revenue Increase:

$\$ 200 /$ metric ton

Electrical Cost:

$\$ 0.03 / \mathrm{kW}-\mathrm{Hr}$

(\$0.83/million Joules)

Steam Cost:

Steam Efficiency:

$\$ 6.60$ per metric ton $(\$ 0.29 /$ million Joules)

Machine Floor Cost: $71 \%$

Operating Days:

On Spec Efficiency:

Dryer Cylinder Cost:

Waveguide Cost:

$\$ 15,240$ per MD meter

$\$ 350$ per year

$95 \%$

$\$ 100,000$ per cylinder

$\$ 42,700$ per Waveguide

Microwave Generator Cost:

Installed Cost:

$\$ 35,600$ per $100 \mathrm{~kW}$ Generator

Capital Depreciation time:

Maximum Power:

Ingoing Solids:

Annual Profit:

2X Capital Cost

20 years

$100 \mathrm{~kW}$ per Waveguide

$40 \%$

Revenue - Depreciated Capital

- Power Costs

- Maintenance Costs

$10^{\circ} \mathrm{C}$ Increase in Sheet Temperature Produces One Percentage Point Increase in Press Solids

Increase in Production Based On:

Eliminate Moisture Streaks

Eliminate Roll Temperature Graduation

Increase Sheet Temperature

Increase Press Solids (Pre-Press only)

Increase Sheet Evaporation (Post-Press only) 


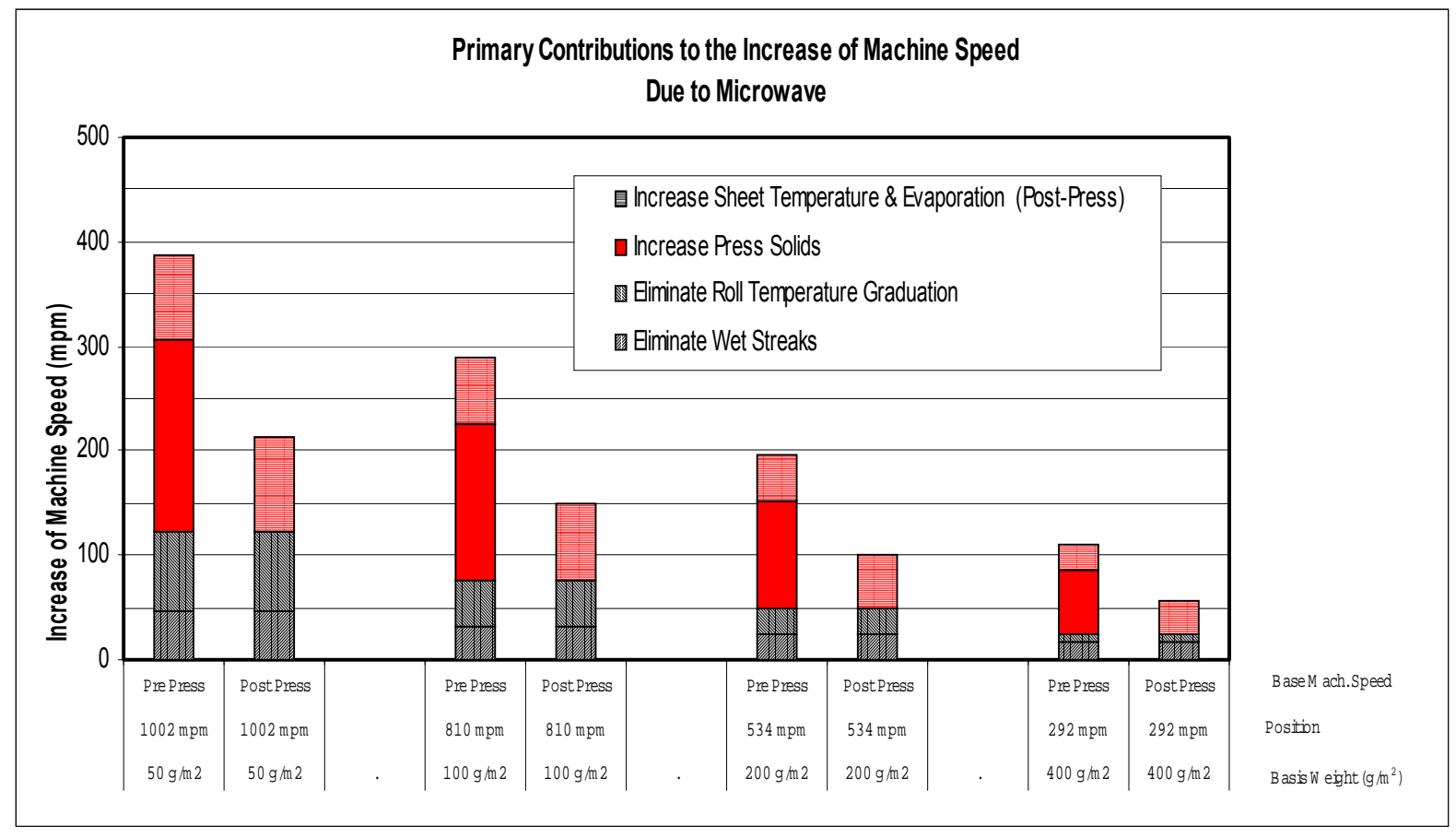

Figure 2. Contributors to Increase Machine Speed (3 meter, 100kW/Waveguide) 
Table 3. Pre-Press Location

COST STUDY RESULTS FOR PRE-PRESS APPLICATION LOCATION

\begin{tabular}{|c|c|c|c|c|c|c|c|c|c|c|c|c|c|c|c|c|c|c|c|c|}
\hline Basis & Active & Power & Incremental & Machine & Base & Additional & Electrical & Capital & Capital & Installed & Depreciated & Maint. & Additional & Number & Incremental & Machine & Capital & Depreciated & Incremental & Additional \\
\hline Weight & Waveguide & per & Machine & Length & Profit & Revenue & Cost & Cost & Cost & Capital & Capital & Cost & Profit & Extra & Machine & Length & Cost & Capital & Steam & Profit \\
\hline & Length & WG & Length & Cost & & & & WGs & Generators & Cost & Cost & & Microwave & Cans & Length & Cost & & Cost & Cost & Cans \\
\hline$\left(\mathrm{g} / \mathrm{m}^{2}\right)$ & (meter) & $(\mathrm{Kw})$ & (meter) & (\$MM) & (\$MM) & (\$MM) & (\$MM) & (\$MM) & (\$MM) & (\$MM) & (\$MM) & (\$MM) & (\$MM) & & (meter) & (\$MM) & (\$MM) & (\$MM) & (\$MM) & (\$MM) \\
\hline 50 & 3 & 100 & 4.6 & 0.75 & 22.9 & 8.15 & 1.03 & 1.75 & 1.50 & 6.50 & 0.36 & 0.328 & 6.43 & 15 & 27 & 4.5 & 1.50 & 0.38 & 0.63 & 7.15 \\
\hline 50 & 4.6 & 50 & 6.1 & 1.00 & 22.9 & 6.65 & 0.52 & 1.75 & 0.75 & 5.00 & 0.30 & 0.163 & 5.67 & 11 & 20 & 3.3 & 1.10 & 0.28 & 0.51 & 5.87 \\
\hline 50 & 9.1 & 100 & 10.7 & 1.75 & 22.9 & 12.54 & 1.03 & 1.75 & 1.50 & 6.50 & 0.41 & 0.328 & 10.77 & 20 & 120 & 6.0 & 2.00 & 0.50 & 0.97 & 11.07 \\
\hline 50 & 9.1 & 50 & 10.7 & 1.75 & 22.9 & 5.78 & 0.52 & 1.75 & 0.75 & 5.00 & 0.34 & 0.163 & 4.76 & 9 & 37 & 2.7 & 0.90 & 0.23 & 0.45 & 5.11 \\
\hline 100 & 3 & 100 & 4.6 & 0.75 & 37.05 & 11.79 & 1.03 & 1.75 & 1.50 & 6.50 & 0.36 & 0.328 & 10.07 & 14 & 26 & 4.2 & 1.40 & 0.35 & 0.87 & 10.57 \\
\hline 100 & 4.6 & 100 & 6.1 & 1.00 & 37.05 & 13.82 & 1.03 & 1.75 & 1.50 & 6.50 & 0.38 & 0.328 & 12.09 & 18 & 33 & 5.4 & 1.80 & 0.45 & 1.02 & 12.35 \\
\hline 100 & 4.6 & 50 & 6.1 & 1.00 & 37.05 & 8.65 & 0.52 & 1.75 & 0.75 & 5.00 & 0.30 & 0.163 & 7.67 & 10 & 18 & 3.0 & 1.00 & 0.25 & 0.65 & 7.75 \\
\hline 200 & 3 & 100 & 4.6 & 0.75 & 48.9 & 15.48 & 1.03 & 1.75 & 1.50 & 6.50 & 0.36 & 0.328 & 13.76 & 23 & 42 & 6.9 & 2.30 & 0.58 & 1.14 & 13.77 \\
\hline 200 & 3 & 50 & 4.6 & 0.75 & 48.9 & 10.46 & 0.52 & 1.75 & 0.75 & 5.00 & 0.29 & 0.163 & 9.49 & 15 & 27 & 4.5 & 1.50 & 0.38 & 0.77 & 9.32 \\
\hline 400 & 3 & 100 & 4.6 & 0.75 & 53.5 & 21.5 & 1.03 & 1.75 & 1.50 & 6.50 & 0.36 & 0.328 & 19.78 & 33 & 60 & 9.9 & 3.30 & 0.83 & 1.58 & 19.10 \\
\hline 400 & 3 & 50 & 4.6 & 0.75 & 53.5 & 10.3 & 0.52 & 1.75 & 0.75 & 5.00 & 0.29 & 0.163 & 9.33 & 20 & 37 & 6.0 & 2.00 & 0.50 & 0.76 & 9.04 \\
\hline
\end{tabular}

Table 4. Post Press Location

COST STUDY RESULTS FOR POST-PRESS APPLICATION LOCATION

\begin{tabular}{|c|c|c|c|c|c|c|c|c|c|c|c|c|c|c|c|c|c|c|c|c|}
\hline Basis & Active & Power & Incremental & Machine & Base & Additional & Electrical & Capital & Capital & Installed & Depreciated & Maint. & Additional & Number & Incremental| & Machine & Capital & Depreciated & Incremental & Additional \\
\hline Weight & Waveguide & per & Machine & Length & Profit & Revenue & Cost & Cost & Cost & Capital & Capital & Cost & Profit & Extra & \begin{tabular}{|l|} 
Machine \\
\end{tabular} & Length & Cost & Capital & Steam & Profit \\
\hline & Length & WG & Length & Cost & & & & WGs & Generators & Cost & Cost & & \begin{tabular}{|l|} 
Microwave \\
\end{tabular} & Cans & Length & Cost & & Cost & Cost & Cans \\
\hline$\left(\mathrm{g} / \mathrm{m}^{2}\right)$ & (meter) & $(\mathrm{Kw})$ & (meter) & (\$MM) & (\$MM) & (\$MM) & (\$MM) & (\$MM) & (\$MM) & $(\$ \mathrm{MM})$ & (\$MM) & (\$MM) & (\$MM) & & (meter) & (\$MM) & (\$MM) & (\$MM) & (\$MM) & (\$MM) \\
\hline 50 & 3 & 100 & 4.6 & 0.75 & 22.9 & 5.55 & 1.03 & 1.75 & 1.50 & 6.50 & 0.36 & 0.328 & 3.82 & 7 & 12.8 & 2.2 & 0.70 & 0.18 & 0.43 & 4.94 \\
\hline 50 & 4.6 & 50 & 6.1 & 1.00 & 22.9 & 3.85 & 0.52 & 1.75 & 0.75 & 5.00 & 0.30 & 0.163 & 2.87 & 5 & 9.1 & 1.2 & 0.50 & 0.11 & 0.30 & 3.45 \\
\hline 50 & 9.1 & 100 & 10.7 & 1.75 & 22.9 & 4.78 & 1.03 & 1.75 & 1.50 & 6.50 & 0.41 & 0.328 & 3.00 & 6 & 11.0 & 1.9 & 0.60 & 0.15 & 0.37 & 4.25 \\
\hline 50 & 9.1 & 50 & 10.7 & 1.75 & 22.9 & 3.54 & 0.52 & 1.75 & 0.75 & 5.00 & 0.34 & 0.163 & 2.52 & 5 & 9.1 & 1.4 & 0.50 & 0.12 & 0.27 & 3.15 \\
\hline 100 & 3 & 100 & 4.6 & 0.75 & 37.05 & 7.35 & 1.03 & 1.75 & 1.50 & 6.50 & 0.36 & 0.328 & 5.63 & 9 & 16.5 & 2.7 & 0.90 & 0.22 & 0.57 & 6.56 \\
\hline 100 & 4.6 & 100 & 6.1 & 1.00 & 37.05 & 8.53 & 1.03 & 1.75 & 1.50 & 6.50 & 0.38 & 0.328 & 6.80 & 10 & 18.3 & 3.1 & 1.00 & 0.26 & 0.66 & 7.62 \\
\hline 100 & 4.6 & 50 & 6.1 & 1.00 & 37.05 & 5.73 & 0.52 & 1.75 & 0.75 & 5.00 & 0.30 & 0.163 & 4.75 & 7 & 12.8 & 2.1 & 0.70 & 0.17 & 0.44 & 5.11 \\
\hline 200 & 3 & 100 & 4.6 & 0.75 & 48.9 & 8.78 & 1.03 & 1.75 & 1.50 & 6.50 & 0.36 & 0.328 & 7.06 & 13 & 23.8 & 3.8 & 1.30 & 0.32 & 0.68 & 7.78 \\
\hline 200 & 3 & 50 & 4.6 & 0.75 & 48.9 & 6.62 & 0.52 & 1.75 & 0.75 & 5.00 & 0.29 & 0.163 & 5.65 & 9 & 27 & 2.8 & 0.90 & 0.23 & 0.51 & 5.88 \\
\hline 400 & 3 & 100 & 4.6 & 0.75 & 53.5 & 9.72 & 1.03 & 1.75 & 1.50 & 6.50 & 0.36 & 0.328 & 8.00 & 19 & 34.7 & 5.8 & 1.90 & 0.48 & 0.75 & 8.49 \\
\hline 400 & 3 & 50 & 4.6 & 0.75 & 53.5 & 7.05 & 0.52 & 1.75 & 0.75 & 5.00 & 0.29 & 0.163 & 6.08 & 14 & 25.6 & 4.2 & 1.40 & 0.35 & 0.55 & 6.16 \\
\hline
\end{tabular}


Additional Profit and Costs with the Microwave Applicator in the Pre Press \& Post Press Positions

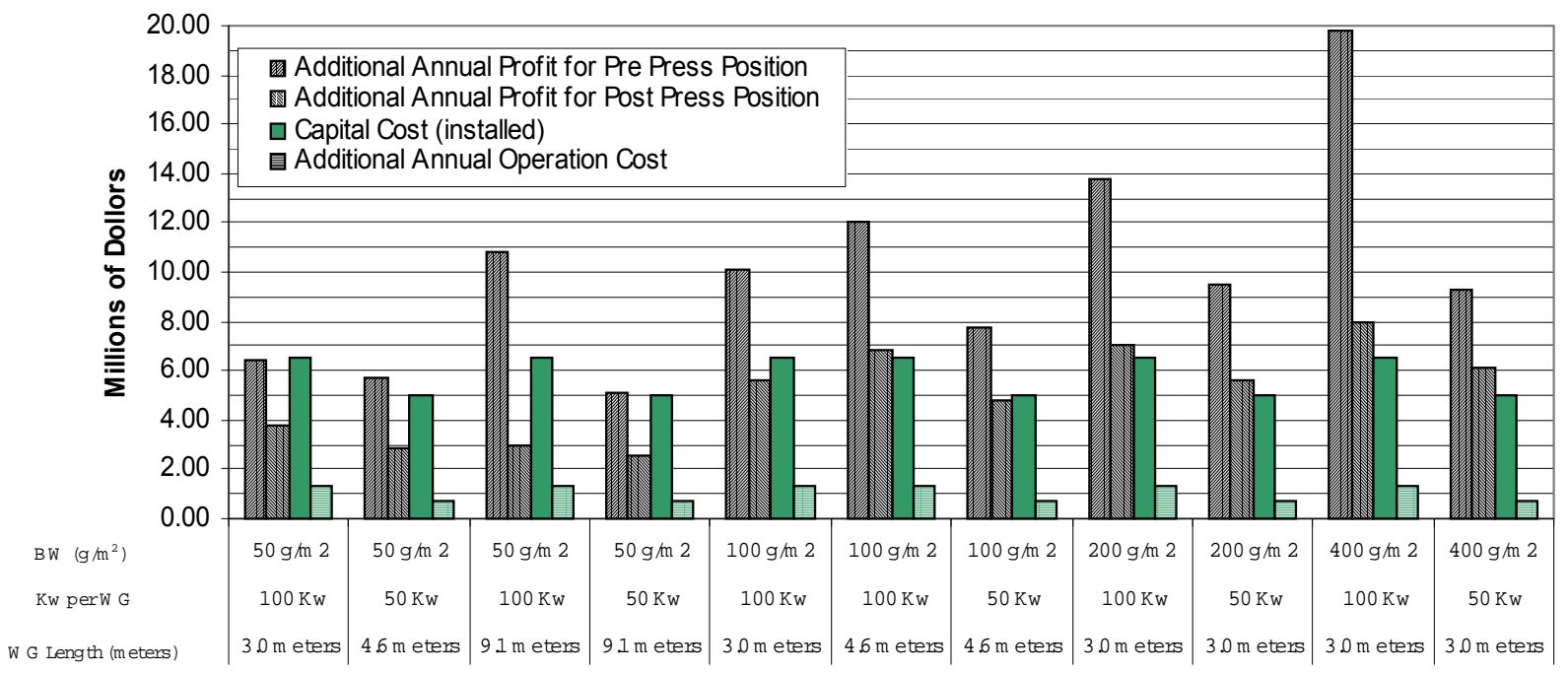

Figure 3. Additional Profit and Costs

Time to Recover Capital Costs with the Microwave Applicator in the Pre Press \& Post Press Positions

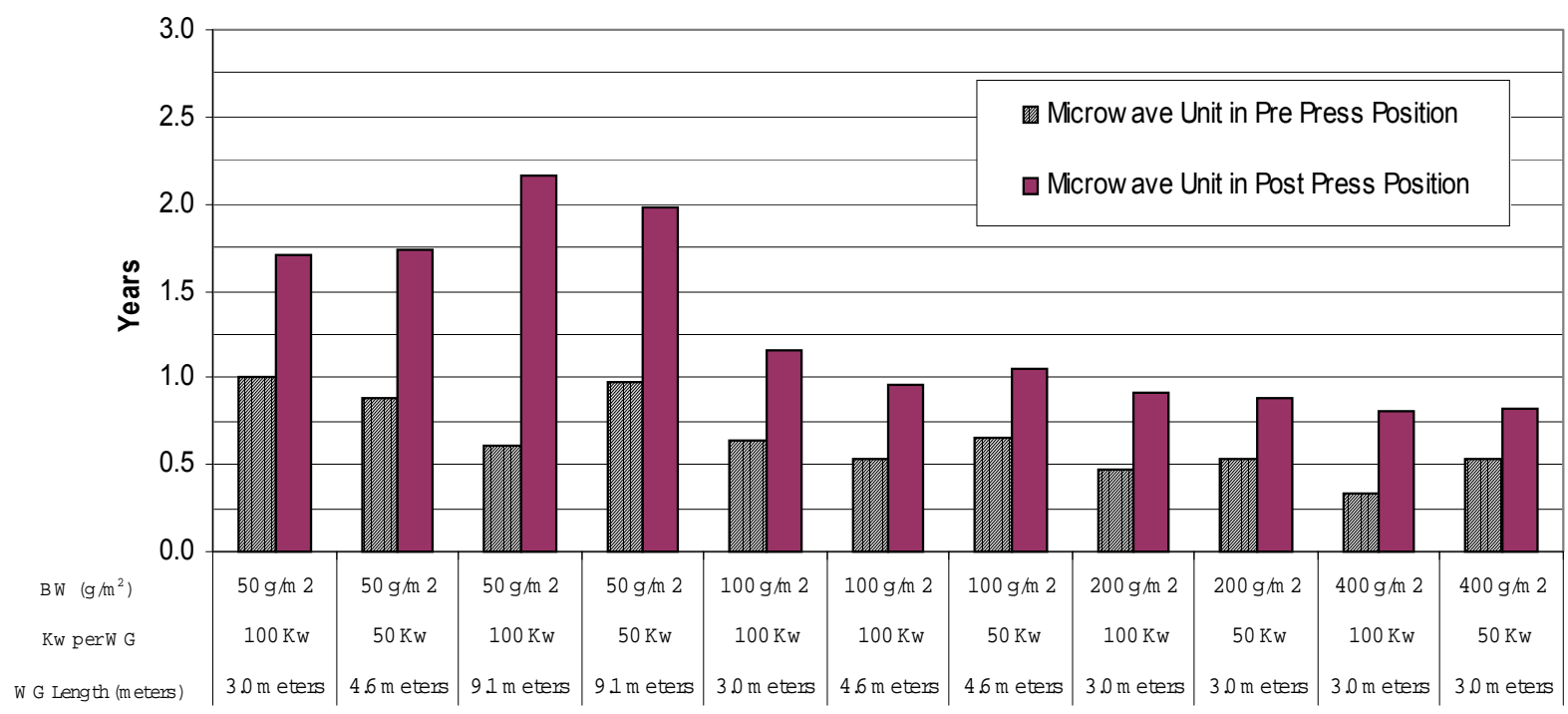

Figure 4. Capital Cost Recovery 
Profit Increase Comparison:

Microwave Press Preheating vs. Use of Additional

Dryer Cans for Same Production Increase

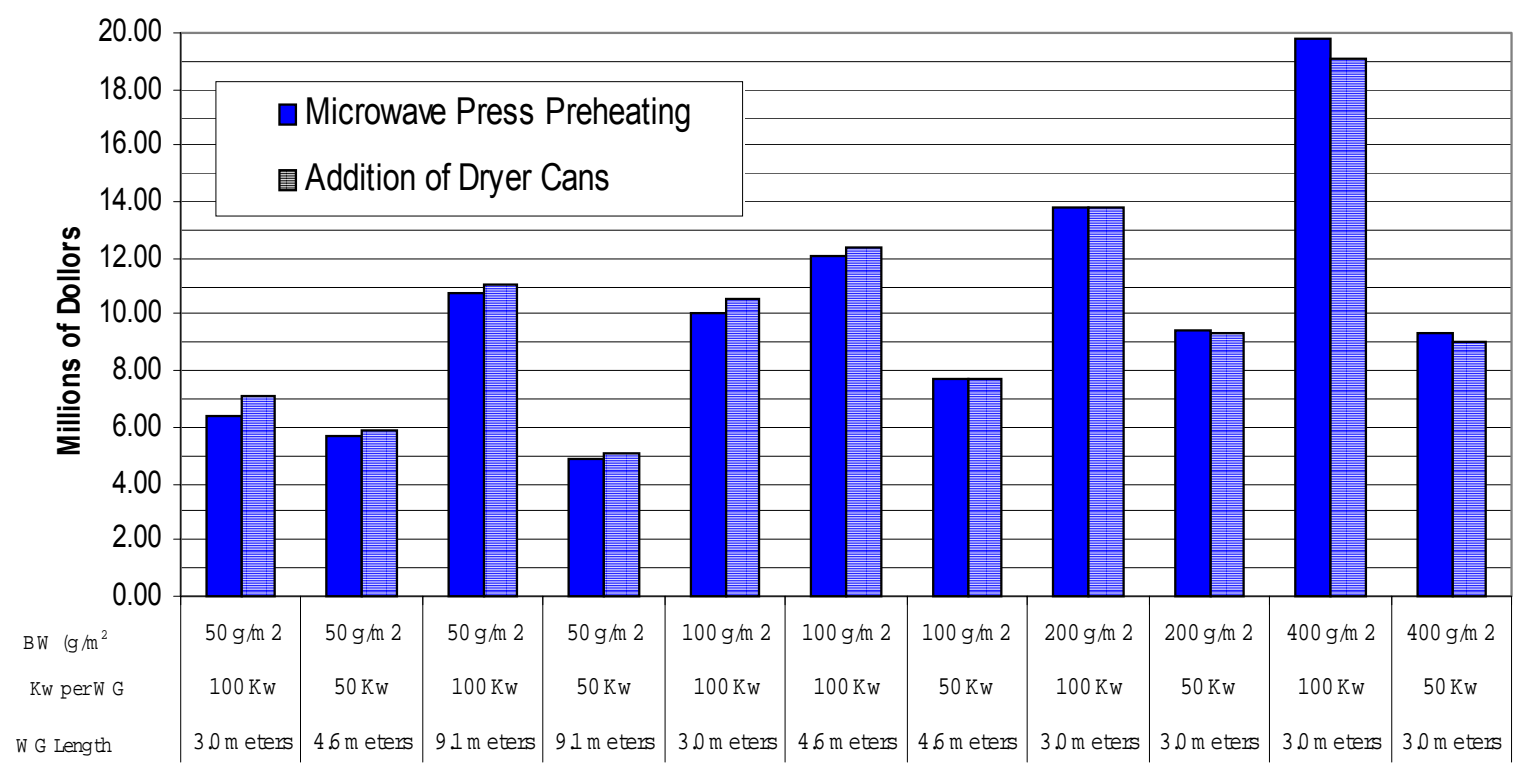

Figure 5. Profit Increase: Pre-Press Implementation

Profit Increase Comparison:

Microwave Post-Press Heating/Drying vs. Use of Additional of Dryer Cans for Same Production Increase

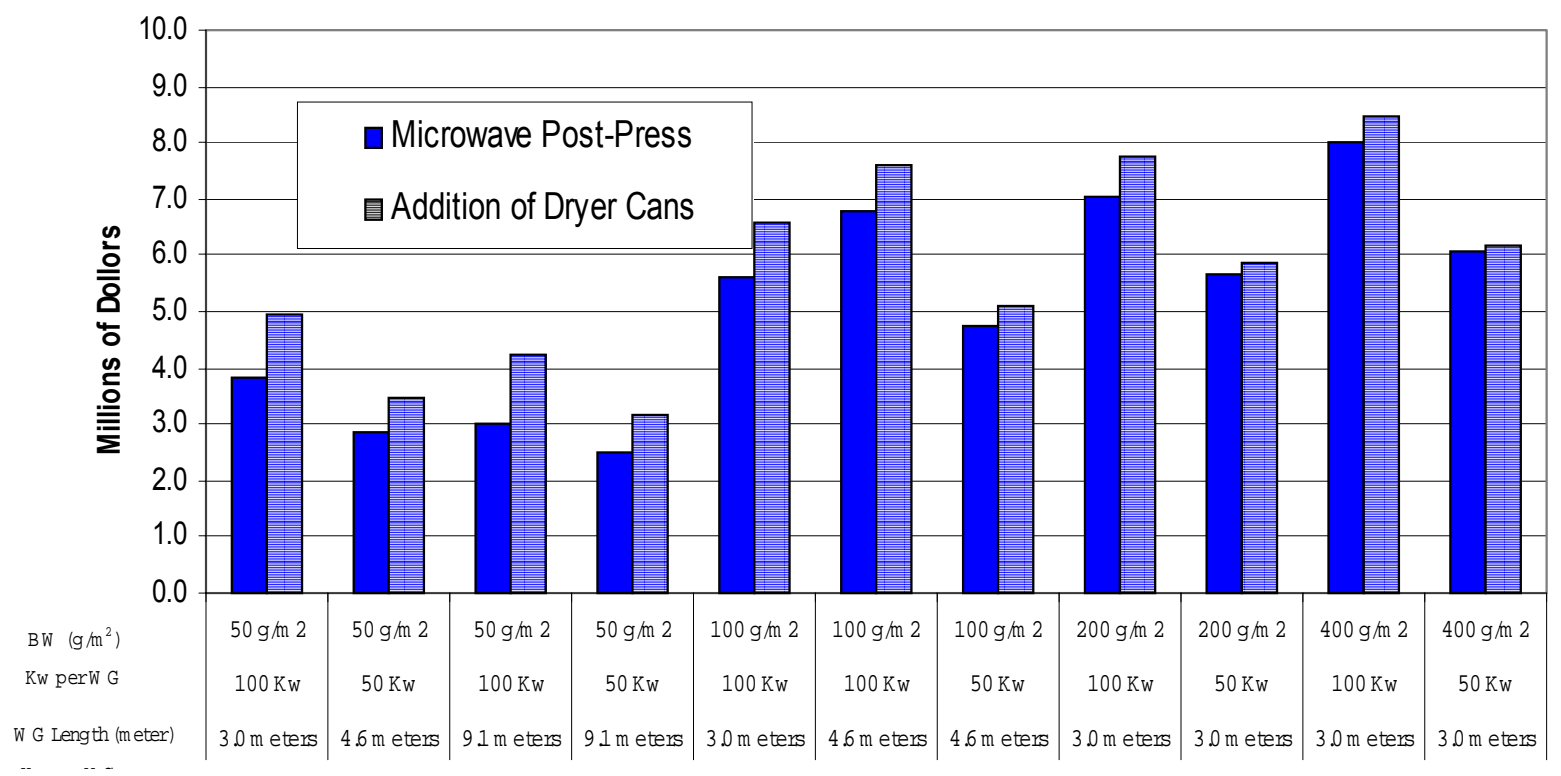

Figure 6. Profit Increase: Post-Press Implementation 


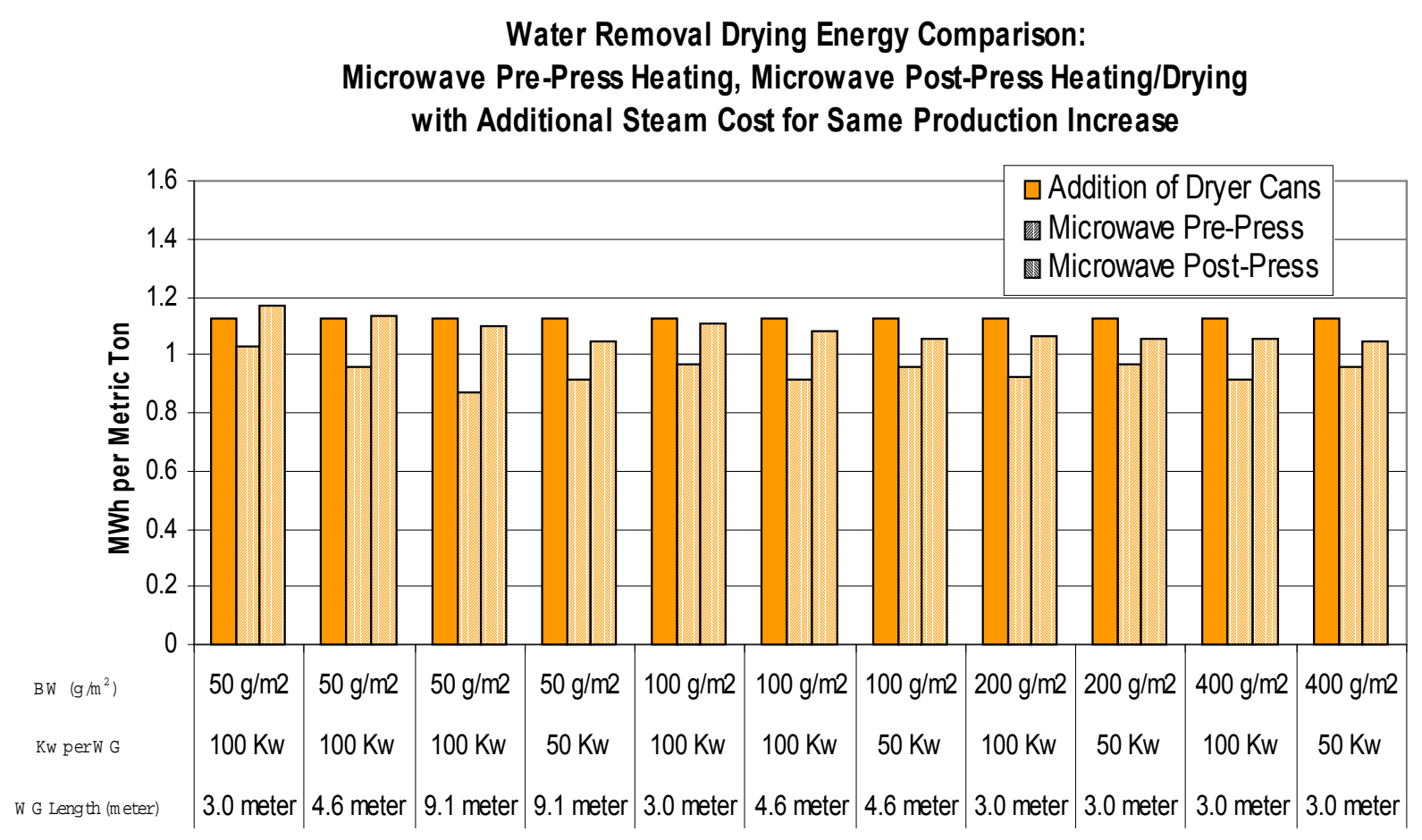

Figure 7. Water Removal Energy Use Comparison

Energy Cost Comparison:

Microwave Pre-Press Heating, Microwave Post-Press Heating/Drying with Additional Steam Cost for Same Production Increase

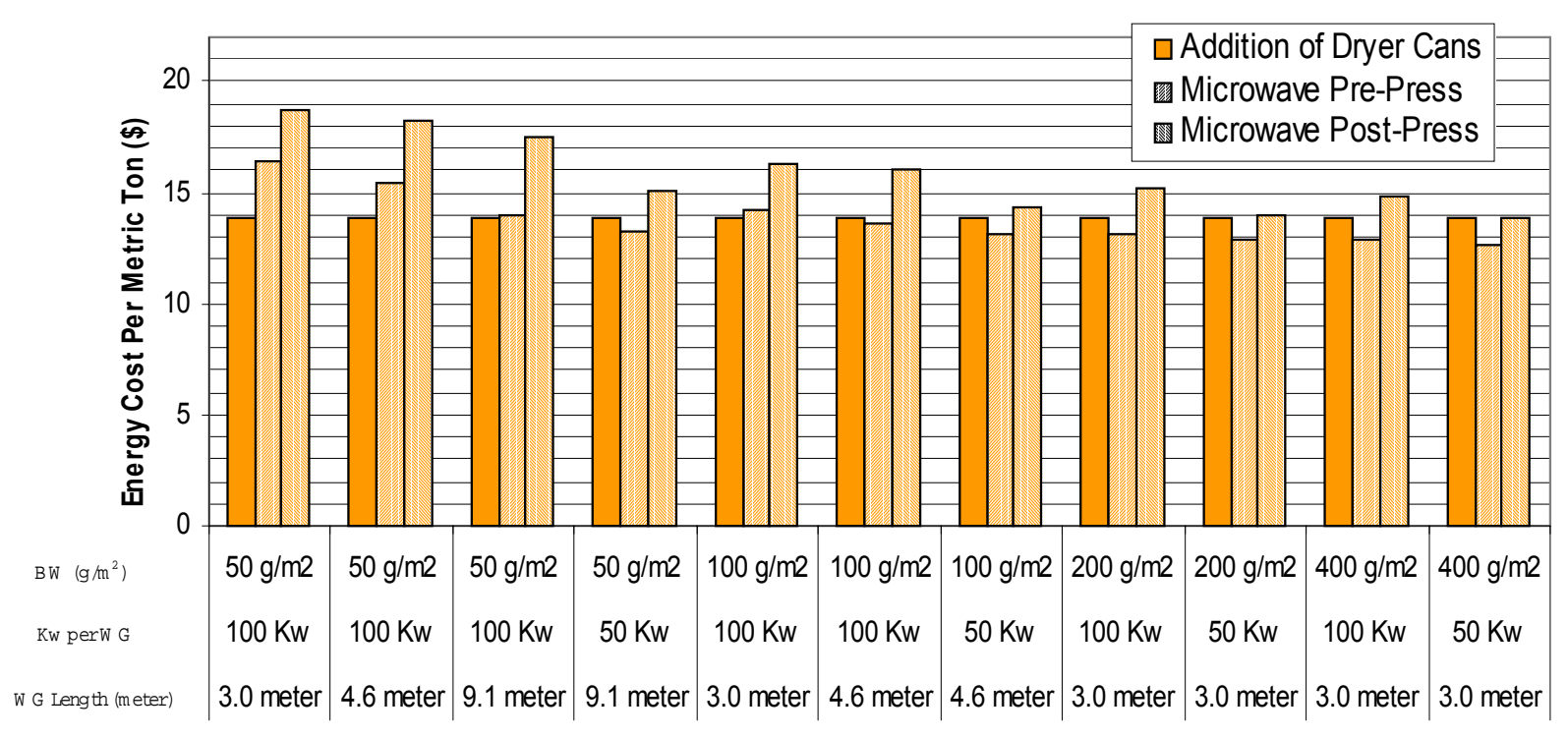

Figure 8. Water Removal Energy Cost Comparison 
Additional Machine Length Needed for the

Additional Drying Capacity for Selected Cases

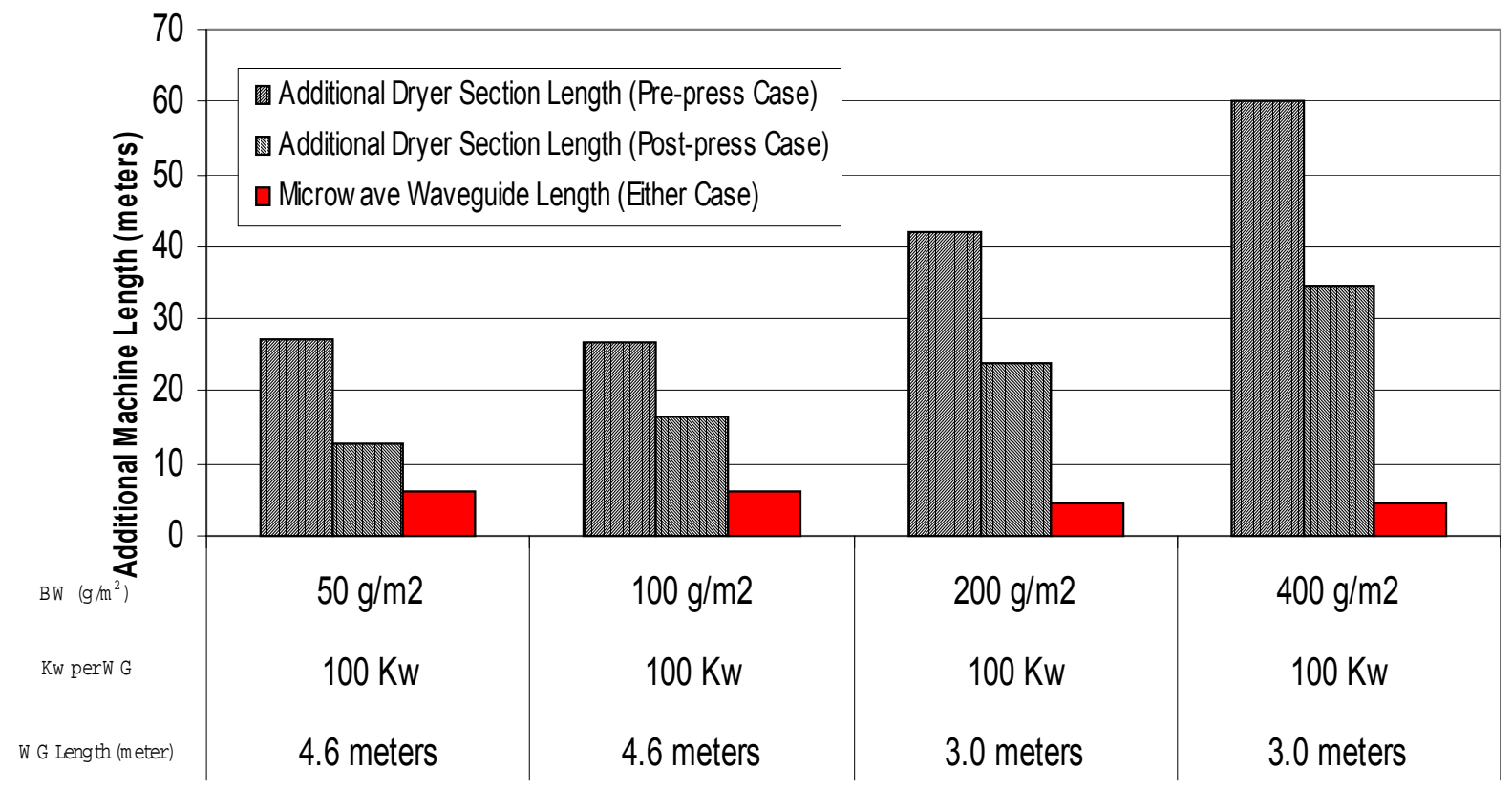

Figure 9. Machine Length Increase 


\section{Table 5. Rebuild Case Study Results}

\section{Rebuild Case Studies}

Basis Weight:

Machine Width:

Number of Dryer Cans:

Base Machine Speed:

Base Annual Profit:

Machine is Dryer Limited

\author{
$200 \mathrm{~g} / \mathrm{m}^{2}$ \\ 5.1 meters \\ 70 \\ 535 meters per minute \\ 48.9 million
}

Scenario One: Post-Press

Remove some dryer cans and add Microwave Waveguides after the press operation and before the dryer sections.

1) Remove 3 dryer cans (about 5.5 meters of Machine length)

2) Put in 3 meter microwave applicators (about 4.6 meters Machine length)

3) Power per Waveguide is $100 \mathrm{~kW}$

4) Removing the 3 dryer cans will cause a $4.3 \%$ reduction in dryer capacity

5) Adding the 3 meters Microwave applicators will add $14.5 \%$ production capacity to the base case.

6) New maximum Machine Speed is 611 meters per minute

7) Potential additional revenue is $\$ 7.6$ million / year

8) Additional Profit is $\$ 5.38$ million/year

9) Capital is $\$ 6.5$ Million (installed)

10) Time to recover Capital is 1.2 years

\section{Scenario Two: $\quad$ Pre-Press}

Remove some dryer cans and add Microwave Waveguides and an addition press before the dryer sections.

1) Remove 4 dryer cans (about 7.3 meters of Machine length)

2) Put in 3 meters microwave applicators (about 6.1 meters Machine length)

3) Put in additional press after waveguides (about 2.75 meters)

4) Power per Waveguide is $100 \mathrm{~kW}$

5) Removing the 4 dryer cans will cause a $5.7 \%$ reduction in dryer capacity

6) Adding the 3 meter Microwave applicators and press will add $31 \%$ production capacity to the base case.

6) New maximum Machine Speed is 700 meters per minute

8) Potential additional revenue is $\$ 15.17$ million / year

9) Additional Profit is $\$ 13.39$ million/year

10) Microwave applicator capital cost is $\$ 6.5$ Million (installed)

11) The capital cost for the additional press is $\$ 4.0$ million (installed)

12) Time to recover Capital is 0.8 years 


\section{CONCLUDING REMARKS}

The following final status of the various project tasks is used to provide a summary of the project.

Task 1. Low Power, Narrow Web, Laboratory Experiments (using the CD-oriented concept).

Earlier efforts by IMS to design an adjustable-geometry capability for the first (CDoriented) prototype led to the recognition that the complexity is too high to be worthwhile, so we elected to build two single-pass, fixed-geometry applicators of the original CD-oriented (transverse feed) style, instead. These were fabricated by IMS, and were received at IPST in July 2001. They comprise one unit with curved top and bottom walls (i.e., "ideal slot geometry"), and one unit with a straight-line approximation ("linear slot") to the ideal geometry (i.e., straight, but inclined, top and bottom walls). The units have an active waveguide length of 6 feet, and use a generator whose maximum power is $3 \mathrm{~kW}$. Testing is complete for both applicator variants. The work included experiments comparing use of a short and a load as termination conditions. We used infrared temperature sensors to monitor the local heating rate. We tested the design theory and investigated the robustness (ability to handle variations in in-going moisture level) during off-design operation. For both variants, we found evidence (alternating wet/dry patches in the sheet) of a standing wave component of the heating, even with a load as termination condition. We also found the expected results, that there is an optimum water basis weight (WBW, mass of water/unit area) at which heating is the most nearly uniform, and that efficiency increases with WBW. Also as expected, we found that the efficiency is generally greater with a short (reflector) as termination, compared to a load, and that the ideal slot applicator offers the best combination of efficiency and tendency toward uniformity. We used an empirical approach to determine the WBW which best matches the "slot geometry" and length combination, in terms of heating uniformity. The limitation on use of fixed slot geometry is that we are not able to test the ability of an adjustable applicator to provide uniform heating for a range of offdesign conditions. As suggested above, and supported by the experimental observation of lack of real uniformity from the ideal slot applicator, it appeared better to focus most project attention on the more promising MD-oriented geometry applicator.

Task 2. MD-Oriented Prototype Applicator Experiments [formerly Wide Web, Low Power Density Laboratory Experiments].

This Task originally called for design and testing of a 25-foot wide CD-oriented applicator. However, as discussed above, we believed it best to focus on the more promising MD-oriented applicator configuration. In this Task we have investigated the performance of a single waveguide MD-oriented applicator, using narrow, but long, paper samples conveyed along the axis of the waveguide.

Prior to designing a prototype for use in the project, we performed some paper heating/drying experiments, on the existing IMS "curing chamber" unit. The first set was performed in March, but two additional sets were performed in May/June 2001. The IMS single-waveguide unit is somewhat similar to the design needed for paper drying 
applications, except that its conveyor belt travels along a path inclined to the waveguide centerline (due to IMS' desire not to overheat certain types of food materials at the power input end of the unit). The unit initially had a water load at the opposite end from the generator, whereas the preferred paper-drying unit would likely have a "short" (reflector), in order to increase the opportunity for energy absorption by the sheet. We ran a range of basis weights and ingoing solids levels, thus giving a range of initial "water basis weights." Our theoretical work has shown that heating efficiency and drying rate should increase with water basis weight. The experiments fully confirmed this expectation. A preliminary comparison of the experimental results with a simplified theoretical analysis (using an estimated relationship for dielectric loss coefficient as a function of moisture content) indicated that our loss coefficient estimate is low (actual efficiency was greater than predicted). In principle, as we acquire a larger database and develop a more complete model, we should be able to use experimental performance results to infer the dependence of dielectric loss coefficient on moisture content and temperature. In particular, results for cases at low power and/or high speed, in which the moisture change is small, will be especially useful for inferring the loss coefficient.

The more recent experiments on the IMS axial unit involved use of a short to reflect power back along the sample. This increased efficiency, as expected. We also investigated the effect of co-current vs. counter-current operation (with respect to the direction of microwave propagation relative to direction of sample travel), but found little difference in performance between the two cases. Our theoretical work indicates that counter-current operation should have a somewhat better efficiency.

Design and construction of the IPST prototype MD-oriented applicator is complete; delivery occurred in early July 2001. It has an active length of about 11 feet, and has been operated with a $3 \mathrm{~kW}$ generator. Testing began in Nov. 2001, and is now complete. Results indicate that, for given total water load (WBW x Active applicator length), the $\mathrm{MD}$ applicator efficiency is appreciably higher than that of either of the $\mathrm{CD}$ applicators tested in Task 2. This is reasonable, since the sample is located at the mid-plane, where the field strength is a maximum. We have also found the expected results that efficiency increases with WBW, and that efficiency is greater (for given ingoing WBW) when the "machine speed" is higher. The latter effect is due to the higher average WBW along the length at higher speed (less drying). We again observed evidence of a standing wave heating component, even with a load, but this is not really a problem with the MDoriented applicator; it is just the cumulative absorption as the sheet travels along the waveguide that matters. Experiments have included looking at the effect of a reflector vs. a dummy load as the termination condition (an important effect), and the (less-important) effect of inputting the microwave energy at the upstream end vs. the downstream end (relative to the direction of sheet travel).

Task 3. Low Speed, Low Power, Pilot Paper Machine Experiments.

The purposes of this task are to work out issues associated with continuous operation and use of multiple/parallel waveguide MD-oriented applicators, and to check the paper properties impacts of using microwave drying. We originally planned to pursue this task at NC State. We expected to base the work on use of a three-waveguide MD-oriented 
applicator, probably with either a $75 \mathrm{~kW}$ generator or multiple $5 \mathrm{~kW}$ generators. However, if funding had not been discontinued, we would now do this work on IPST's newly acquired Continuous Web System. Conceivably, wet paper rolls produced on the NCSU pilot machine could be used in some of the experiments. Because this project was terminated, we have cancelled our order for a four-waveguide MD applicator from IMS, accompanied by a $75 \mathrm{~kW}$ generator.

Task 4. High Speed, High Power, Pilot Paper Machine Demonstration Trials.

The purposes of this task are to demonstrate the microwave drying of continuous paper webs at higher speeds, to confirm the efficiency and design principles, and to deal more with web transport and ventilation issues. The experiment was to be run on a Herty Foundation pilot machine in 2002. We had expected to base the work on use of a multiple-waveguide MD-oriented applicator, with at least one $75 \mathrm{~kW}$ generator. As discussed above, if the project had not been terminated, we would now do this work on IPST's newly acquired Continuous Web System. Thus, Tasks 3 and 4 would have been combined.

Task 5. Develop Design/Scale-up Model.

The most recent modeling efforts have been focused on the new MD-oriented waveguide concept to support the Task 2 experimental work. A simplified, uniform temperature model has been completed for the case with a load at the end opposite the power-input end of the waveguide. The model can be extended to the general case with variable temperature and the option of a short or a load at the end. An interesting theoretical and practical question can be addressed: whether a countercurrent or co-current configuration (direction of sheet motion vs. direction of microwave propagation) is better for efficiency.

In support of our design/scale-up model development, our M.S. student (D. Cameron) been considered the experimental approaches for determining the dielectric loss coefficient as a function of moisture and basis weight. We decided to abandon the offline approach in favor of using selected sample heating/drying experiments in the MDoriented applicator. In effect, the dielectric loss coefficient was "back-calculated," by matching theory and experiment for various water loads and sheet temperatures. In spite of the lack of continuing DOE support, D. Cameron continued his efforts, at IPST's expense, until April 2003. Portions of his report are included in the Appendix.

Task 6. Develop Design Guidelines.

This Task was not completed, due to lack of continued funding. However, the theory and experimental data presented here would serve as a basis for the design of microwave applicators.

Task 7. Energy and Economic Analysis.

We completed an energy and economic analysis of the microwave technology, and submitted a report to the Task Group and DOE in mid 2002. The MD-oriented microwave applicator performance model for assessing energy efficiency and required equipment size was based on appropriate scale-up projections using our low power 
laboratory data. To complement this model of microwave-applicator performance, we adapted a model of the conventional multi-cylinder dryer section, recently developed in connection with another IPST drying project, to the simulation of various scenarios for incorporating microwave technology on the paper machine. This integrated model allowed us to make estimates of the productivity benefits of using microwave technology for various purposes. The results served as input to the energy/economic analysis.

The scenarios considered for employing microwave technology were of two types, reflecting the most promising applications. In one, the microwave applicator was placed before the last press nip, for the purpose of preheating the sheet to achieve higher postpress solids (and temperature). In the other, the microwave applicator was placed at the beginning of the dryer section, before the first dryer can, to preheat/pre-dry the sheet. In both cases, the higher sheet temperature and solids content resulting from microwave application before the first dryer can was assumed to be capable of reducing picking and sticking enough to allow elimination of temperature graduation in the first dryer section. For the microwave cases, it was also assumed that, by using CD control of power input to the various waveguides, any non-uniform sheet moisture profile at the reel can be eliminated.

The economic assessment of microwave paper heating/drying technology showed:

10) The time to recover the capital and installation cost should be appreciably less than 2.5 years for most dryer limited machines and implementation scenarios. For high basis weight machines $\left(200 \mathrm{~g} / \mathrm{m}^{2}-400 \mathrm{~g} / \mathrm{m}^{2}\right)$, the time to recover capital and installation costs is only 0.5 to 1.0 year.

11) Increases of over $30 \%$ in machine speeds can be realized. Additional revenue is proportional to the increase in machine speed (assuming no additional down time).

12) The greatest economic benefits will be realized if the microwave applicator is positioned before a final press nip. This can yield drying energy (per ton) savings of about $20 \%$. 


\section{SUGGESTED FUTURE WORK}

The project work reported here has shown that the MD - oriented applicator concept has significant technical, energy and economic potential. However, the development and evaluation were based on use of an experimental single waveguide applicator at low power. A paper machine installation would require a multiple/parallel waveguide applicator, as depicted in Figure 1. Thus, there is a need to progress to a multiple/parallel waveguide scale-up experiment. The purposes would be to work out issues associated with continuous operation and to check the paper properties impacts of using microwave drying. Of concern is the behavior of the microwave field strength at the slots between adjacent waveguides. Those zones (at the sidewall slots) might produce a non-uniform heating intensity. This effect has needs to be studied. Additionally, there is a need to demonstrate the microwave drying of continuous paper webs at higher speeds, to confirm the efficiency and design principles, and to deal more with web transport and ventilation issues. Other issues that should be addressed include cleaning, threading and handling of sheet breaks.
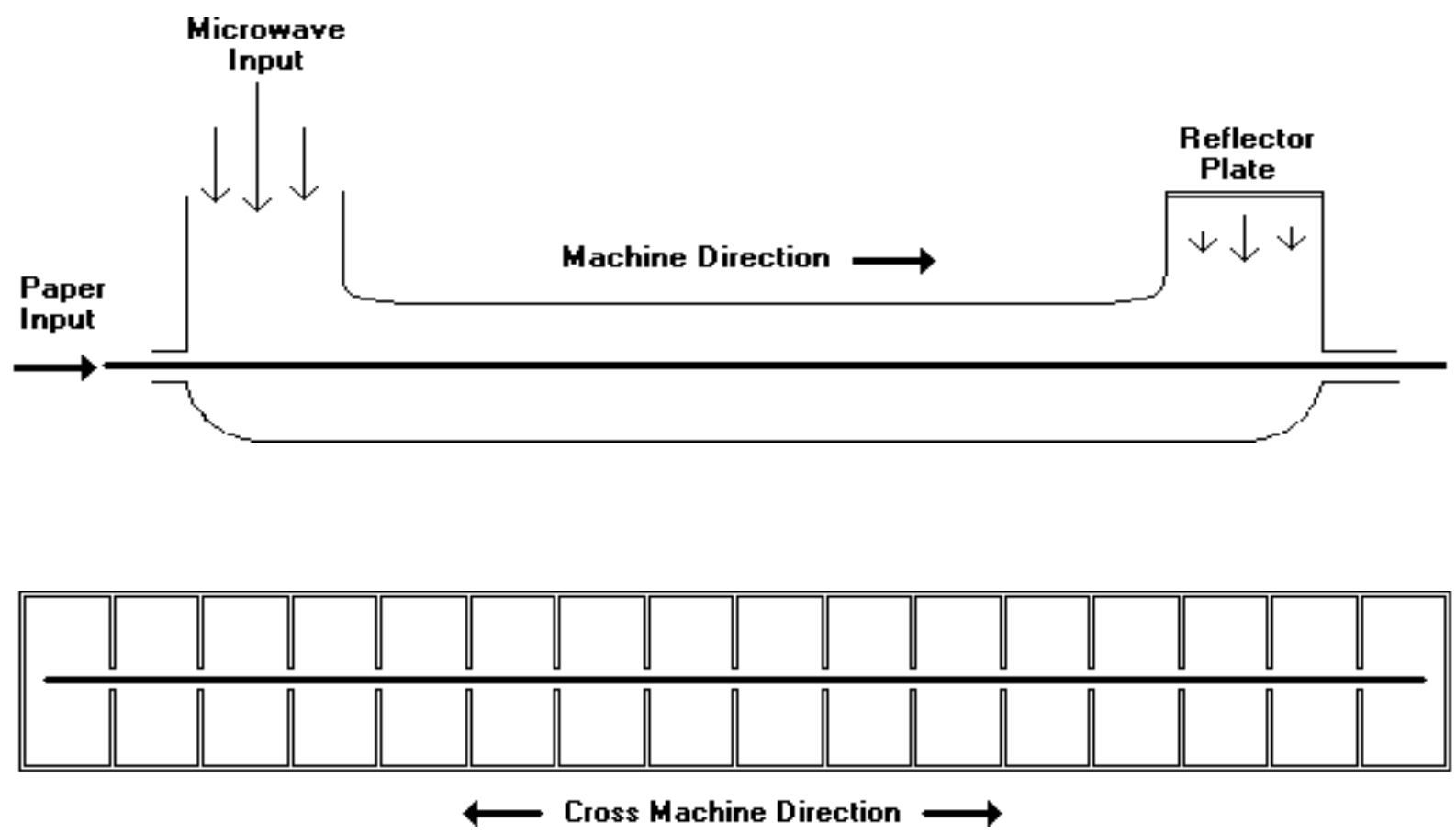

Figure 1. MD Applicator, Centerline Slot, Multiple Waveguides 


\section{APPENDIX}

Determination of the Absorption Coefficient in Dielectrically Dried Paper

Excerpts from a Report

By

\section{Douglas Cameron}

April 16, 2003

\{Caution: The 'loss coefficient' values presented in this Appendix exhibit a significant dependence on the various experimental techniques used to obtain them.

Therefore, one should not rely on these data for design purposes until further evaluation of the techniques and analysis methods has been performed.\} 


\section{Table of Contents}

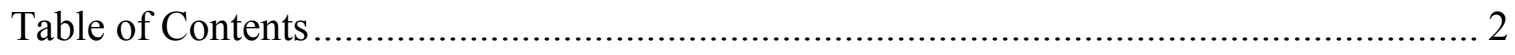

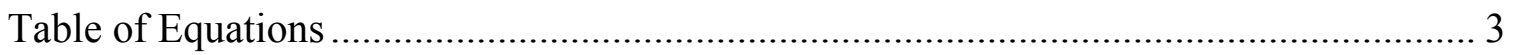

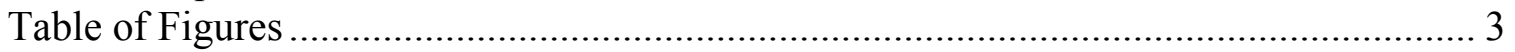

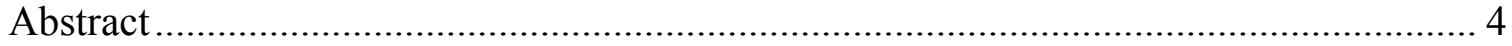

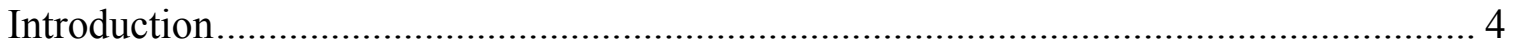

Literature Review............................................................................................... 5

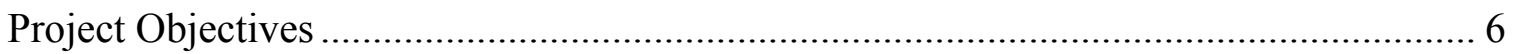

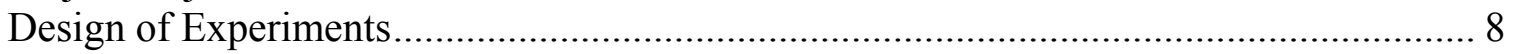

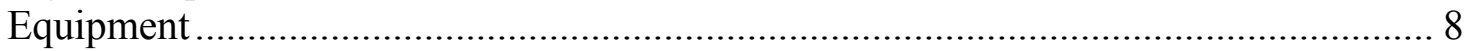

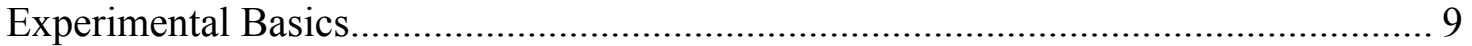

Background: Equations and Functioning of System............................................... 10

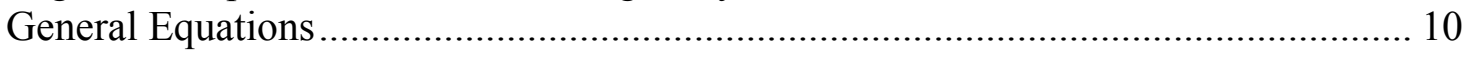

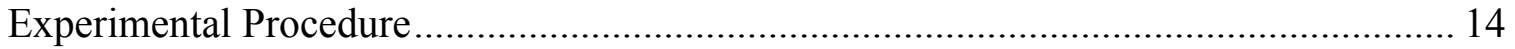

Experimental Procedure (Power Method and Thermodynamic Methods) .................. 15

Experimental Procedure (Saran Wrap ${ }^{\circledR}$ Coated Blotter Paper)................................ 15

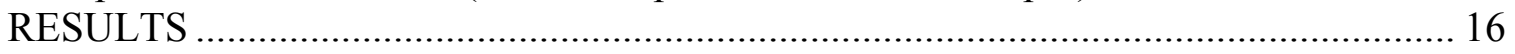

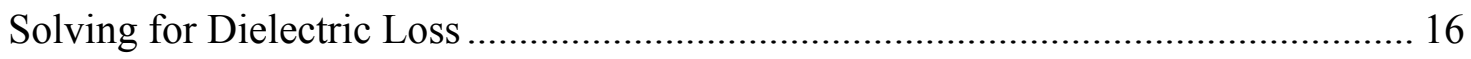

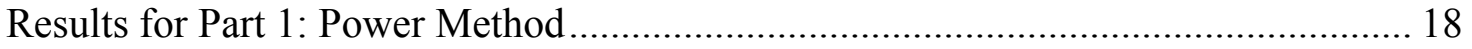

Results for Part 2: Thermodynamic Method for Dielectric Loss * Thickness $\left(\varepsilon_{r}^{\prime \prime} t\right) \ldots 19$

Results for Part 3: Saran Wrap ${ }^{\circledR}$ Maintaining Constant Moisture ............................. 21

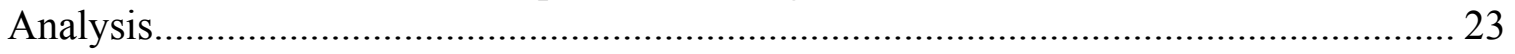

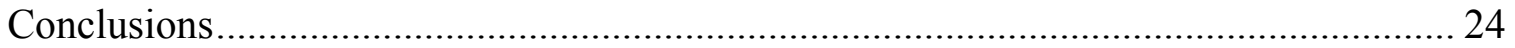

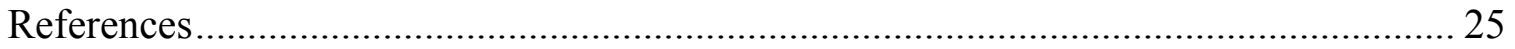

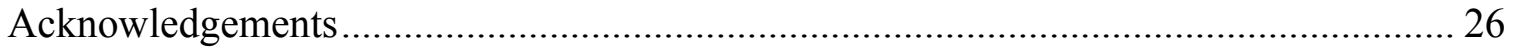

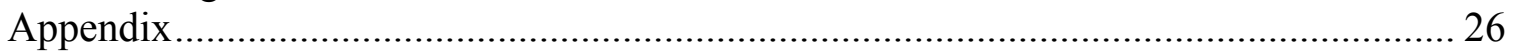




\section{Table of Equations}

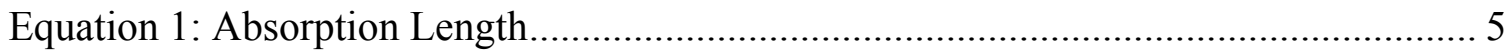

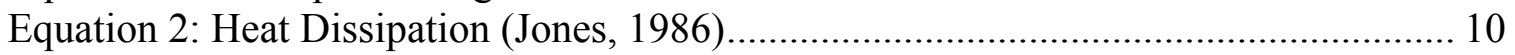

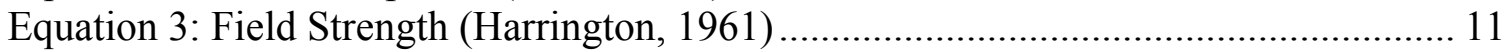

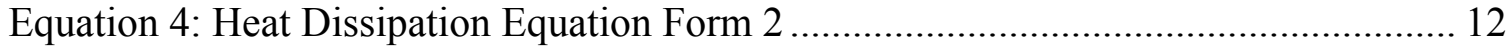

Equation 5: Heat Dissipation Equation, Form 3 (Ahrens and Habeger, 2001)................ 13

Equation 6: Heat Dissipation Equation BW and Heat Capacities ................................ 13

Equation 7: Heat Balance........................................................................................ 14

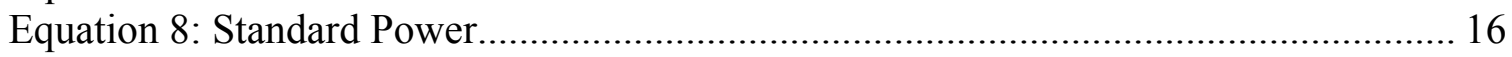

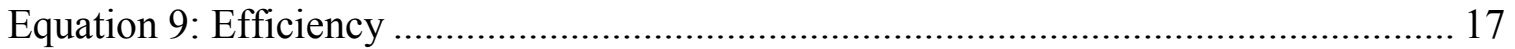

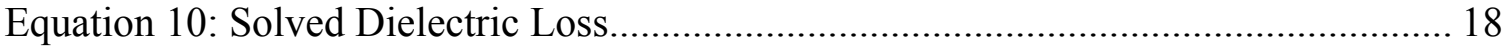

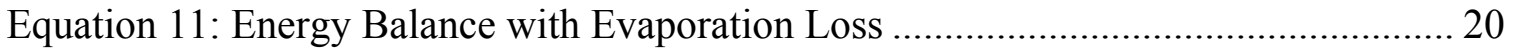

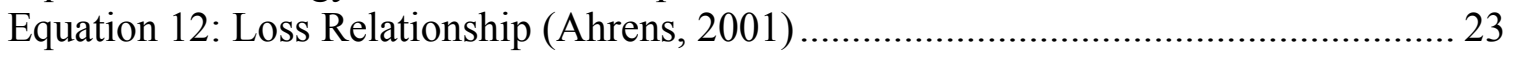

\section{Table of Figures}

Figure 1: Dielectric Loss Coefficient versus Water Density in Paper. Fit of Data Made to

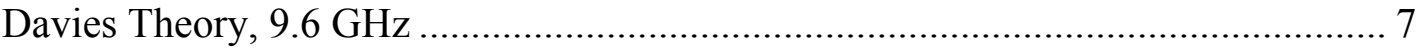

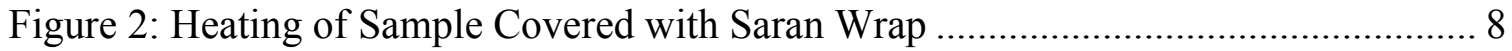

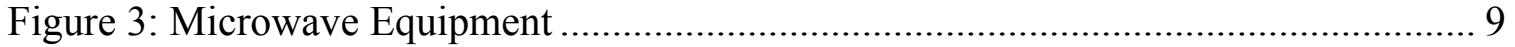

Figure 4: Configuration of Microwave System ....................................................... 12

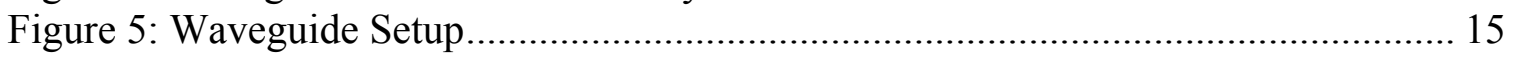

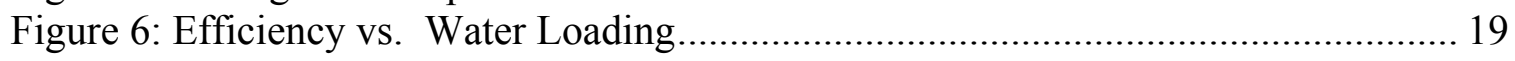

Figure 7: Dielectric Loss vs. Water Loading, Power Calculation Method ....................... 19

Figure 8: Dielectric Loss vs. Water Loading Thermodynamic Method .......................... 20

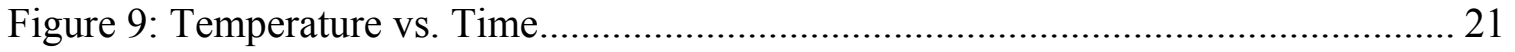

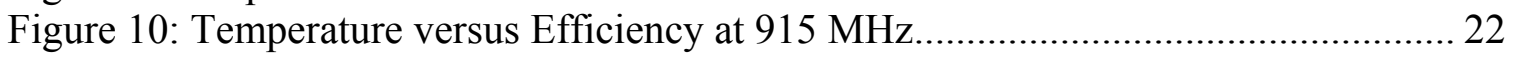

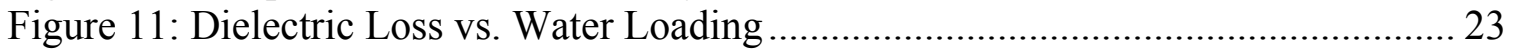

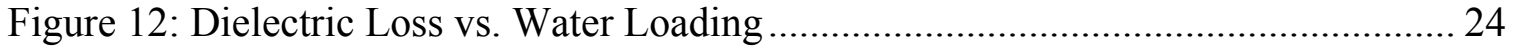




\begin{abstract}
This project studied the dielectric, microwave drying of paper using equipment located at the Institute of Paper Science and Technology. In this research, it was proposed to alter certain factors of this microwave drying process and look for a predictable correlation in the dielectric loss coefficients. A connection between the dielectric loss coefficient and predictability of the system was observed. In particular, this work examined how the temperature and moisture content of the paper affect the dielectric constant. It was shown that a previous model proposed by Dr. Ahrens was accurate in describing this relationship. This study also looked at a comparison of the results of two calculation methods. This will make it possible to compare and contrast the validity of testing the system using two methods. Ideally, this data will aid in the ability to predict values for the described system. This information will hold value to current and future research in the field of microwave drying.
\end{abstract}

\title{
Introduction
}

During the production of paper, large amounts of water must be removed along the production route. This is primarily accomplished through free drainage, hydrofoil assisted dewatering, vacuum assisted dewatering, mechanical pressing and thermal drying. The heating process currently uses large steam-heated cylinders to heat the paper and evaporate the water. The use of microwave energy to supplement this process is also being studied. This research was designed to explore some of the aspects of microwave drying. This study may assist in the determination of advantages microwave aided water removal offers the paper industry.

Certain aspects of microwave drying are quite appealing, such as its ability to transfer energy directly to the water in the paper. Inefficiency in current methods is often due to the fact that heat cannot be applied directly to the water in the paper. Instead, heat must be transferred from the source through several media, which may include a layer of air, to finally reach the water in the paper. Another problem resulting from conventional methods of water removal is the fact that the sheet must be "over cooked" during drying to remove all water. Indeed, water is not specifically targeted and the bulk materials of the sheet also experience heating. Microwave drying, in theory, solves these problems by transferring the energy directly to the sheet-imbedded water, thus overcoming the inefficiencies discussed above.

One critical factor in the current research involves the dielectric loss coefficient. The dielectric loss coefficient is represented by the symbol $\varepsilon "$ (Habeger and Baum, 1983). The dielectric loss coefficient is dependent on moisture content, temperature, microwave frequency, and water impurity concentration (Williams, 1966). As discussed by Ahrens and Habeger (2001), this factor can be used to predict the drying properties of a selected paper. This project involves the execution of experiments designed to quantify the loss coefficient, and help assess the current model for the system. The effects of factors such as water loading and temperature on the model were also examined. 


\section{Literature Review}

Several researchers have made significant contribution to the study of the microwave drying of paper. In the Journal of Microwave Power, 1966, Norman Williams observed the leveling of moisture in dielectric sheets and addressed the relationship between moisture content, basis weight and microwave frequency. Some interesting results were obtained in his research. Wet spots in the dielectric sheet will absorb more energy, because microwaves target water. Williams also described the "ability to dry wet spots significantly faster than dry ones" with the variable $\mathrm{k}_{2}$, which he called the leveling constant of dielectric.

Another important contribution to the field was the publication of The Microwave Dielectric Constants of Water-Paper Mixtures: The Role of Sheet Structure and Composition by C. Habeger and G. Baum (1983). Their work also examined the sensitive interaction between electromagnetic radiation and the moisture content of paper. They determined that the dielectric constant $\varepsilon$ is a significant parameter that governs this interaction. The dielectric loss term is defined as $\varepsilon^{\prime \prime}$ and is graphed against the effective density of water in the sheet, shown in Figure 1, of the project objectives section. A strong correlation in the data is clearly shown, between water loading of the sheet and the loss term, $\varepsilon^{\prime \prime}$.

In 1986, Jones presented a theory of microwave heating with a particular focus on the moisture profile correction of paper and board (1986). Jones describes the dielectric loss factor, $\varepsilon_{r}$, also known as the dielectric loss coefficient. In Equation 1, the dielectric loss constant is one factor used to determine the absorption length, $\mathrm{L}_{0}$. Ahrens and Habeger describe $\mathrm{L}_{0}$ shown in equation 1, as "the meaningful length scale for absorption of microwave energy by the moist paper" (2001).

$$
L_{0} \equiv b /\left(Z \omega \varepsilon_{0} \varepsilon_{r} t\right)
$$

\section{Equation 1: Absorption Length}

Where:

$L_{0}=$ Absorption length (m)

$\mathrm{b}=$ Broad dimension of waveguide cross-section $(\mathrm{m})$

$\mathrm{Z}=$ Waveguide impedance (Ohms)

$\omega=$ Angular frequency $(1 / \mathrm{s})$

$\varepsilon_{0}=$ Permittivity of free space (farads $/ \mathrm{m}$ )

$\varepsilon_{r}^{\prime \prime}=$ Dielectric loss coefficient

$\mathrm{t}=$ Paper thickness $(\mathrm{m})$

Stuerga and Gailland (1996) describe dielectric loss as "the capacity of the substance to convert electromagnetic energy into heat." Microwave energy can be described as an oscillating electric field. The torque caused by the electric field results in rotations in polar molecules, which cannot orient themselves with the electric field at the 
same rate as the oscillation. The delay between electromagnetic stimulation and response is the basis for dielectric loss (Stuerga and Gaillard).

F. Ahrens and C. Habeger investigated microwave drying in 2001 in Use of Applicator Design Ideas to Improve Uniformity of Paper Drying via Microwave Energy, and primarily focused on examining the uniformity of paper drying in a microwave field. Newly proposed microwave guide configurations were examined. This research also examines the dissipation per unit distance along the waveguide.

\section{Project Objectives}

The objective of this research is to investigate the dielectric heating properties of paper. Specifically, it examines the relationship between the dielectric loss coefficient $\left(\varepsilon^{\prime \prime}\right)$ and the effective water density in the sheet. The definitions of $\varepsilon, \varepsilon^{\prime}$ and $\varepsilon^{\prime \prime}$ (Habeger and Baum, 1983) are important aspects in this research. In this case $\varepsilon$, can be defined by as the dielectric loss coefficient, with $\varepsilon^{\prime}$ representing the real part of the coefficient and $\varepsilon$ " representing the imaginary part. The imaginary part $\varepsilon$ " is dependent only on water density (Habeger and Baum, 1983) and deals directly with dielectric loss. Therefore, in this research, the imaginary coefficient will be used exclusively and will be defined as $\varepsilon_{r}$ (Ahrens and Habeger, 2001). Figure 1 was taken directly from Habeger and Baum's paper. It shows the predictability of the data, with excellent correlation between the density of the water and dielectric loss coefficient. A square fit was made as per Davies' Theory for media with cylindrical inclusions (Davies, 1974). The scope of this theory is outside the range of this study; however, the predictability of the system should be noted. 


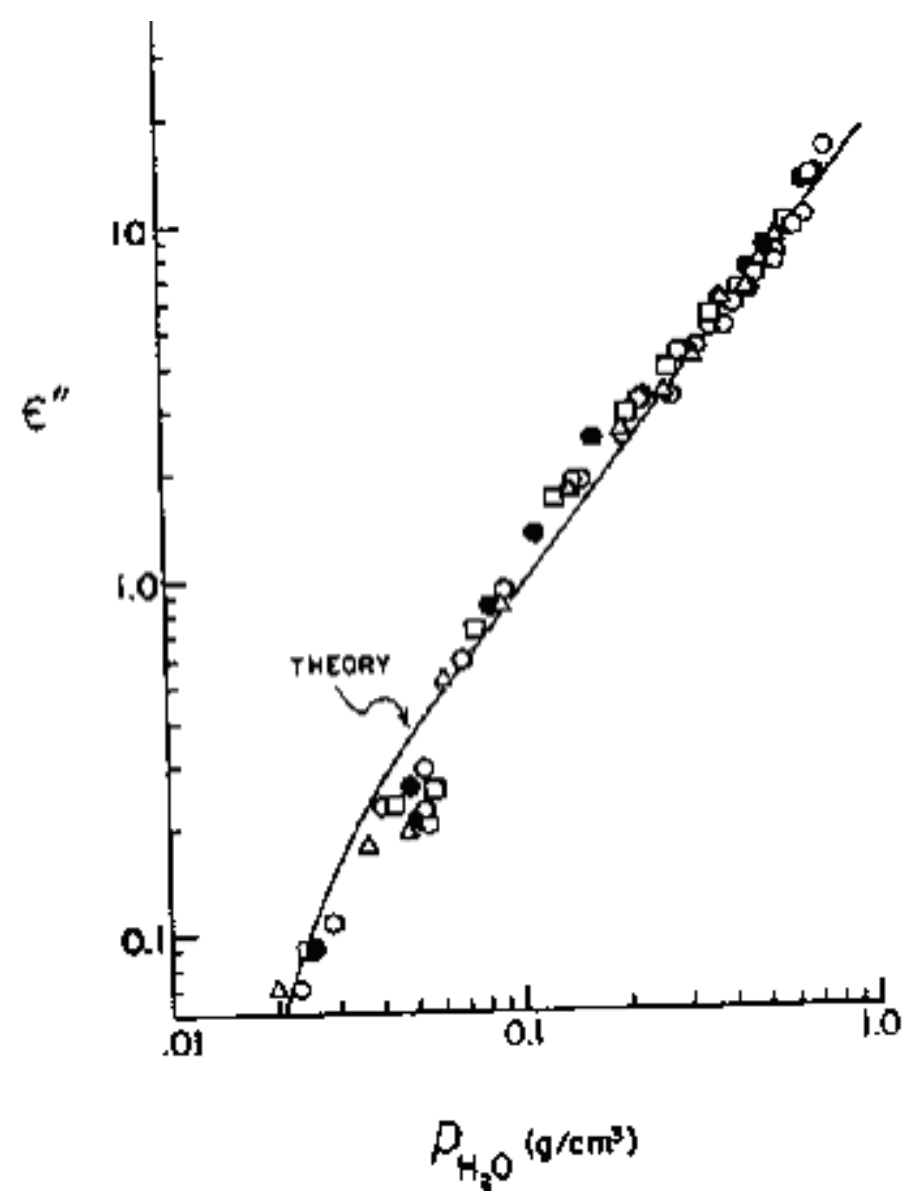

Figure 1: Dielectric Loss Coefficient versus Water Density in Paper. Fit of Data Made to Davies Theory, $9.6 \mathrm{GHz}$

One major difference between this current work and earlier work is the frequency of the microwave energy used for drying. While Habeger and Baum performed their experiments at $9.6 \mathrm{GHz}$, this research uses $915 \mathrm{MHz}$. The possible differences this could have on the relationship between water density and the dielectric constant curve are unknown. It is possible that the shape of the curve in the above graph, showing the dielectric constant as a function of water density, will change. Any effect that the change in frequency has on the correlation in the above graph would be of interest.

As performed in previous research, the addition of a thin Saran Wrap ${ }^{\circledR}$ membrane to the paper sample is employed in this project (Habeger and Baum, 1983). This membrane is a material that does not heat due to microwaves and also does not allow steam to escape. The expected effect of this membrane on sheet temperature versus time during microwave heating is shown in Figure 2. The effect of temperature on the dielectric loss term, $\varepsilon_{r}^{\prime \prime}$ is also of interest. 


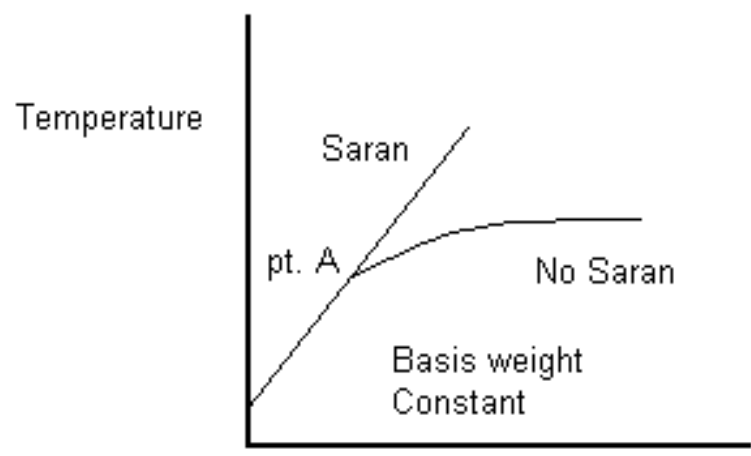

Time

Figure 2: Heating of Sample Covered with Saran Wrap

The leveling off observed in Figure 2 is due to the fact that much of the heat and therefore temperature is lost in the form of steam. By applying the non-permeable polymer layer it is possible to observe the trends as the microwaves continue to heat the sheet-imbedded water. This data can also be used to compare the amount of heat lost from convection to the amount of heat lost to vaporization.

Another major point in this research is the inclusion of the paper thickness variable, $\mathrm{t}$, into the comparison graph of $\varepsilon_{r}$ " versus water density. Here, the graph would be labeled $\varepsilon_{r} * \mathrm{t}$ vs. water density $* \mathrm{t}$, where $\mathrm{t}$ is the thickness of the paper. The importance of this change cannot be overlooked. As shown in the background section of this paper it is possible to link $\varepsilon_{r}$, and thickness, $\mathrm{t}$, for calculation purposes. It is also a more logical form for displaying the data, because it accounts for the thickness of the paper. It is important to note that water density, $\rho_{\mathrm{H}_{2} \mathrm{O}},\left(\mathrm{g}\right.$ water $\left./ \mathrm{m}^{3}\right)$ shown in Figure 1 multiplied by thickness, $\mathrm{t}$, (meters) will yield $m_{w}^{\prime \prime}$, water basis weight, in (g water/, $\mathrm{m}^{2}$ ). This will prove useful in later sections of this report.

\section{Design of Experiments}

\section{Equipment}

All of the proposed experiments for this research made use of the existing laboratory equipment, and machine configurations at IPST. The frequency for all 
experiments was 9.15 MHz. All experiments were performed on a configuration in which the microwave waveguide is oriented in the machine direction, with respect to potential paper machine application, the system can be described as a transverse feed wave-guide with a feed slot in the CD direction. The equipment was developed by IPST and Industrial Microwave Systems (IMS). The configuration of the equipment used for this research incorporates a dummy load at the termination of the wave guide to absorb excess microwave energy not absorbed by the sheet. This load serves the purpose of preventing excess energy from being reflected back through the waveguide. A layout of existing is shown below in figure 3 .

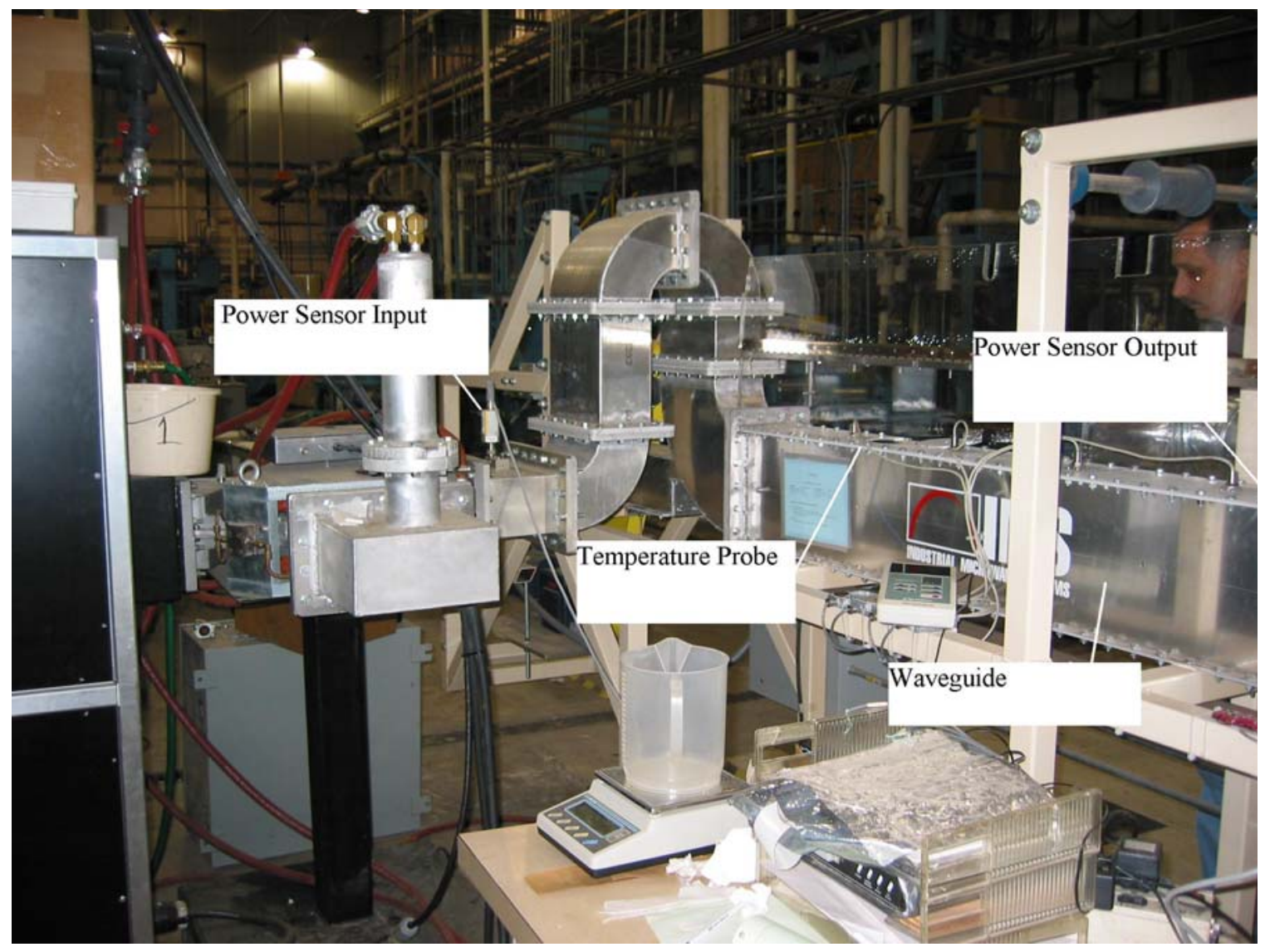

Figure 3: Microwave Equipment

\section{Experimental Basics}

For this research, the moisture content of paper was measured by weighing both wet and dry paper samples of equal area and thickness. The weight of the wet sample minus the weight of the dry sample is equal to the amount of water in the sample. This can be defined as water loading, $m_{w}^{\prime \prime}$, where $m_{w}^{\prime \prime}$ is defined as the water mass per unit area, in grams per square meter. In this way, the thickness of the sample is not relevant. With the existing configuration, it is possible to measure the power input, the power 
output, the temperature change and the mass change. Knowing these variables it is possible to calculate $\varepsilon_{r} *$ t, through the use of certain equations which will be discussed in the background section of this paper. The ability of $\varepsilon_{r} *_{t}$ to predict the drying rate is an area of interest. The first stage of this research involved the investigation and modification of various equations to determine which are best suited for this research. It was believed that it might be possible to create an equation to describe the system based on the $1^{\text {st }}$ law of thermodynamics. This involves creating an energy balance for the system, using the fact that energy is conserved.

Another key experimental design step is the addition of Saran Wrap ${ }^{\circledR}$ type barrier to the paper to prevent heat loss due to water vaporization. The use of Saran Wrap ${ }^{\circledR}$ allows higher temperatures to be considered. It was expected that $\varepsilon_{r} *_{\mathrm{t}}$ is temperature dependent. Testing this theory with the methods described in the previous section is an additional aspect to this research.

\section{Background: Equations and Functioning of System}

As stated previously, the first step in this project was to gain some background knowledge of the system. To acquire this knowledge, the system's governing equations were outlined and defined in some detail. The following section contains a brief background of system fundamentals.

\section{General Equations}

$$
D_{v}=2 * \pi * f^{*} \varepsilon_{0} * \varepsilon_{r}^{\prime \prime} * E^{2}(z)
$$

\section{Equation 2: Heat Dissipation (Jones, 1986)}

Equation 3 predicts the volumetric heat rate as a function of frequency, dielectric loss coefficient and electric field strength.

Where:

$D_{v}=$ Volumetric dissipation rate in paper Heat transferred to given unit of material (Dissipation rate/cubic meter) (Watts/cubic meter)

$\mathrm{f}=$ Frequency $($ Hertz)

The frequency at which the microwaves are generated, this value is constant for these experiments and is set prior to data acquisition 
$\varepsilon_{0}=$ Permittivity of free space (farads/meter)

This value is constant at $8.85 * 10^{-12}$ farads/meter.

$\varepsilon_{r}^{\prime \prime}=$ Dielectric loss coefficient (dimensionless)

This value is effectively the imaginary part of the expression for permittivity with respect to frequency (Niskanen, 1998)

$\mathrm{E}(\mathrm{z})=$ Electric field strength (Volts/meter)

This value can be determined by measuring the field power in watts, this value along with values for width, height and impedance can be plugged into equation 4. This field strength varies with distance from the wave source. This distance is referenced to wave propagation in the z-direction and is shown in connection with the $\mathrm{z}$ variable.

\section{Equation Relating Field Strength and Power}

$$
P(z)=\frac{a b}{2 Z} * E_{\max }^{2}(z)
$$

\section{Equation 3: Field Strength (Harrington, 1961)}

Equation 4 predicts the electromagnetic power as a function of electric field strength, waveguide height, waveguide width and impedance.

Where:

$$
\begin{aligned}
& \mathrm{a}=\quad \text { Waveguide width (meters) } \\
& \mathrm{b}=\quad \text { Waveguide height } \quad \text { (meters) } \\
& \mathrm{Z}=\quad \text { Waveguide impedance (ohms) } \\
& \mathrm{E}=\quad \text { Electric field (volts/meter) } \\
& \mathrm{P}(\mathrm{z})=\text { Electromagnetic Power }(\mathrm{W})
\end{aligned}
$$

Figure 4 shown below is a conceptual drawing of the waveguide setup. The paper travels into the guide in the $\mathrm{z}$-direction, ' $\mathrm{t}$ ' represents the paper thickness. 


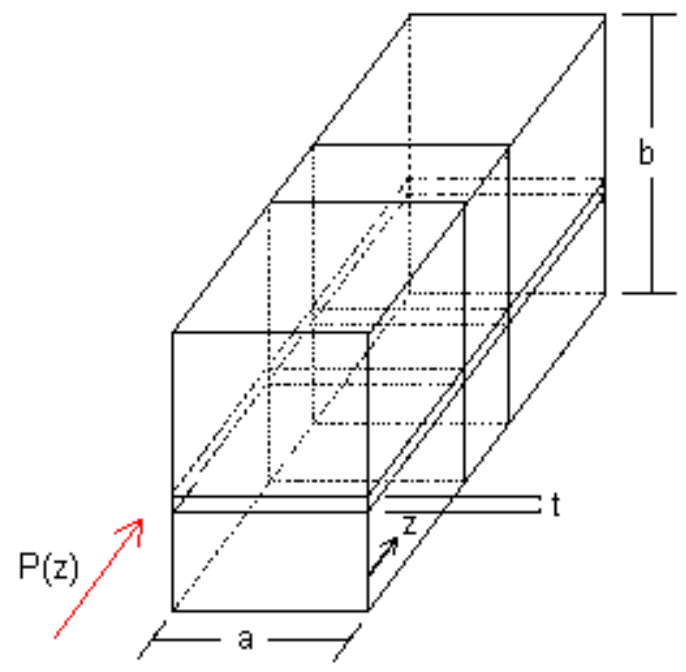

Figure 4: Configuration of Microwave System

\section{Heat Dissipation Equation, Power Absorbed: Form 2}

$$
\text { Watts }=2 * \pi * f * \varepsilon_{0}^{*} \varepsilon_{r}^{\prime \prime} E^{2}(z) *(\text { volume })
$$

\section{Equation 4: Heat Dissipation Equation Form 2}

Equation 5 predicts the heat rate as a function of frequency, dielectric loss coefficient, volume and electric field strength.

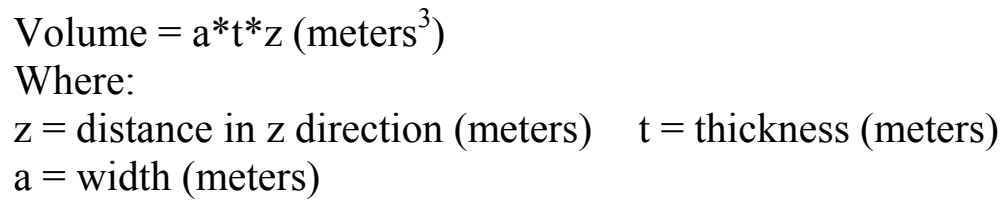

Additional variables listed with following equation. 


$$
D^{\prime \prime}=\frac{\text { Watts }}{\text { meter }^{2}}=2 * \pi * f^{*} \varepsilon_{0} * \varepsilon_{r}^{\prime \prime} * E^{2}(z) * t
$$

Equation 5: Heat Dissipation Equation, Form 3 (Ahrens and Habeger, 2001)

Equation 6 predicts the area heat rate as a function of frequency, dielectric loss coefficient and electric field strength.

Where:

$$
\begin{array}{ll}
D^{\prime \prime}(z)= & \text { Power transferred (dissipated) per unit area (Watts } \left./ \text { meter }^{2}\right) \\
\mathrm{f} & =\text { Frequency (Hertz) } \\
\varepsilon_{0} \quad=\text { Permittivity of free space (farads/meter) } \\
\varepsilon_{r}^{\prime \prime} \quad=\text { Dielectric loss coefficient } \\
\mathrm{E} \quad=\text { Electric field strength (Volts/meter) } \\
\mathrm{t} \quad=\text { Thickness of paper sheet }
\end{array}
$$

\section{Heat Dissipation Equation: Form 4, relating heat capacities and basis weight}

$$
\left(m_{f}^{\prime \prime} * c_{f}+m_{w}^{\prime \prime} * c_{w}\right) \Delta T=D^{\prime \prime *} s
$$

\section{Equation 6: Heat Dissipation Equation BW and Heat Capacities}

Equation 7 serves to link heat dissipation to the amount of energy used for heat up of material, assuming no phase change occurs.

Where:

$$
\begin{array}{ll}
\Delta T & =\text { Change in temperature (degrees Celsius) } \\
m_{w}^{\prime \prime} & =\text { Mass of water per unit area (kilograms } / \text { meter }^{2} \text { ) } \\
c_{w} & =\text { Heat Capacity of water (Joules/(kilogram* degrees Celsius)) } \\
m_{f}^{\prime \prime} & =\text { Mass of fiber per unit area (kilograms } / \text { meter }^{2} \text { ) } \\
c_{f} & =\text { Heat Capacity of fiber (Joules/(kilogram* degrees Celsius)) } \\
\mathrm{s} & =\text { Time (Seconds) }
\end{array}
$$


Arrangement of equations:

$\left(m_{f}^{\prime \prime} * c_{f}+m_{w}^{\prime \prime} * c_{w}\right) \Delta T=D^{\prime \prime} * s$

$D^{\prime \prime}=\frac{\text { Watts }}{\text { meter }^{2}}=2 * \pi * f * \varepsilon_{0} * \varepsilon_{r}^{\prime \prime} * E^{2}(z) * t$

It is then possible to make the following arrangement:

$$
2 * \pi * f * \varepsilon_{0} * \varepsilon_{r}^{\prime \prime} * E^{2}(z) * t * s=\left(m_{f}^{\prime \prime} * c_{f}+m_{w}^{\prime \prime} * c_{w}\right) \Delta T
$$

\section{Equation 7: Heat Balance}

Equation 8 is a functional linkage between energy input and heating effects on the material.

\section{Experimental Procedure}

The experimental procedures used in this research are summarized below. For this section of the experiment the prepared test strips were placed in the waveguide under the first infrared sensor. Temperature data was read from the infrared, and the output and power readings were read off of the Agilent Technologies Power Meter. Samples were weighed on a standard mass balance. Figure 9 shows a conceptual schematic of the waveguide used for this research. The sample was placed directly under the IR temperature sensor for all sections of this trial. 
Water Load

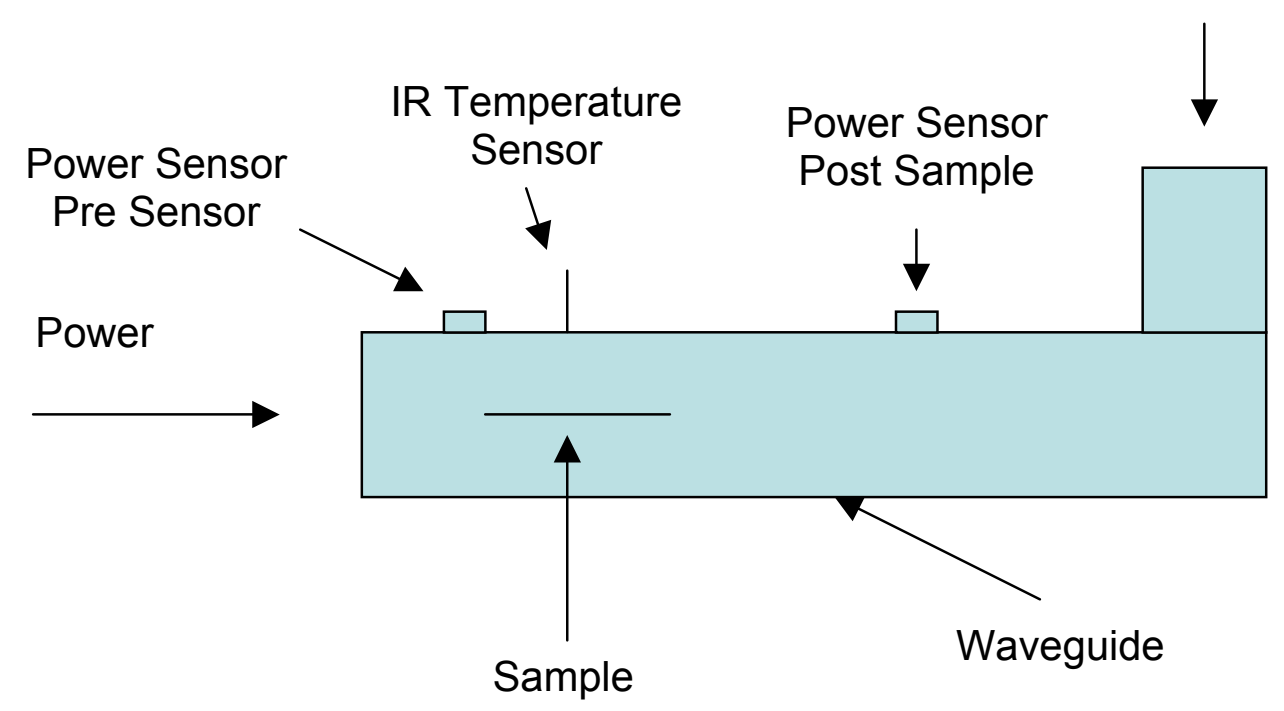

Figure 5: Waveguide Setup

\section{Experimental Procedure (Power Method and Thermodynamic Methods)}

1. Waveguide was configured with water load/dummy load

2. Standard calibration of power sensors as noted in Agilent User Guide

3. Required offset value entered into system

4. Cut and weigh 6-one foot by 2.5 inch sections of test strip from $337 \mathrm{gram} / \mathrm{m}^{2}$ linerboard

5. Soak test strips in water until saturated and then record new weight

6. Set first sample in waveguide

7. Turn on microwave with 3000 watt input, wait one minute, then remove and weigh the sample and note the power meter and temperature reading at this time

8. For the second sample repeat process, this time leaving sample in for 2 minutes

9. Continue until last sample has been left in for 6 minutes

\section{Experimental Procedure (Saran Wrap ${ }^{\circledR}$ Coated Blotter Paper)}

The experimental method for coating the test sheet in Saran Wrap was developed with the help of James Loughran, Associate Technology Specialist. This method enables higher maximum temperatures to be obtained. The experiment was carried out as follows;

1. Waveguide to be configured with water load/ dummy load.

2. Standard calibration of power sensors as noted in Agilent User Guide. 
3. Required offset values entered into system.

4. Cut 2.5 inch $\times 12$ inch sections of blotter paper. The blotter paper had a basis weight of approximately $267 \mathrm{~g} / \mathrm{m}^{2}$.

5. These strips were weighed and recorded.

6. The strips were then soaked briefly in water at room temperature, approximately 20 degrees Celsius.

7. The mass of the wet samples was recorded.

8. The samples were immediately sealed with tape in Saran Wrap ${ }^{\circledR}$ with a dielectric tipped optical fiber temperature sensor attached to the center of the sheet.

9. Samples were placed in wave guide at $1 \mathrm{KW}$ system power input setting and the temperature rise was recorded.

10. When the temperature rise leveled off, the microwave generator was turned off and the cooling temperatures were recorded.

\section{RESULTS}

\section{Solving for Dielectric Loss}

As previously stated, the objective of the first set of experiments was to establish a clear relationship between water loading and the dielectric loss constant relationship $\left(\varepsilon_{r}^{\prime \prime} t\right)$. A mathematical relationship between the power absorbed and power input can be devised to calculate $\varepsilon_{r} t$. A possible method for calculation is shown below.

Where:

All definitions are defined in background section of paper.

Actual method of calculation

$$
D^{\prime \prime}=\frac{\text { Watts }}{\text { meter }^{2}}=\omega \varepsilon_{0}\left(\varepsilon_{r}^{\prime \prime} t\right) E^{2}(z)
$$

\section{Equation 8: Standard Power}

$$
\begin{aligned}
& P(z)=\frac{a b}{2 Z} E^{2}(z) \\
& E^{2}(z)=\frac{P(z)}{\left(\frac{a b}{2 Z}\right)}
\end{aligned}
$$




$$
\begin{aligned}
& D^{\prime \prime}=\omega \varepsilon_{0}\left(\varepsilon_{r}^{\prime \prime} t\right)\left(\frac{P(z)}{\frac{a b}{2 Z}}\right) \\
& \frac{d P}{d z}=-a D^{\prime \prime}=\frac{-2 Z \omega \varepsilon_{0}\left(\varepsilon_{r}^{\prime \prime} t\right) P}{b} \\
& \int_{P(0)}^{P(z)} \frac{d P}{P}=-\int_{0}^{z} \frac{2 Z \omega \varepsilon_{0}\left(\varepsilon_{r}^{\prime \prime} t\right) d z}{b}
\end{aligned}
$$

All variables defined as per background section.

Assuming that the paper does not heat or dry much, we can assume that $\varepsilon_{r} t t$ remains constant.

K was removed to simplify math.

$$
K=\frac{2 Z \omega \varepsilon_{0}\left(\varepsilon_{r}^{\prime \prime} t\right)}{b}
$$

Therefore:

$$
\ln \frac{P_{(z)}}{P_{(0)}}=-K L
$$

Efficiency is equal to

$$
\eta=\frac{P_{\text {in }}-P_{\text {out }}}{P_{\text {in }}}
$$

\section{Equation 9: Efficiency}

So for a given experiment it is possible to solve for $\varepsilon_{r} t t$ : 


$$
\varepsilon_{r}^{\prime \prime *} t=\frac{\ln \left(\frac{1}{1-\eta}\right)}{\left(\frac{4 * \pi * f^{*} \varepsilon_{o} * Z * L}{b}\right)}
$$

\section{Equation 10: Solved Dielectric Loss}

Equation 27 describes $\left(\varepsilon_{r}^{\prime \prime} t\right)$ as a function of efficiency.

\section{Results for Part 1: Power Method}

As described in the experimental section of the report 2.5" wide blotter sheets were cut into 1' long sections. The sections were then dried in the microwave apparatus to achieve different water loading levels. Once the power differences are known, it was possible to calculate the $\left(\varepsilon_{r}^{\prime \prime} t\right)$, or dielectric loss value, as shown in Equation 27. One interesting aspect of this calculation is the compensation for built-in system losses. It was observed that even when the waveguide was run empty there existed an approximate $10 \%$ discrepancy in the power input and power output. So this additional 10\% loss was taken into consideration in the efficiency term, $\eta$. This may have been due to moisture in the air, waveguide imperfections or measurement error. A graph of post correction efficiency was made and is shown below in Figure 10.

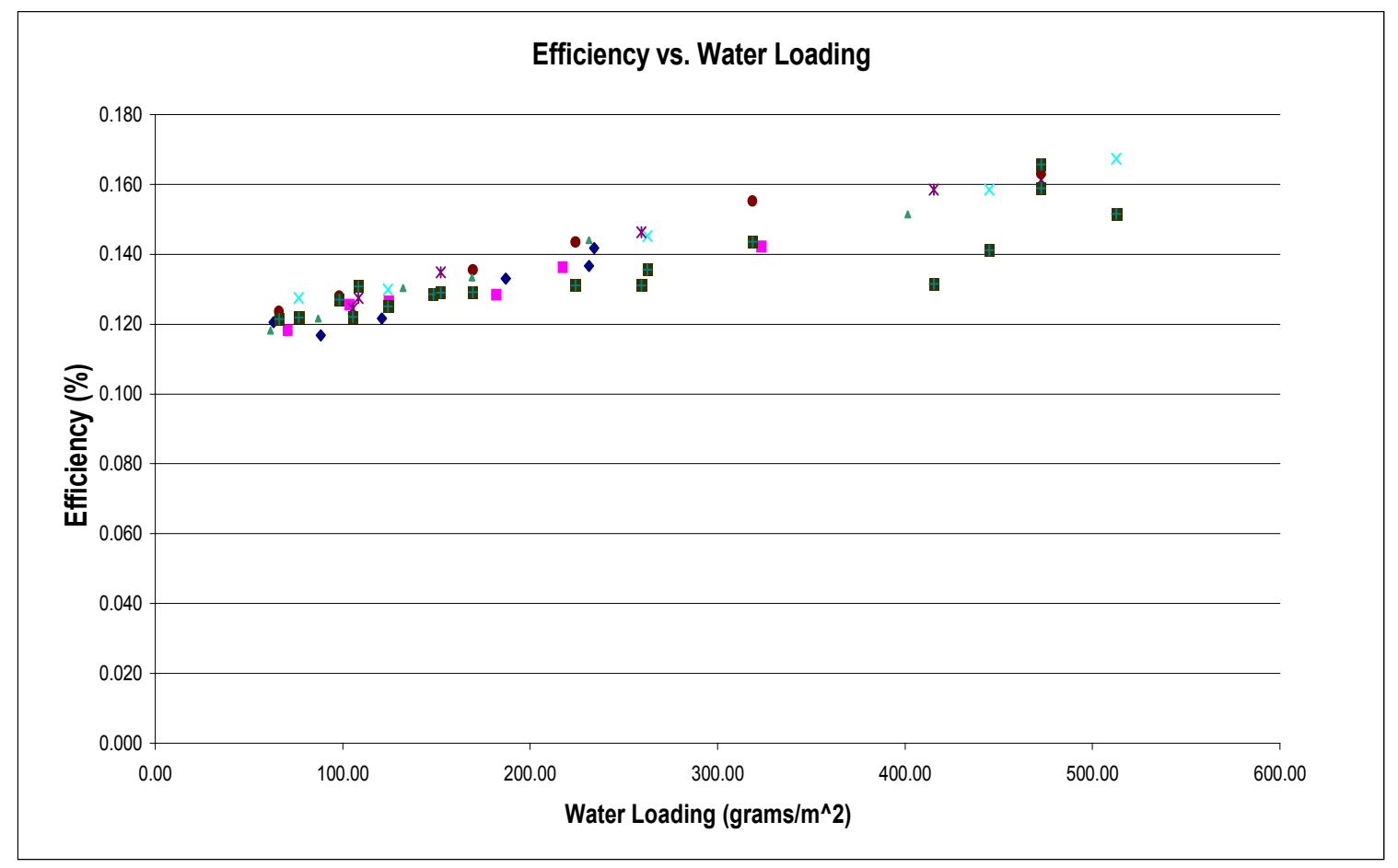




\section{Figure 6: Efficiency vs. Water Loading}

It is clear that the efficiency increases with water loading. This is supported by much of the work done by James Loughran. Examples of this direct increase are reported in "Web Drying and Preheating Using Microwave Energy" (Loughran, 2001).

The Dielectric loss term follows the same trend as efficiency when compared with water loading. This trend is shown in Figure 11.

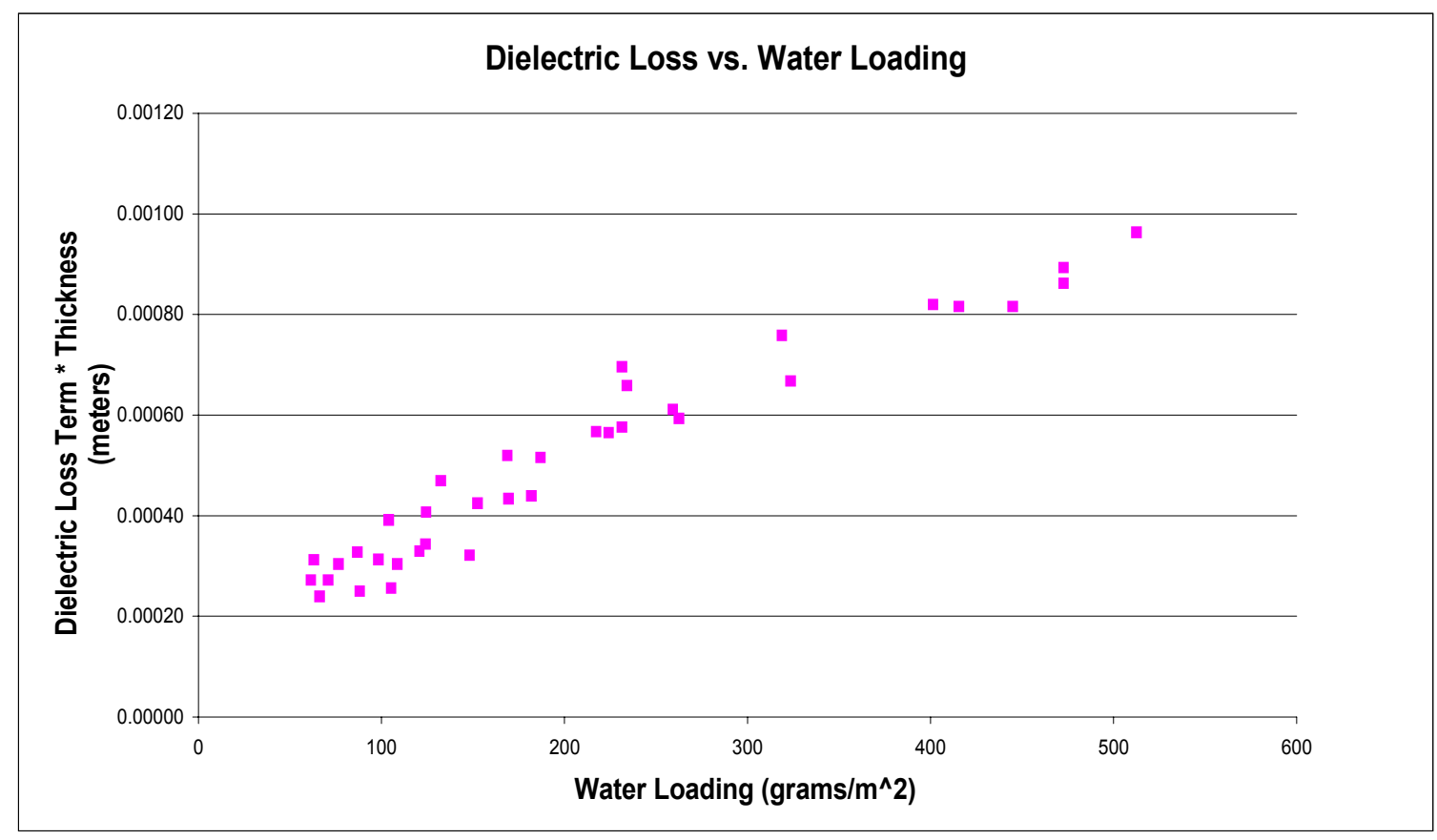

Figure 7: Dielectric Loss vs. Water Loading, Power Calculation Method

Figure 11 shows $\left(\varepsilon_{r}^{\prime \prime} t\right)$, dielectric loss, (meters) vs. water loading of the sheet in grams $/ \mathrm{m}^{2}$. A clear trend is apparent; as expected since increased water loading will result in an increase of the dielectric loss term.

\section{Results for Part 2: Thermodynamic Method for Dielectric Loss * Thickness $\left(\varepsilon_{r}^{\prime \prime} t\right)$}

As discussed in detail in the background section of this paper, it is also possible to calculate the dielectric loss term $\left(\varepsilon_{r}^{\prime \prime} t\right)$ from temperature, water loss and power data. This is done through the use of Equation 28, energy balance, which is based on equation 13. Through the use of thermodynamic principles, it is possible to determine how much power the paper absorbed. For this calculation one must know the temperature change, the weight change power input and the various physical properties of water and fiber. Once the total absorbed power is calculated, it is then possible to use equation 28 shown below, to solve for the dielectric loss term, $\left(\varepsilon_{r}^{\prime \prime} t\right)$.

The enthalpy of evaporation is defined as $h_{f g}, \mathrm{~kJ} / \mathrm{kg}$. 


$$
2 * \pi * f * \varepsilon_{0} * \varepsilon_{r}^{\prime \prime} * E^{2}(z) * t * s=\left(m_{f}^{\prime \prime} * c_{f}+m_{w}^{\prime \prime} * c_{w}\right) \Delta T+\Delta m_{\text {water,evap }}^{\prime \prime} * h_{f g}
$$

\section{Equation 11: Energy Balance with Evaporation Loss}

The energy balance from which equation 28 is based on comes from equation 13, with the acceptation of the heat loss term, $\int_{0}^{s} q_{\text {loss }}^{\prime \prime} d s$, which was dropped due to its difficultly to measure.

Where electric field strength was determined below as per equation 4 repeated below. Where the power term $\mathrm{P}(\mathrm{z})$ was taken to be the average power as seen by the sample.

$$
E^{2}(z)=\frac{P(z)}{\left(\frac{a b}{2 Z}\right)}
$$

The results of solving and graphing the $\left(\varepsilon_{r}^{\prime \prime} t\right)$, calculation can be seen in figure 12 .

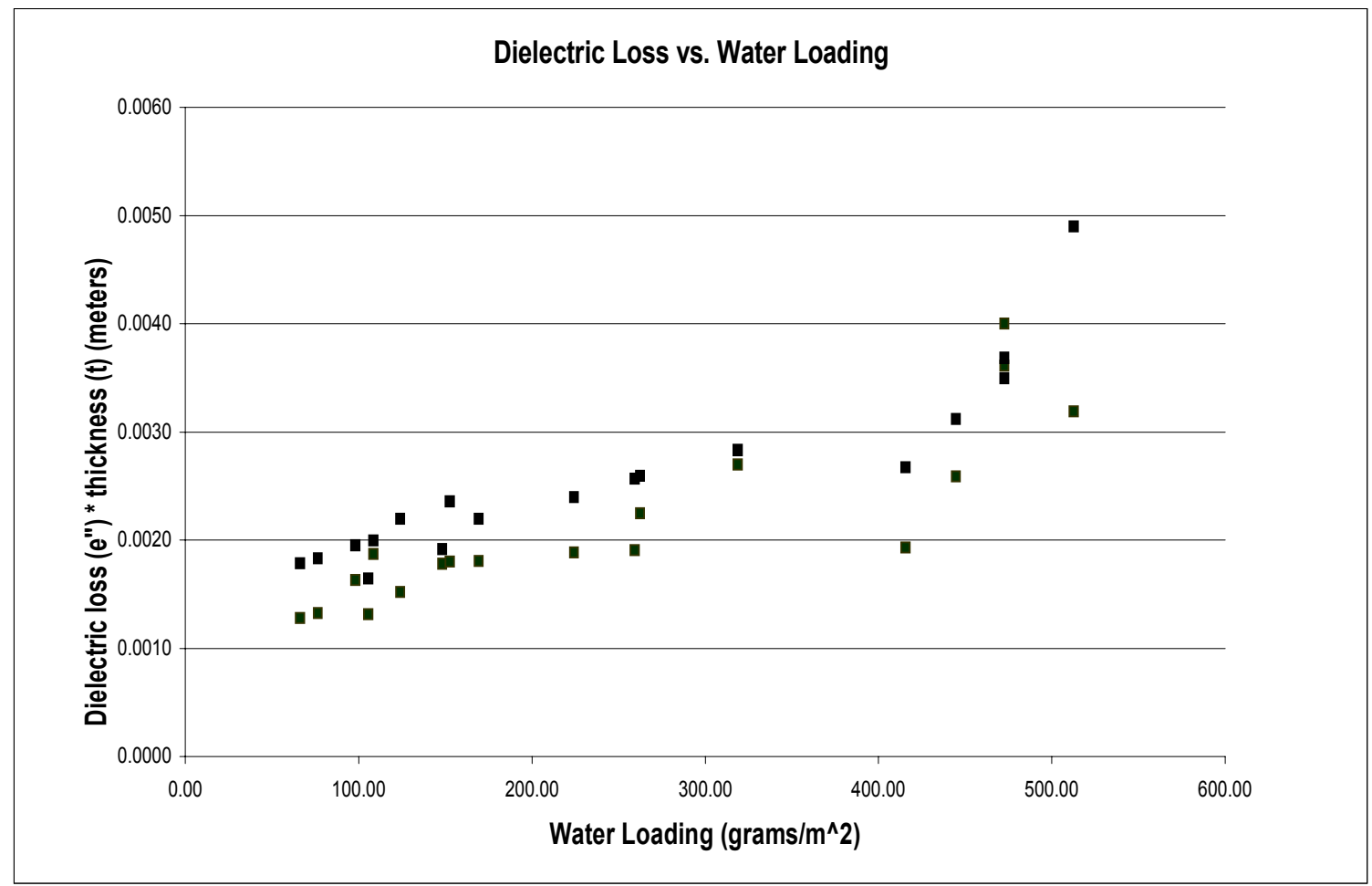

Figure 8: Dielectric Loss vs. Water Loading Thermodynamic Method 


\section{Results for Part 3: Saran Wrap ${ }^{\circledR}$ Maintaining Constant Moisture}

As discussed previously in the paper, an examination of the relationship between the dielectric loss term $\left(\varepsilon_{r}^{\prime \prime} t\right)$ and temperature should be made. It was stated in the background section of this paper that the addition of some type of non-permeable membrane to the paper sheet would allow the temperature of the sheet to increase while keeping the water loading constant by retaining steam. The setup and experimental procedure is described in greater detail in the experimental section of this report. For most cases of method one and two, the temperature would stabilize around $55^{\circ} \mathrm{C}$.

Figure 13 shows the temperature versus time curve of a sample with Saran Wrap ${ }^{\circledR}$.

Temperature Change Vs. Time

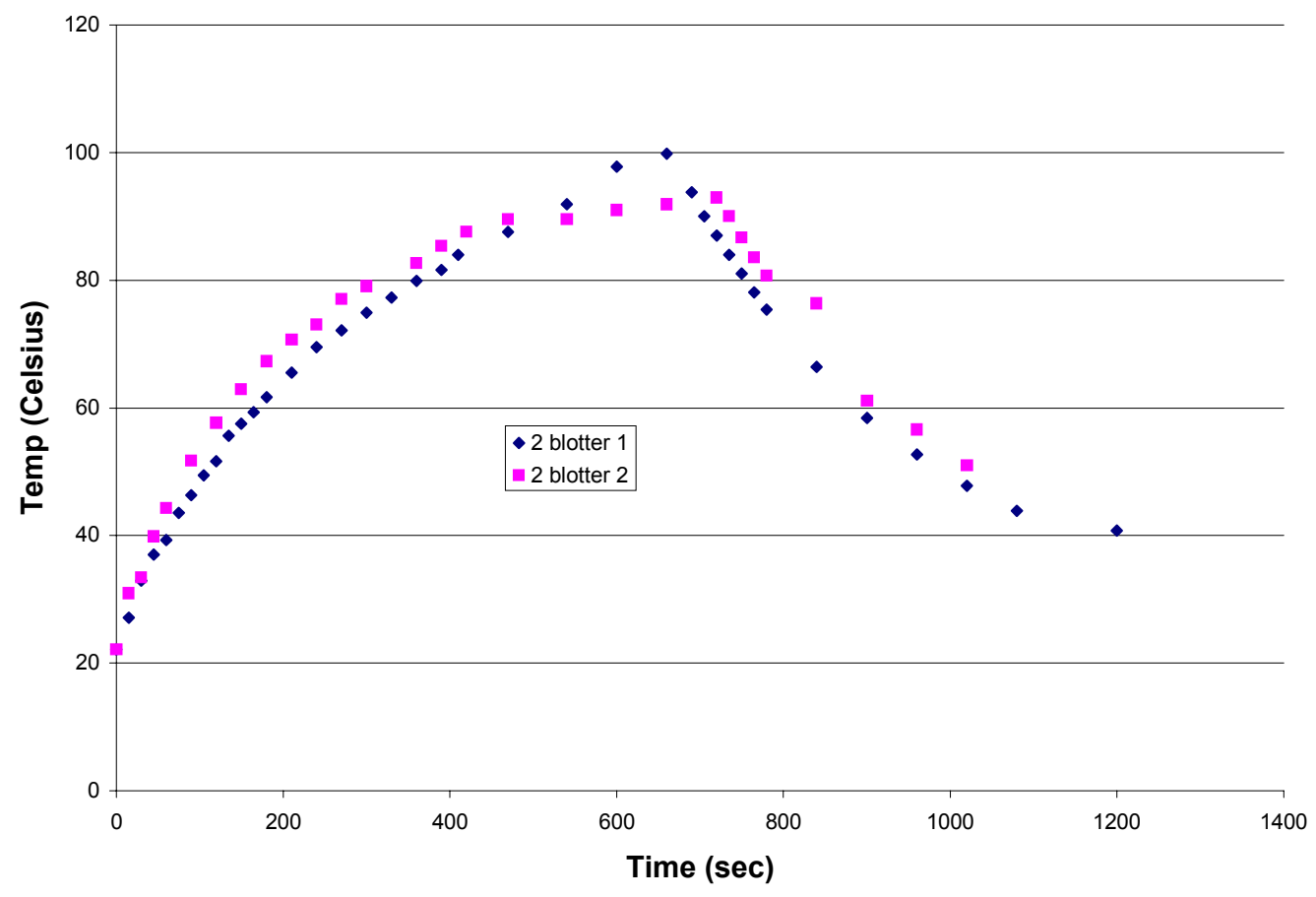

Figure 9: Temperature vs. Time

The Saran Wrap ${ }^{\circledR}$ did indeed allow the temperature to increase higher than had previously been allowed. During this increase in temperature, the water loading was virtually unchanged. The point at which the microwave unit was turned off is very visible; as the temperature shows an immediate decline. The next step was to determine what effect, if any, this temperature difference had on the dielectric loss term, $\left(\varepsilon_{r}^{\prime \prime} t\right)$. It was decided that the best method for analysis of the data would make use of Equation 28 or the power based method. This method seemed to yield more consistent results than the thermodynamic method. The power calculation method is based on efficiency so the first step was to see if any notable change in efficiency was present. 
Figure 14 shows the effect of temperature versus efficiency.

Temperature Change versus Efficiency

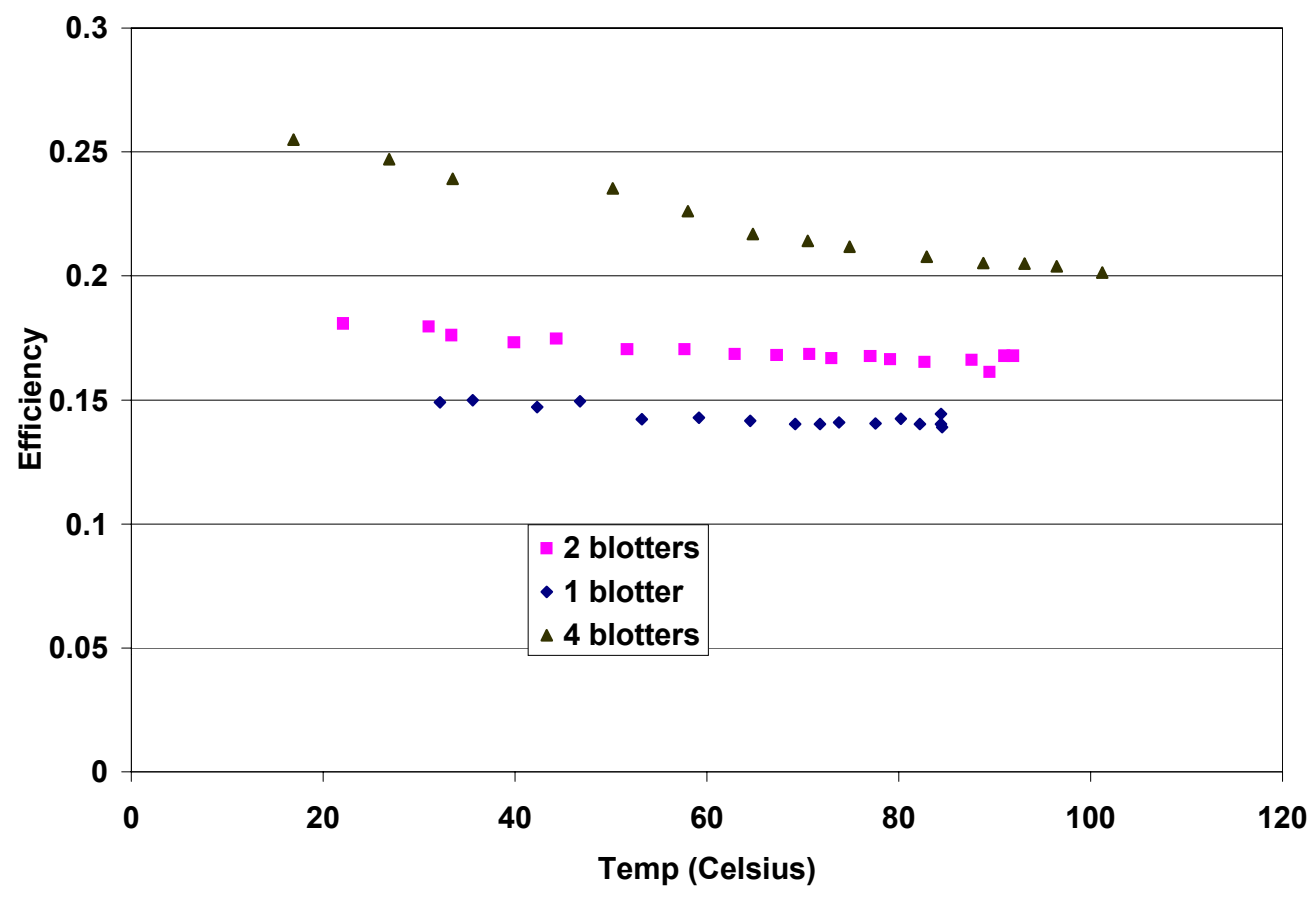

Figure 10: Temperature versus Efficiency at $915 \mathrm{MHz}$

From Figure 14, it appears that a trend is present when comparing temperature with efficiency. It would be expected that the graph of dielectric loss term vs. temperature would follow the same trend. Since the cases of 2 and 4 blotters yielded the most apparent trend, they were chosen for use in the dielectric loss section.

Figure 14 shows the relationship between the dielectric loss term $\left(\varepsilon_{r}^{\prime \prime} t\right)$ and water loading. 


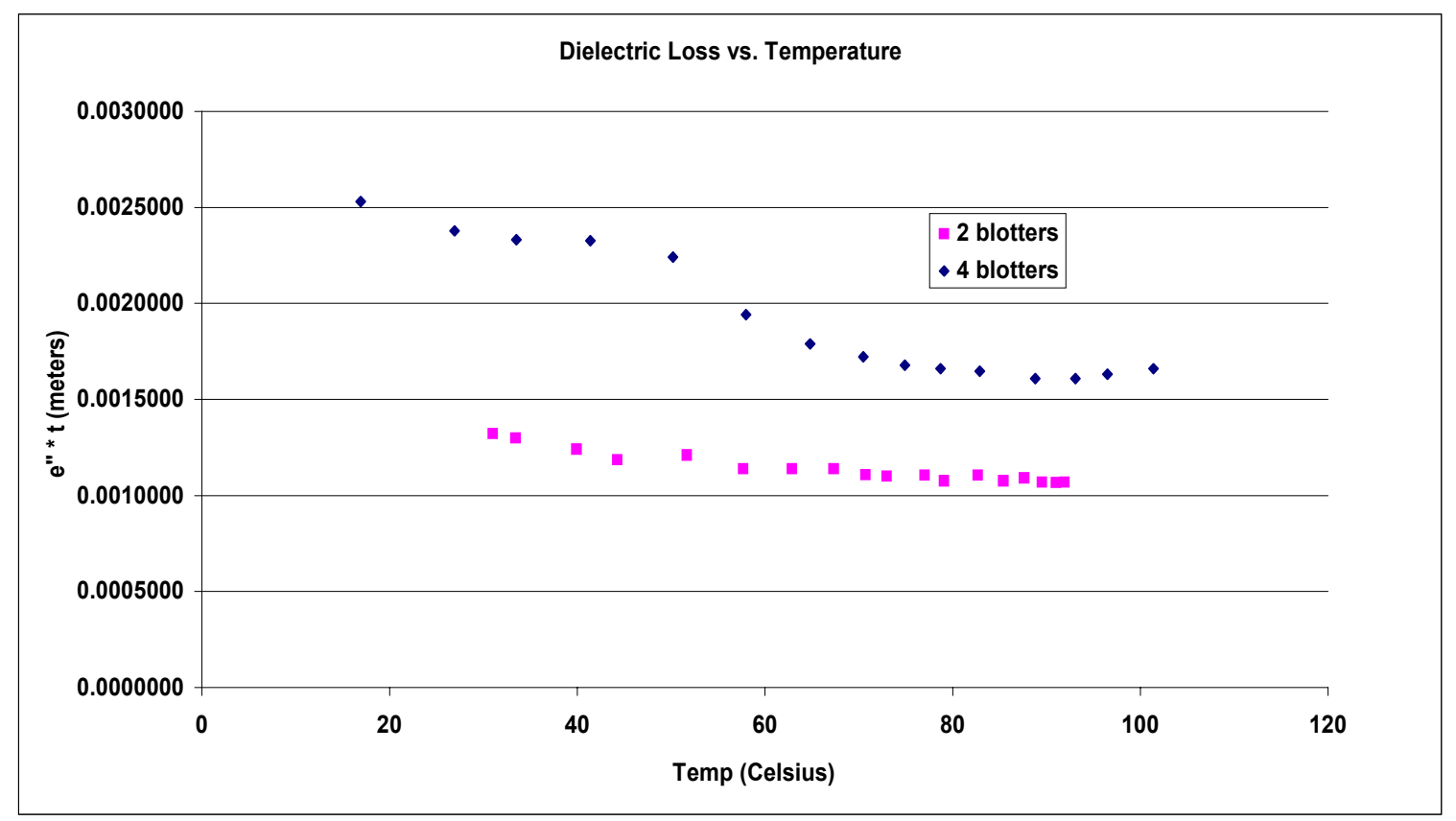

Figure 11: Dielectric Loss vs. Water Loading

Figure 15 shows a clear trend, as temperature is increased the dielectric loss value will decrease. Therefore, the power method yields a good correlation between temperature and the dielectric loss term $\left(\varepsilon_{r}^{\prime \prime} t\right)$. It is also noted from the graph that the 4 blotter test sheet which had a higher water loading also had a higher dielectric loss term. The results shown in sections 1 and 2 of the Results Section also support this finding.

\section{Analysis}

One of the first steps in analyzing the data was to compare methods. As shown in graph 16, there exists a clear correlation in the power method series; however, the thermodynamic method does not fit as closely as the power method. This may be due to the fact that it was hard to quantify the loss due to evaporation or other forms of energy migration. It may also be due to the fact that the IR temperature probe had a delay or that it was difficult to measure the water content accurately enough for this method.

Another means of comparing the accurately of the data is to use an equation relating the dielectric loss term, $\left(\varepsilon_{r}^{\prime \prime} t\right)$ to moisture loading. In Ahrens' paper the relationship is defined as follows

$$
\varepsilon_{r}^{\prime \prime} t \approx 0.5 * 10^{-6} \varepsilon_{r, \text { water }}^{\prime \prime} m_{w}^{\prime \prime}
$$

Equation 12: Loss Relationship (Ahrens, 2001) 
Where:

$$
\begin{aligned}
m_{w}^{\prime \prime}= & \text { water loading in }\left(\mathrm{grams} / \mathrm{meter}^{2}\right) \\
\varepsilon_{r, \text { water }}^{\prime \prime}= & \text { the water loss coefficient parameter (dimensionless) }(3.5 \text { was used for this } \\
& \text { research })
\end{aligned}
$$

This data was compared with both power and thermo methods as shown below in figure 16.

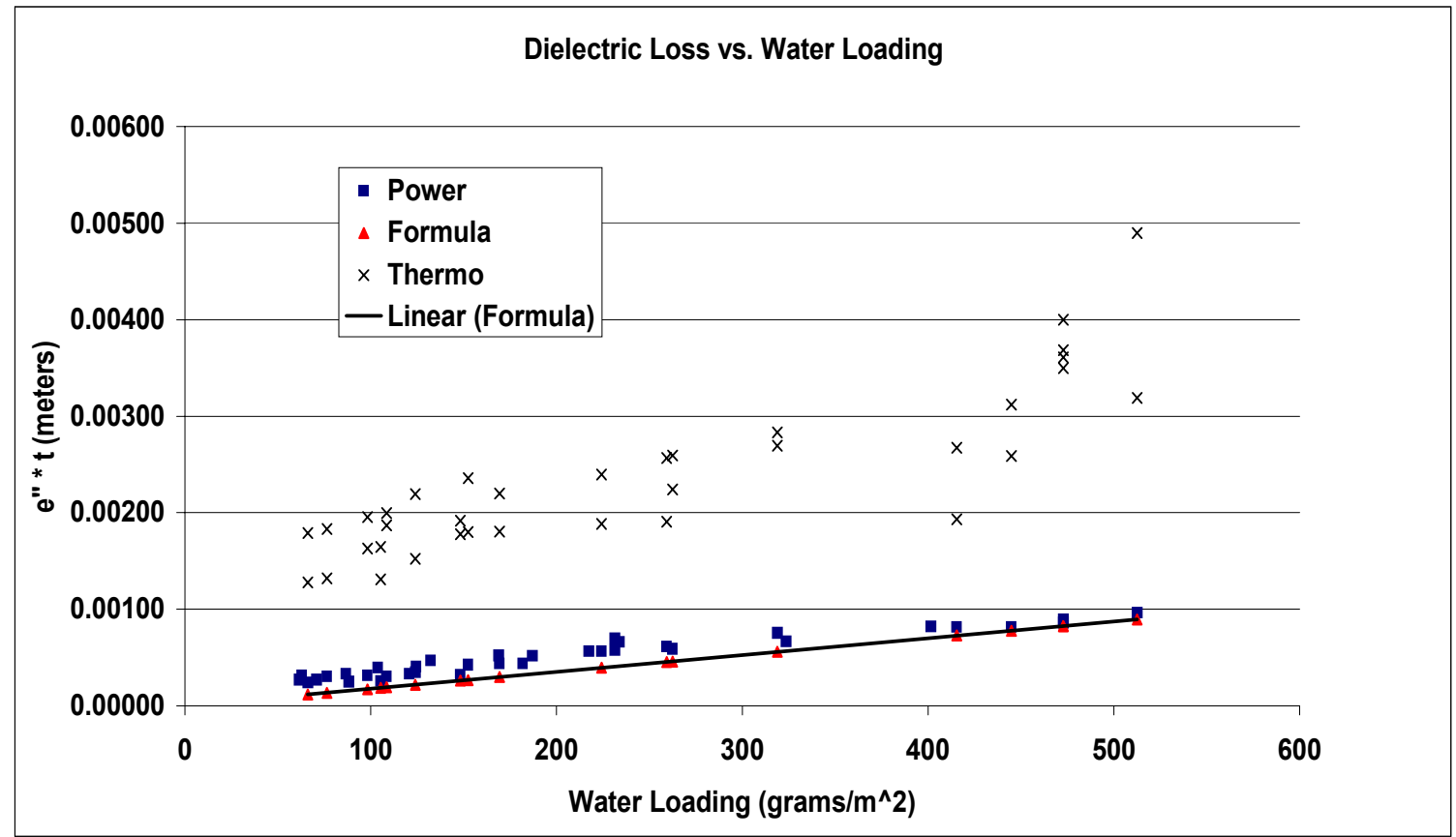

Figure 12: Dielectric Loss vs. Water Loading

Although the thermodynamically calculated data is not very close to the trend line predicted by Ahrens, the data for the power method series is certainly close. This indicates that the power method of calculation agrees with the suggested trend.

\section{Conclusions}

It can be concluded that a correlation exists between water loading of a sheet of paper and its dielectric loss term, $\left(\varepsilon_{r}^{\prime \prime}\right)$. This term can be expressed individually or in the case of this work with the thickness term $t$ included. The trend is that the dielectric loss term $\left(\varepsilon_{r}^{\prime \prime} t\right)$ is a function of water loading and as the water loading (grams $\mathrm{H}_{2} \mathrm{O} /$ meter $^{2}$ ) increases the dielectric loss term also increases. It is also noted that as the amount of water in the system decreases, the dielectric loss term $\left(\varepsilon_{r}^{\prime \prime} t\right)$ decreases. The relationship between temperature and dielectric loss term $\left(\varepsilon_{r}^{\prime \prime} t\right)$ is also examined in this research. It is concluded that dielectric loss term $\left(\varepsilon_{r}^{\prime \prime} t\right)$ is also dependent on temperature with the 
relationship that, "as temperature increases - the loss term decreases". This may be due to the alignment of the dipoles as discussed in the literature review section of this paper.

\section{References}

Adam, Stephen. Microwave Theory and Applications, Prentice-Hall, Inc., 1969.

Ahrens, F.W. and Habeger C.C., 2001, Use of New Applicator Design Ideas to Improve Uniformity of Paper Drying Via Microwave Energy, Drying Technology, 19(10), pp. 2531-2548.

Habeger, C. and Baum, G., 1983, The Microwave Dielectric Constants of Water-Paper Mixtures: The Role of Sheet Structure and Composition, Journal of Applied Polymer Science, 28, pp. 969-981.

Harrington, R.F., 1961, Time-Harmonic Electromagnetic Fields, McGraw-Hill, New York, pp. 70-71.

Joines, W.T. and Drozd, J.M., 2000, Method and Apparatus for Electromagnetic Exposure of Planar or Other Materials, U.S. Patent No. 6,075,232.

Jones, P.L., 1986, High Frequency Dielectric Heating in Paper Making, Drying Technology, 4(2), pp. 217-244.

Jones, P.L. and Rowley, A.T., 1996, Dielectric Drying, Drying Technology, 14(5), pp. 1063-1098.

Loughran, J., 2001, Experimental Report MW-001, Web Drying and Preheating Using Microwave Energy. Unpublished.

Niskanen, Kaarlo ed. Paper Physics. Fapet Oy, Finland, 1998.

Sonntag, R., Borgnakke, C., and Van Wylen, G. Fundamentals of Thermodynamics, $5^{\text {th }}$ ed., John Waley \& Sons, Inc., 1998, pp. 96-100. 
Stuerga, D and Gaillard, P., 1996, Microwave Athermal Effects in Chemistry: A Myth's Autopsy, Journal of Microwave Power and Electromagnetic Energy, 31(2), pp. $102-113$.

Williams, N.H., 1966, Moisture Leveling in Paper, Wood, Textiles and Other Mixed Dielectric Sheets, Journal of Microwave Power, 1(3), pp. 73-80.

\section{Acknowledgements}

I would like to thank my advisor, Dr. Fred Ahrens, his help and patience was necessary for the completion of this work. I would also like to thank James Loughran, for his invaluable help and guidance with this project. I would also like to thank those who aided in the editing of this paper, including John Cameron and Cameron Thompson. Lastly I would like to thank Dr. Barry Crouse, he was one of the most helpful individuals I have ever met.

\section{Appendix}

[Tables of raw and calculated data are contained in the full student report, but are omitted here] 
Temperature Change Vs. Time

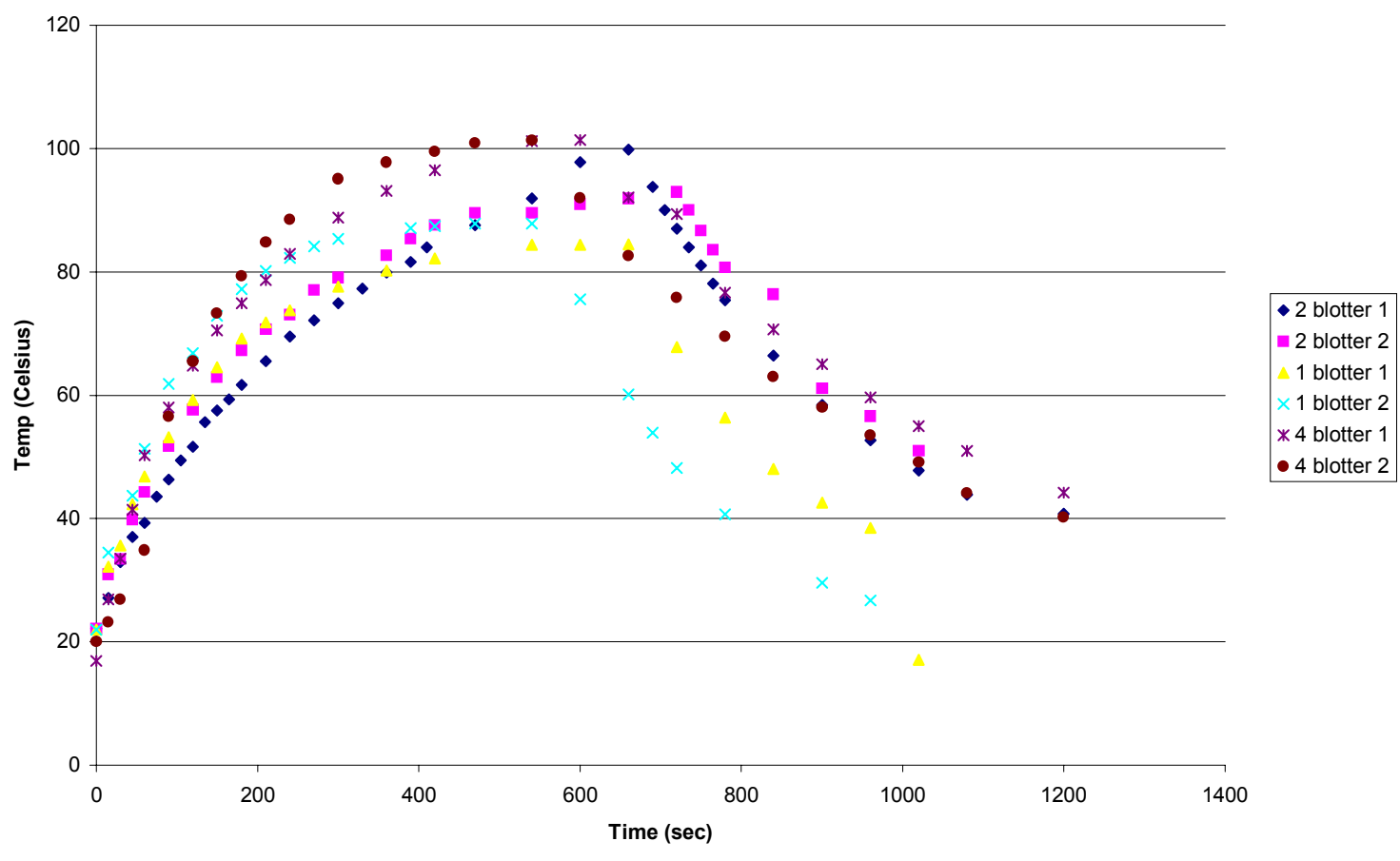

